\title{
WHAT COLLEGE WOMEN KNOW, THINK, AND DO ABOUT HUMAN PAPILLOMAVIRUS (HPV) AND HPV VACCINE
}

\section{A DISSERTATION IN}

Nursing

Presented to the Faculty of the University of Missouri-Kansas City in partial fulfillment of the requirements for the degree

DOCTOR OF PHILOSOPHY

\section{by \\ NOP THODSAMA RATANASIRIPONG}

B.S.N, Boromarajonani Nursing College, 1994

M.S.N, Mahidol University, 1998

Kansas City, Missouri

2012 
(C) 2012

\section{NOP THODSAMA RATANASIRIPONG}

ALL RIGHTS RESERVED 


\title{
WHAT COLLEGE WOMEN KNOW, THINK, AND DO ABOUT HUMAN PAPILLOMAVIRUS (HPV) AND HPV VACCINE
}

\author{
Nop Thodsama Ratanasiripong, Candidate for the Doctor of Philosophy Degree \\ University of Missouri-Kansas City, 2012
}

\begin{abstract}
Background: The development of cervical cancer nearly always begins with a sexuallytransmitted Human Papillomavirus (HPV) infection. Approximately 20 million Americans between the ages of 15 and 49 are currently infected with HPV and another 6 million people become newly infected each year. Among these HPV infections, 74\% occur in the 15 to 24 year old age group. In 2006, HPV vaccine (Gardasil®) was approved for girls and women aged 9 to 26 . However, the national vaccine uptake rate among young women has been low. HPV vaccine mandatory proposals have also been met with controversy. Some advocacy groups have voiced concerns about whether receipt of HPV vaccine might encourage unsafe sexual behaviors. Little is known about how public controversies have influenced the uptake of HPV vaccine or whether HPV vaccinees indeed engage in more unsafe sexual behaviors, compared to their non-HPV vaccinee counterparts. Purposes: This cross-sectional study aimed to: (1) identify factors that influence HPV vaccine uptake among college women and


(2) examine the post-vaccine sexual behaviors of college-aged women. Methods:

Participants were a convenience sample of college women $(n=384)$ ages 18 to 26 attending a large, public university in Southern California. An electronic self-administered survey was utilized to collect data. The theory of planned behavior provided a framework for understanding the factors associated with vaccine uptake and with post-vaccine sexual behaviors. Results: College women had good HPV/HPV vaccine knowledge. Over 90\% of vaccinees and non-vaccinees knew that Pap test is still needed after the vaccination and an HPV vaccine does not protect against all STIs. Both groups also had positive attitudes toward mandatory vaccination. However, knowledge and attitudes toward the vaccine were not directly linked to the outcome predictors-intention to obtain the vaccine and vaccine uptake. While attitude toward getting vaccinated, subjective norms, and perceived behavioral control were correlated with the outcome predictors, subjective norms consistently predicted intention to obtain HPV vaccine and vaccine uptake. There were no significant differences in sexual behaviors (numbers of sexual partners in a life time, numbers of sexual partners in the past 12 months, condom use, condom use frequency) between non-vaccinees and vaccinees. The numbers of sexual partners before and after vaccination among vaccinees were also not significantly different. Conclusions: Strategies to ensure that those who are eligible for catch-up vaccination are vaccinated should include attention to college women's subjective norms. Vaccine mandatory proposal would not be unacceptable to this population and concerns that the HPV vaccine encourages unsafe sexual behaviors and practices among college aged women may be disregarded. 


\title{
APPROVAL PAGE
}

The faculty listed below, appointed by the Dean of the School of Nursing have examined a dissertation titled "What College Women Know, Think, and Do about Human Papillomavirus (HPV) and HPV Vaccine," presented by Nop T. Ratanasiripong, candidate for the Doctor of Philosophy degree, and certify that in their opinion it is worthy of acceptance.

\author{
$\underline{\text { Supervisory Committee }}$ \\ An-Ling Cheng, Ph.D., Committee Chair \\ School of Nursing \\ Maithe Enriquez, RN, ANP, Ph.D. \\ School of Nursing \\ Patricia Kelly, RN, FNP, MPH, Ph.D. \\ School of Nursing \\ Jennifer Hunter, RN, Ph.D. \\ School of Nursing \\ Rafia S. Rasu, MPham, MBA, Ph.D. \\ School of Nursing \\ School of Pharmacy
}




\section{CONTENTS}

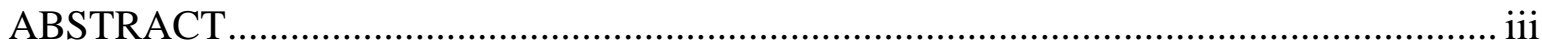

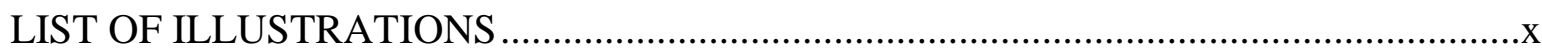

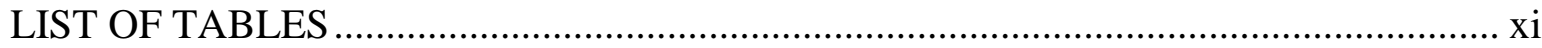

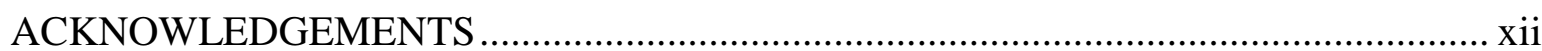

Chapter

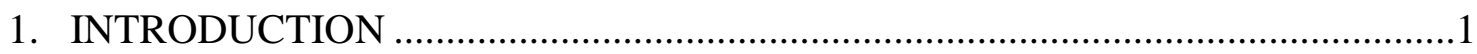

Study Purpose and Research Questions ................................................4

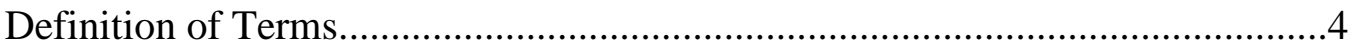

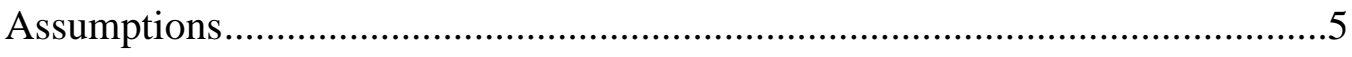

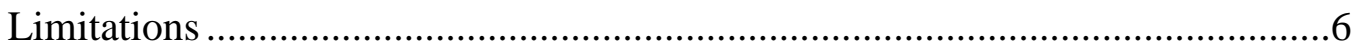

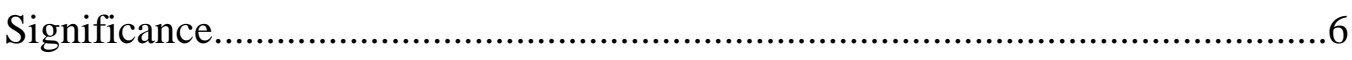

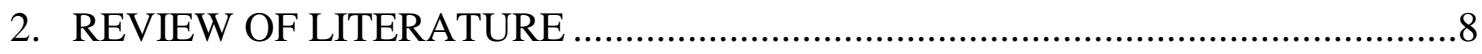

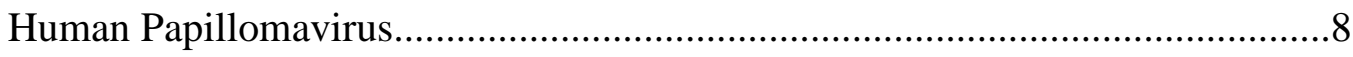

HPV Prevalence and Transmission.................................................. 8

HPV Clinical Management ............................................................. 10

Impact of HPV infection .............................................................. 13

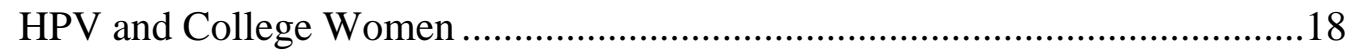

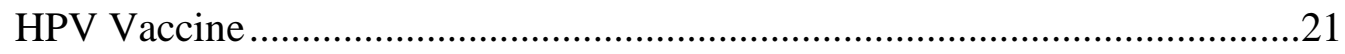

HPV Vaccine as a Primary Prevention Method.......................................21

HPV Vaccine Uptake Rate...............................................................23

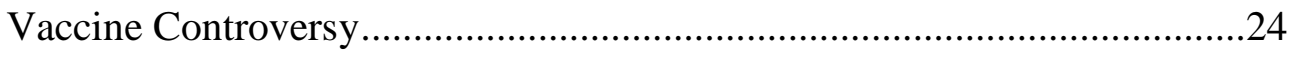


Factors Influencing HPV Vaccine Uptake and Sexual

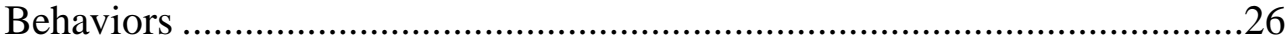

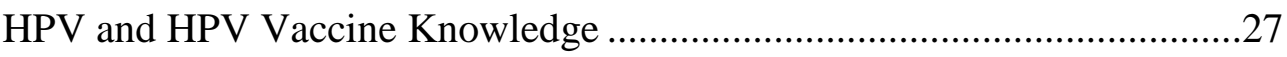

HPV and HPV Vaccine Related Attitudes..................................................28

Sexual Behaviors Associated with Receipt of

HPV Vaccine ...............................................................................

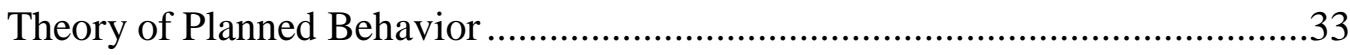

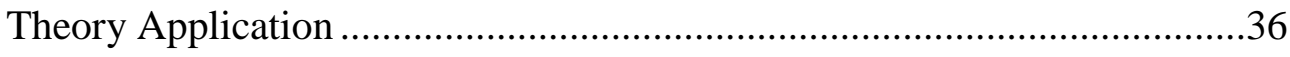

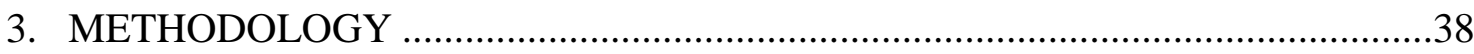

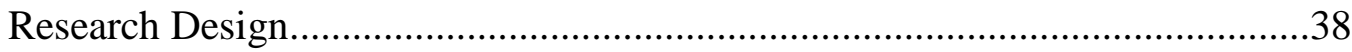

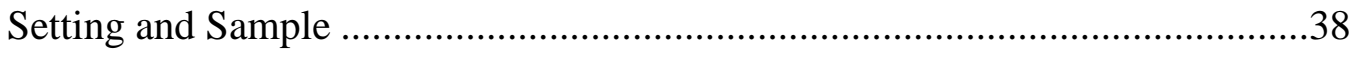

Procedure for Data Collection ............................................................................39

Protection of Human Subjects ...................................................................... 40

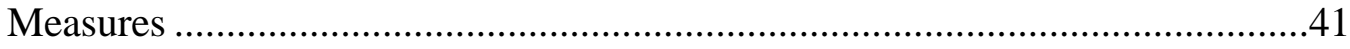

Validity and Reliability Testing ...............................................................42

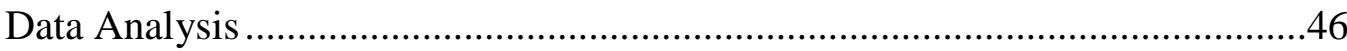

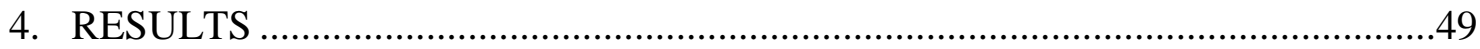

Reliability of the 'HPV and HPV vaccine related Knowledge,

Attitudes, and Behaviors' questionnaire ...............................50

Participant Characteristics ............................................................................52

Demographic Characteristics ..................................................................52

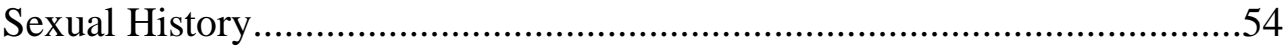

Descriptions of the Variables of Interest ………………………......................55

HPV/HPV Vaccine Knowledge .................................................................55 
Attitudes toward HPV Vaccine .56

Attitude toward Getting Vaccinated Against HPV ....................................57

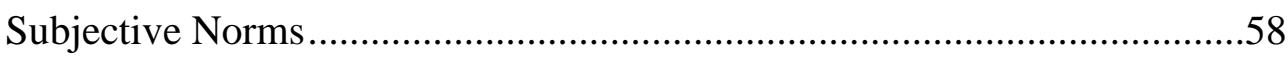

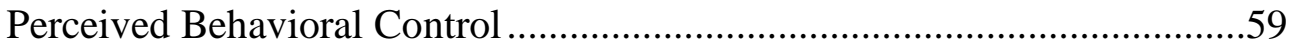

Research Question One.....................................................................60

Relationships between Indirect Predictors, Direct

Predictors, and Vaccine Uptake ...................................................61

Determining Predictors of Vaccine Uptake ...........................................63

Determining Predictors of Intention to obtain HPV Vaccine among Non-Vaccinees .....................................................64

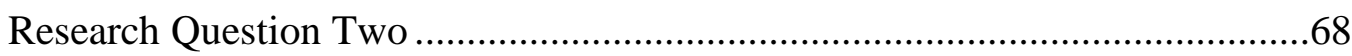

Comparisons of Sexual Behaviors between NonVaccinees and Vaccinees ..............................................................68

Comparison of Numbers of Sexual Partners Before and After Vaccination ................................................................. 71

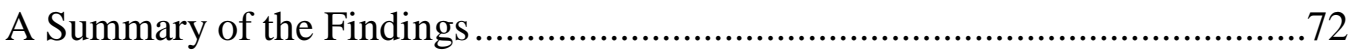

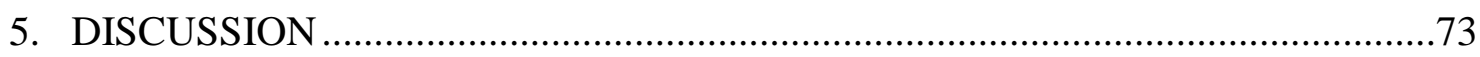

Indirect Predictor of HPV Vaccine Uptake .............................................74

Direct Predictors of HPV Vaccine Uptake ...............................................76

Predictors of Intention to Obtain HPV Vaccine among

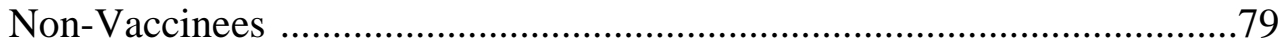

Sexual Behaviors/Practices and HPV Vaccination ....................................8

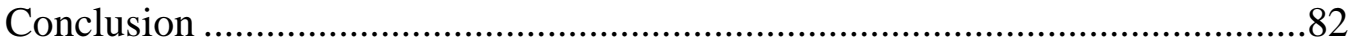

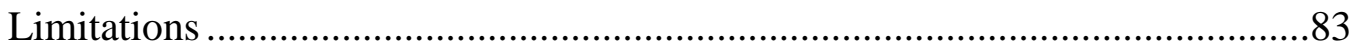

Recommendations for Future Research .......................................................8

viii 
Implication for Practice.

Appendix

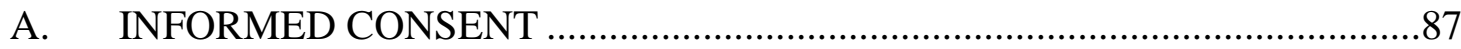

B. IRB AUTHORIZATION AGREEMENT

BETWEEN UMKC AND CSULB ................................................. 90

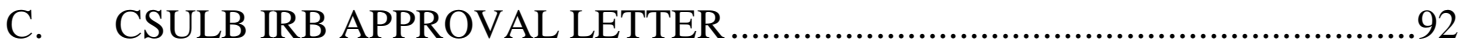

D. HPV AND HPV VACCINE RELATED KNOWLEDGE, ATTITUDES, AND

BEHAVIORS QUESTIONNAIRE

E. LETTER OF SUPPORT FROM CSULB

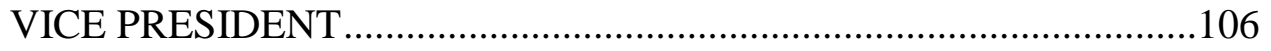

F. EMAIL LETTER OF SUPPORT FROM CSULB ENROLLMENT SERVICES............................................................ 108

G. LETTER OF SUPPORT FROM CSULB STUDENT HEALTH SERVICES

H. EMAIL INVITATION FOR PARTICIPATION

IN A RESEARCH STUDY

I. EMAIL REMINDER FOR WEEK ONE .................................................... 114

J. EMAIL REMINDER FOR WEEK TWO................................................. 116

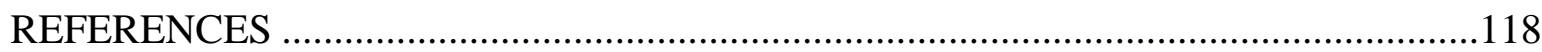

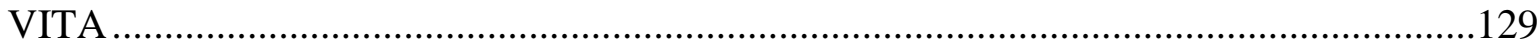




\section{LIST OF ILLUSTRATIONS}

Figure

Page

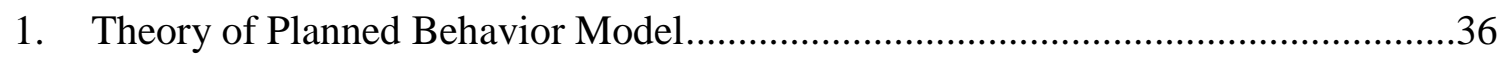

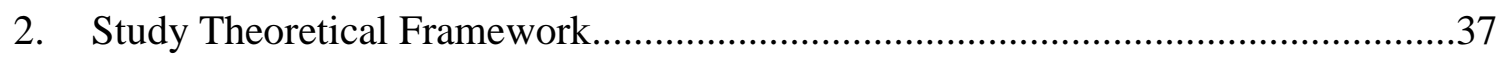

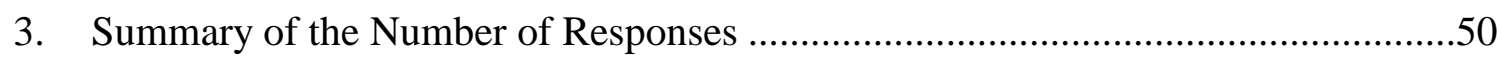




\section{LIST OF TABLES}

Table

Page

1. Demographic Characteristics of Vaccinees and

Non-Vaccinees

2. Sexual History of Vaccinees and Non-Vaccinees

3. HPV/HPV Vaccine Knowledge: Percentages of

Correct Answers .56

4. Attitudes toward HPV Vaccine

5. Attitude toward Getting Vaccinated against HPV

6. Percentage of Participants Who either Agreed or

Strongly Agreed with Subjective Norms Statements

7. Percentage of Participants Who either Agreed or Strongly

Agreed with Perceived Behavioral Control Statements

8. Bivariate Correlation Results between Indirect Predictors,

Direct Predictors, and Vaccine Uptake $(n=384)$

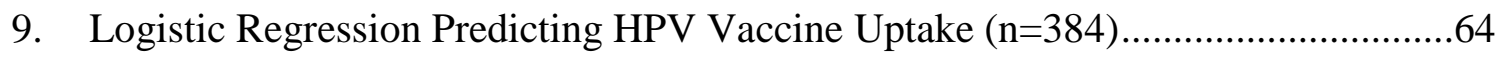

10. Reasons for Not Obtaining an HPV Vaccine

11. Hierarchical Multiple Regression Analysis Summary for

Attitude toward Getting Vaccinated against HPV,

Subjective Norms, and Perceived Behavioral Control,

Controlling for HPV Knowledge and Attitudes toward

HPV Vaccine, Predicting Intention to Obtain HPV

Vaccine $(\mathrm{n}=164)$

12. Analysis of Covariance for the Number of Sexual Partner(s) in a

Lifetime as a Function of Vaccine Uptake, Using Age

of First Sexual Intercourse and HPV/HPV Vaccine

Knowledge as Covariates

13. Analysis of Covariance for the Number of Sexual Partner (s)

in 12 Months as a Function of Vaccine Uptake, Using

the Number of Sexual Partner(s) in a Lifetime as a

Covariate 


\section{ACKNOWLEDGEMENTS}

Studying for this Ph.D. in nursing not only gives me the knowledge and skills needed for my career, it also teaches me to be humble and be thankful for those who are around me. I simply wish this Ph.D. degree could be divided. I would give half of my degree to those who supported and encouraged me in going through this journey with confidence and joy.

I want to thank my husband who literally takes care of most things in my life (e.g., household chores, booking flights and hotel to UMKC, and scheduling weekend activities). His comfort and encouragement through words ensure me that "everything will be OK." His skills (as a psychologist) have also proven to be very useful in helping me cope with stressful school and life events during the past three years. My gratitude also goes to my family and friends. Through their emails, phone calls, prayers, and home-made food, I learned that I am loved and cared for. I am thankful to have a great mother and sister who always say "you will make it as you have done. We believe in you."

I am thankful for my dissertation committee members: Drs. An-Lin Cheng, Maithe Enriquez, Patricia Kelly, Jennifer Hunter, and Rafia Rasu. Their questions and advice are so valuable to my research study. I so much appreciated Dr. Enriquez and Dr. Cheng for their guidance, support, and time in mentoring me. With their help, I never felt I was walking alone on this journey. UMKC faculty confirmed that choosing to attend the school here is one of the best educational decisions I have ever made.

I am also thankful for Dr. Icek Ajzen who provided the theoretical guidance. With his expertise, the final study questionnaire had much higher quality than otherwise would have been possible. This dissertation research was also supported by CSU Long Beach, 
Student Services Division administrators who allowed me to collect the data with college women and supported me in obtaining the grants to complete this project.

Last and most importantly, I thank God who provided all these important people in my life. He has proven again that with His help, all things are possible. 
To:

My mother: The woman who taught me to live my life courageously.

End stage cervical cancer patients in Thailand: The women who inspired me to conduct this study. 


\section{CHAPTER 1}

\section{INTRODUCTION}

Cervical cancer is the second most common cancer among women worldwide and over 300,000 women die from this cancer each year (World Health Organization [WHO], 2006). In the United States (US), 12,000 women are diagnosed with cervical cancer and 4,000 women die from it each year (Centers for Disease Control and Prevention [CDC], 2011a). Southeast Asian and Latino women experience cervical cancer disparities, with rates three to five times higher than other racial/ethnic groups (Kline \& Huff, 2007). Healthy People 2020 called for an increase in cervical cancer screening rate and a reduction in the rates of invasive cervical cancer and Human Papillomavirus (HPV) infections among women (Department of Health \& Human Services, 2010).

The development of cervical cancer nearly always begins with HPV infection (Weinstock, Berman, \& Cates, 2004; WHO, 2006). More than 100 different HPV types have been identified and approximately thirty types infect the genital tissues. High-risk, oncogenic HPV types (e.g., HPV 16 and HPV 18) are responsible for $99.7 \%$ of all cervical cancers while low-risk HPV types (e.g., HPV 6 and HPV 11) can result in mild cervical abnormalities, genital and respiratory tract warts (Ault, 2006; Beutner, Reitano, \& Richwald, 1998). Approximately twenty million (15\%) of Americans, between the ages of 15 and 49 are currently infected with HPV and another six million people become newly infected each year (Weinstock et al., 2004). Among these HPV infections, 74\% occur in the 15 to 24 year old age group, with almost $29 \%$ of this population having at least transient infection (CDC, 2009). About $10 \%$ of women who contract high risk HPV types develop persistent infections that can cause cervical cancer and negative health outcomes (Ault, 2006). 
While there is no cure for HPV infection, the opportunity for prevention of HPV infection occurred in 2006 when the first HPV vaccine (HPV 4, or Gardasil ${ }^{\circledR}$ ) was approved for girls and women aged 9-26. In 2009, another HPV vaccine (HPV2, or Cervarix ${ }^{\circledR}$ ) was licensed for use in females aged 10-25 (CDC, 2010a). Both vaccines require three doses and have high efficacy against HPV 16 and 18 related cervical, vulvar, and vaginal cancers and pre-cancer lesions (CDC, 2010a). Recently, HPV4 was also approved for use in males aged 9-26 for prevention of anal intraepithelial neoplasia, anal cancer, and genital warts (U.S. Food \& Drug Administration, 2010).

Researchers have documented an increased awareness of HPV and HPV vaccine among college-aged women since the first HPV vaccine was released (Allen et al., 2009; Caron, Kispert, \& McGrath, 2008; Jain et al., 2009). However, national data shows low vaccine uptake. For adolescents aged 13-17, 44.3\% have received at least one dose and 26.7\% have received three doses of HPV vaccine (CDC, 2010b). For women aged 19-26, 17.1\% have received at least one dose of an HPV vaccine (CDC, 2011b). A review of literature reports that, depending on settings, the HPV vaccine completion rate is between 4-47\% among college-aged women (Sheinfeld Gorin, Glenn, \& Perkins, 2011). In November 2010, a survey conducted at a large, public university in California showed that only $30 \%$ of women aged 18-26 had received at least one dose of HPV vaccine (California State University Long Beach [CSULB], 2011). From these results, low uptake arose the question "why have college women not obtained the HPV vaccine while most of them are sexually active (70-77\%)?” (CSULB, 2011; The Kinsey Institute, 2011).

Proposals to make HPV vaccination mandatory for girls have been met with controversy. Concerns have been raised about giving children a "license" for sex, sending 
mixed messages between abstinence and premarital sex, vaccine cost of $\$ 450$, vaccine side effects, and misunderstanding about the need for continued Pap testing (Hager, 2009; Rothman \& Rothman, 2009; Vamos, McDermott, \& Daley, 2008). Politicians, religious groups, and advocacy groups have voiced concerns about whether receipt of HPV vaccine might also encourage unsafe sexual practices because it might create a misunderstanding that HPV vaccine prevents all sexually transmitted infections (STIs) (Hager, 2009; Vamos, et al., 2008). In addition to psychosocial concerns, the duration of efficacy for available HPV vaccines is unknown (CDC, 2010a).

A review of the literature found no study that has directly examined what college women think about getting vaccinated against HPV and whether the HPV vaccine controversies that exist are indeed related to a woman's decision to obtain the HPV vaccine (Ratanasiripong, in press). Published data examining the sexual behaviors/practices of women who have not received HPV vaccine compared to women who have been vaccinated is also very limited. There is a need to better understand why college women do not obtain the HPV vaccine and to examine post- HPV vaccine sexual behaviors/practices among college-aged women.

The theory of planned behavior (TPB) has been widely used to understand healthrelated behaviors in various populations, including the college-aged population. The theory provides a framework for understanding the antecedents to desired behaviors, such as HPV vaccine uptake and sexual behaviors. The theory explains that a person's behavior is determined by his/her intention to perform the behavior and that this intention is, in turn, a function of attitude toward the behavior, subjective norms, and perceived behavioral control (Ajzen, 1991). 


\section{Study Purpose and Research Questions}

This study used a theory-driven approach to (1) identify factors that influence HPV

vaccine uptake among college women and (2) examine the post-vaccine sexual

behaviors/practices of college-aged women. Two research questions were addressed:

1. What is the relationship between HPV/HPV vaccine related knowledge, attitudes toward HPV vaccine, attitude toward getting vaccinated against HPV, subjective norms, perceived behavioral control, intention to receive the vaccine, and vaccine uptake among college women?

2. Are there differences in sexual behaviors between college women who have received (vaccinees) and have not received the HPV vaccine (non-vaccinees)?

\section{Definitions of Terms}

Human Papillomavirus (HPV): A group of viruses that include more than 100 different strains. Genital HPV spreads via genital contact. HPV infection is the most common STI in the U.S. High-risk HPV can cause cervical, vulva, vagina, penis, or anus cancers. Low-risk HPV can cause genital warts (CDC, 2007).

Knowledge: The fact or condition of knowing something with familiarity and gained through experience or association. It is the fact or condition of having information or of being learned (Merriam-Webster, 2011).

Attitudes: The degree of positive or negative evaluation of the behaviors. Attitude is made up of the beliefs people hold about the object of the attitude and the associated evaluation of that belief. Attitude toward a behavior (i.e., getting vaccinated against HPV) is concerned with one's belief about the consequences of performing the behavior (Azjen, 1991). Attitudes are assumed to form a bipolar continuum, from negative evaluation on one end to a positive evaluation on the other (Ajzen, 1991). Attitude toward an object (i.e., HPV 
vaccine) is a feeling, emotion, or tendency to respond toward the certain object (Business Dictionary, 2010; Merriam-Webster, 2011).

Subjective norms: One's beliefs about how people one cares about will view the behavior in question. Subjective norms are the products of each normative belief (a perceived social pressure to engage or not to engage in a behavior) weighted by motivation to comply (Ajzen, 2010a).

Perceived behavioral control: People's perceptions of their ability to perform a given behavior (Ajzen, 2010a). Perceived behavioral control is determined by the beliefs about the presence factors that may facilitate or impede performance of the behavior.

Intention to behave: The cognitive representation of a person's readiness to perform a given behavior (Ajzen, 1991).

Uptake: The action of accepting, taking up or making use of something that is available (Farlex, 2011).

Sexual behaviors/practices: Activities associated with sexual intercourse (Farlex, 2011).

\section{Assumptions}

Based on the theory of planned behavior, study assumptions are following:

1. College women make decisions based on the information available to them.

2. College women's HPV vaccine related behaviors are determined by their intention to perform the behaviors. Intention is the immediate antecedent of behavior.

3. College women's intentions are determined by attitude toward the behavior, subjective norms, and perceived behavioral control.

4. The more favorable the attitude toward the behavior and the subjective norms, and the greater the perceived behavioral control, the stronger the college women's 
intention should be to perform HPV vaccine related behaviors.

5. Knowledge, attitudes toward HPV vaccine, demographic characteristics, past behavioral experiences, and social norms influence HPV vaccine related behaviors indirectly by their effects on attitude toward getting vaccinated against HPV, subjective norms, and perceptions of control.

\section{Limitations}

Potential limitations for this study included threats to internal validity, construct validity, and external validity. Known limitations for this study include the following:

1. A convenience-based sample of college women from one university may not be generalizable to all college women throughout the US.

2. Self-report measures can be subjected to reporting biases that may be present among participants with strong feelings for HPV and HPV vaccine. Participants may also over or under-estimate their actual feelings or behaviors.

3. Data on vaccination timeline, sexual history, and sexual behaviors were collected through self-report and were not confirmed with medical records. Recall bias may occur. Retrospective reports on attitudes, subjective norms, and perceived behavioral control among vaccinees may also be biased.

4. Low response rate may be subjected to non-response bias. A method to explore non-response bias by comparing background characteristics between the early and late respondents was performed (Sax et al., 2003). The results indicated that there were no differences in demographic and sexual history among the respondents who completed the survey after the first e-invitation, who completed the survey after the first reminder, and who completed the survey after the second reminder. With the indifference between three groups of respondents, it is assumed that nonresponse bias may not be significant.

\section{Significance}

HPV infection is the most common STI in the U.S. and cervical cancer caused by HPV remains prevalent worldwide (WHO, 2006). HPV infection and cervical cancer related morbidity result in emotional and physical distress at the individual level and also result in increased health care costs for invasive procedures to remove precancerous and cancerous lesions. In order to prevent HPV infection and cervical cancer, HPV vaccination and routine 
Pap testing are essential. The US Department of Health and Human Services encourages health care providers to actively engage in developing and implementing programs to increase the HPV vaccine uptake rate. Nurses, in particular public health and school nurses, are in an ideal position to take an active role in the development and implementation of HPV and cervical cancer prevention programs.

This research, guided by theory of planned behavior, provides new and important information that contributes to the understanding of HPV vaccine uptake rates and the complex interplay of HPV/HPV vaccine knowledge, attitudes toward HPV vaccine, attitude toward getting vaccinated against HPV, subjective norms, perceived behavioral control, and intention to obtain HPV vaccine. The study findings yielded a research-based foundation for the development of clinical interventions to increase the number of young women who receive the HPV vaccine. Increased HPV vaccine uptake will in turn reduce the rate of HPV infection, and decrease cervical cancer and negative HPV-related health outcomes. Moreover, it addresses the current controversy about whether or not HPV vaccine status impacts sexual behaviors/practices. Finally, the results of this study help dispel the controversy surrounding HPV vaccine and inform public policy decision-making regarding mandating HPV vaccine. 


\section{CHAPTER 2}

\section{REVIEW OF LITERATURE}

\section{Human Papillomavirus}

Papillomaviruses are DNA viruses that infect squamous epithelia inducing proliferative lesions (Stanley, 2010). These viruses are species-specific, hence Human Papillomavirus (HPV) only infect humans. Currently, there are 130 types of HPVs that have been identified and approximately 30 types infect the genital system. The genital HPVs can be separated into low- or high-risk types, depending upon their oncogenic potential (Stanley, 2010). Low-risk HPV types (e.g., HPV 6 and 11) can result in mild cervical abnormalities, genital and respiratory tract warts. High-risk HPV types (e.g., HPV 16, 18, 31, 33, 35, and

45) are associated with anogenital cancers and the precursor lesions (intraepithelial neoplasia), particularly of the cervix. Most, 99.7\%, of cervical cancers show HPV DNA sequences from a high-risk oncogenic genital HPV. The most prevalent types are HPV 16, found in 55-70\%, and HPV 18, found in 7-20\%, of cervical cancer cases (Ault, 2006; Beutner et al., 1998).

\section{HPV Prevalence and Transmission}

HPV infection is very common among young sexually active women and men. Approximately 20 million Americans between the ages of 15 and 49 are currently infected with HPV and another 6 million people become newly infected each year (Weinstock et al., 2004). Among these HPV infections, 74\% (4.6 millions) occur in the 15 to 24 year old age group (Weinstock et al., 2004). In the male population, the prevalence of genital HPV infection is difficult to assess because it is unclear which are the optimal anatomic sites or specimens to test (CDC, 2004). One systemic review of literature reported that HPV 
prevalence in men was between 1.3 to $72.9 \%$ (Dunne, Nielson, Stone, Markowitz, \& Giuliano, 2006). Many of the reviewed studies (56\%) reported a prevalence of $20 \%$ or higher among men.

In the female population, the prevalence of genital HPV infection peaks among women aged 20 to 24 years (44.8\%) and gradually declines among women aged 25 to 59 years $(19.6-27.5 \%)$ (Castellsague, 2008; Dunne et al., 2007). In a study of college-enrolled women who were HPV negative at the time of study enrollment, the cumulative 24-month incidence of HPV was 38.5\% among virgins who initiated sexual intercourse (Winer et al., 2003). In addition, the cumulative prevalence rate among adolescent women in selected populations was as high as $82 \%$ : indicating that nearly all sexually active adolescents are at high-risk for acquiring HPV (Moscicki, 2005). Most women in the world will be infected with genital $\mathrm{HPV}(\mathrm{s})$ at some time in their lives, with a lifetime risk for infection of 50 to $80 \%$ (Stanley, 2010).

The primary route of genital HPV infection is sexual intercourse, both vaginal and anal. HPV transmission occurs via skin-to-skin contact and penetration of the vagina or anus is not essential (Stanley, 2010). The only absolute way to prevent HPV infection is to refrain from genital contact with another individual (CDC, 2004).

Similar to other STIs, the risk factors for acquiring genital HPV infection are predominantly related to sexual behaviors. These factors include younger age, early age of first sexual intercourse, lack of condom use, having multiple sexual partners, acquisition of new sexual partners, and having partners who have multiple sexual partners or have a history of HPV infection (CDC, 2007; Dunne et al., 2007; Stanley, 2010). In a study of college women, a significant association was found between HPV infection and current smoking 
status, current oral contraceptive use, and having a new sexual partner who has had at least one prior female sexual partner (Winer et al., 2003). Regular and consistent use of condoms offers $60 \%$ protection against HPV infection; however, HPV can still be transmitted through contact with unprotected genital skin areas such as the vulva or scrotal sacs (Winer et al., 2006). The source of HPV transmission is usually from asymptomatic HPV infected persons who do not realize that they are infected (CDC, 2004).

\section{HPV Clinical Management}

While there is no cure for HPV infection, the current clinical practice strategy is to detect precancerous cervical lesions through regular Papanicolau (Pap) testing and treat highgrade precursors in order to reduce a woman's risk of developing invasive cervical cancer (Association of Reproductive Health Professionals [ARHP], 2009).

\section{Pap Testing}

Pap test, sometimes called Pap smear or cervical cytology, is used to examine cells collected from the cervix in order to detect cancer or abnormal cells that may lead to cancer (National Cancer Institute [NCI], 2010). In the U.S., the Pap test results are usually reported by using the standardized Bethesda System. Under the Bethesda System, samples that have no cell abnormalities are reported as "negative for intraepithelial lesion or malignancy" (NCI, 2010). Benign (non-neoplastic) findings may also be reported. The Bethesda System considers abnormalities of squamous cells and glandular cells. Sample with cell abnormalities are divided into the following categories, ranging from the mildest to the most severe (NCI, 2010): 
Squamous cell abnormalities:

1. ASC-atypical squamous cells, the most common abnormal finding in Pap tests. The Bethesda System divides this category into two groups:

- ASC-US-Atypical Squamous Cells of Undetermined Significance: The squamous cells do not appear completely normal, but specific cell changes cannot be determined. Sometimes the changes are related to HPV infection but they can also be caused by other factors.

- ASC-H-Atypical Squamous Cells, cannot exclude a High-grade squamous intraepithelial lesion: The cervical cells do not appear normal and specific cell changes cannot be determined. ASC-H lesions may be at higher risk of being precancerous compared with ASC-US lesions.

2. LSIL-Low-grade Squamous Intraepithelial Lesion: There are early changes in the size and shape of cells. Intraepithelial refers to the layer of cells that forms the surface of the cervix. LSILs are considered mild abnormalities caused by HPV infection. LSILs are sometimes referred to as mild dysplasia (abnormal cells that are not cancer but have the potential to become cancer). LSILs may also be referred to as cervical intraepithelial neoplasia (CIN-1). Neoplasia means an abnormal growth of cells and the number describes how much of the thickness of the lining of the cervix contains abnormal cellsonly the top layer, in this case.

3. HSIL_High-grade Squamous Intraepithelial Lesion: There are more evident changes in the size and shape of the abnormal (precancerous) cells which are more severe and have a higher likelihood of progressing to cancer. HSILs include lesions with moderate or severe dysplasia or carcinoma in situ (abnormal cells are present only on the surface of the cervix). Although HSILs are not cancer, they may become cancer and spread into nearby healthy tissue. HSIL lesions are sometimes referred to as CIN-2, CIN-3, or $\mathrm{CIN}-2 / 3$, indicating that the abnormal cells occupy most of the layers of the lining of the cervix.

4. Squamous cell carcinoma: Cervical cancer is when abnormal cervical squamous cells invade deeper into the cervix or to other tissues or organs.

Glandular cell abnormalities:

1. AGC-Atypical Glandular Cells: The glandular cells do not appear normal, but specific cell changes cannot be determined.

2. AIS - endocervical Adenocarcinoma In Situ: Precancerous cells are found in the glandular tissue. 
3. Adenocarcinoma : Such cancers can include not only endocervical cancer but also endometrial and extrauterine.

In developed countries, Pap testing, as a secondary prevention method has reduced the incidence of invasive cervical cancer by up to $80 \%$ (Adams, Jasani, \& Fiander, 2007). Although generally successful, limitations related to this Pap testing prevention strategy include anxiety and physical discomfort of screening investigation and poor Pap test uptake by some ethnic minorities (Adam et al., 2007). In addition, while both conventional Pap test (smear and slide) and new liquid-based cytology are acceptable screening methods, Pap test sensitivity and specificity are varied (ARHP, 2009; CDC, 2007). The sensitivity of the conventional Pap test ranges from $30 \%$ to $87 \%$ and the specificity ranges from $86 \%$ to $100 \%$. The sensitivity of liquid-based cytology ranges from $61 \%$ to $95 \%$ and the specificity ranges from $78 \%$ to $82 \%$ (CDC, 2007).

\section{Abnormal Pap Test Management}

Several medical organizations including CDC, American Cancer Society, and American College of Obstetrics and Gynecologists (ACOG) have issued guidelines for cervical cancer screenings that include HPV testing (CDC, 2007). If the Pap test shows mild abnormality, only repeated Pap test follow up may be required. For women who have ASC-US, a sample of cells may be tested for the presence of high-risk HPV types. If highrisk HPV is present, colposcopy (an examination using a magnifying device to observe the cervix) will usually be performed. On the other hand, a negative HPV test can provide reassurance that cancer or a precancerous condition is not present (NCI, 2010). 
If colposcopy finds abnormal tissues, endocervical curettage (scraping cells from inside the endocervical canal) or a biopsy may be performed. If testing shows abnormal cells that have a high chance of becoming cancer, further treatment options include:

1. Loop Electrosurgical Excision Procedure (LEEP) uses an electrical current that is passed through a thin wire loop to act as a knife to remove tissue.

2. Cryotherapy destroys abnormal tissue by freezing it.

3. Laser therapy uses a narrow beam of intense light to destroy or remove abnormal cells.

4. Conization removes a cone-shaped piece of tissue using a knife, a laser, or the LEEP technique (NCI, 2010).

\section{Impact of HPV Infection}

HPV has an incubation period of three weeks to eight months or more (Stanley, 2010). Most HPV infections are not serious. As a result of the human immune response, HPV infection may either resolve or become undetectable over time. Studies show that 7090\% of infections will clear without intervention within 36 months (Frazer et al., 2006). If HPV infection is not clear, it can cause several different diseases in men and women.

\section{HPV-Related Physical Health Outcomes}

\section{Low-risk HPV}

Low-risk HPVs cause anogenital condyloma, commonly referred to as genital or anal warts. Low risk HPVs can result in mild cervical abnormalities but it does not lead to cancer (Ault, 2006; Beutner et al., 1998). The most common outcome of low-risk HPV infection is condyloma acuminata. A national survey conducted from 1999-2004 demonstrated that $5.6 \%$ of sexually active $18-59$ years old self-reported a history of a anogenital condyloma diagnosis and the diagnosis trend is increasing (CDC, 2007). The majority of individuals 
who develop anogenital condyloma do so about two to three months after infection (Stanley, 2010). The main consequence of anogenital condyloma is aesthetic. Anogenital condyloma is usually asymptomatic; but, depending on the location and size, it can be pruritic, painful, or brittle. If left untreated, anogenital condyloma may remain unchanged or disappear (ARHP, 2009). Spontaneous regression of anogenital condyloma occurs in 10-30\% of infected individuals within three months (Stanley, 2010). However, anogenital condyloma often grows in size or numbers.

Rarely, these low-risk HPV types can also cause recurrent respiratory papillomatosis (warts) of the throat which can block the airways, causing a hoarse voice or breathing difficulty (CDC, 2011a). During pregnancy, anogenital condyloma may proliferate and become friable (ARHP, 2009). A pregnant woman with genital HPV who does not receive treatment with antivirals can transmit HPV to her baby during vaginal delivery (CDC, 2011a). In these cases, the child can develop Juvenile-Onset Recurrent Respiratory Papillomatosis. Approximately 2,000 children develop RRP every year in the U.S. (CDC, 2011a).

High-risk HPV

High-risk HPV infection is strongly associated with cervical, vulvar, vaginal, penile, anal, head, and neck cancers. Virtually $100 \%$ of cervical cancers are attributed to high-risk HPV (Stanley, 2010). Anal cancer (90\%), vaginal cancer (65\%), penile cancer (35\%), vulvar cancer $(50 \%)$, and oropharyngeal cancer $(60 \%)$ are also attributed to high-risk HPV (CDC, 2011c). Almost 7,600 HPV-associated cancers occur yearly in men. Approximately 400 men are diagnosed with HPV-relate penile cancer and 1,500 men are diagnosed with HPVrelated anal cancer each year (CDC, 2011d). Men who have sex with men (MSM) are 17 
times more likely to develop HPV-related anal cancer than men who only have sex with women (CDC, 2011d). Human Immunodeficiency Virus (HIV)-negative MSM have an estimated incident rate of anal cancer similar to the incidence of cervical cancer in women before the introduction of Pap testing. However, HIV- positive MSM are up to 40 times more likely to be diagnosed with the disease, resulting in a rate of 70-100 anal cancer cases per 100,000 persons (Kreuter et al., 2010; Margolies \& Goeren, 2009).

Women are also more likely to experience negative outcomes from HPV infection than heterosexual men. High-risk HPV infection follows the same pattern as low-risk HPV infection, but the time to clearance is 12 to 18 months (Stanley, 2010). Approximately 10$15 \%$ of women do not have a successful immune response to HPV and they remain HPV DNA-positive with persistent viral infection. The risk factors for persistent HPV infection and/or neoplastic progression include smoking, HPV type, increasing age, lack of condom use, immunodeficiency, other STIs, and oral contraceptive use (AHRP, 2009).

Women with persistent HPV infection are at higher risk for the development of highgrade cervical intraepithelial neoplasia (CIN) and invasive cervical cancer. The estimated time from the detection of high-risk HPV to the development of CIN3 is three to 15 years with HPV infection occurring in the late teens or early twenties and CIN-3 diagnosis peaking around 25-30 years of age (Moscicki et al., 2006; Schiffman \& Castle, 2003; Stanley, 2010). The progression to invasive cancer may take another 10-20 years with approximately 30$40 \%$ of CIN3 dysplasias actually progressing to invasive cervical cancer (Herraro, 2000; Stanley, 2010). However, a prospective, intensive follow-up study documented a more rapid development of CIN-2 and -3, sometimes within a few months after incident infection. The study noted that CIN-3 lesions tended not regress over short-term period and an 
observational follow-up of these lesions would be unethical (Winer et al., 2005). In the U.S., 12,000 women are diagnosed with cervical cancer and 4,000 women die from it each year (CDC, 2009). Southeast Asian and Latino women experience cervical cancer disparities, with rates 3 to 5 times higher than other racial/ethnic groups (Kline \& Huff, 2007).

\section{HPV-Related Psychosocial Health Outcomes}

HPV infection can have negative psychological consequences. Studies conducted with sexually active young women showed that most participants reported relief or happiness if HPV results were negative, and anxiety or distress if results were positive (Kahn et al., 2005; McCaffery et al., 2004). Some participants used coping mechanisms such as denial of an abnormal test result or its implications. Some participants who did not intend to disclose to their sexual partners tended to be HPV-positive and to view abnormal results as stigmatizing or shameful. The HPV-infected women also reported feeling worse about their past and future sexual relationships (Kahn et al., 2005; McCaffery et al., 2004). Another study that examined the psychological impact on women being tested for HPV also reported that women with borderline or mild dyskaryotic Pap test results who were HPV-infected described more anxiety and distress, and had more interpersonal concerns than women with borderline or mild dyskaryotic smear results who were not HPV-infected (Maissi et al., 2004). Anxiety, distress, and concern were higher when the perceived risk of developing cervical cancer was greater (Maissi et al., 2004). These results indicated that HPV-infection alone could have a negative psychological impact on women. In summary, research has indicated that possible psychosocial responses to an HPV diagnosis are anxiety, denial, regret, fear of cancer, shame, stigma, concern about loss of reproductive function, concern about negative reactions from sexual partners, concern about partner infidelity or hostility 
towards the person believed to be the source of HPV infection, and decrease in physically intimate activities (Kahn et al., 2005; Maissi et al., 2004; McCaffery et al., 2004).

For women with abnormal Pap test results, studies have shown significant increases in worry about cancer, and impairments in mood, daily activities, sexual interest, and sleep patterns (Bell et al., 1995; Lerman et al., 1991; Rubin \& Tripsas, 2010). A qualitative study conducted among women who had received HPV-related abnormal Pap test results showed that these women experienced confusion over test results, stigma, fear, self-blame, powerlessness, and anger (Daley et al., 2010). Women with an abnormal Pap test also reported feeling less attractive, tarnished, let down by their bodies, and reduced enjoyment in their sexual relationships (Bell et al., 1995).

In addition, women with abnormal Pap test may have to go through another emotional distress when an invasive procedure (e.g., colposcopy, LEEP, conization) is required. A published literature review reported that adverse psychological effects are also caused by the colposcopy examination itself, or anticipation of it (Rogstad, 2002). Women undergoing colposcopy reported anxiety, distress, fear, and concerns whether colposcopy would be painful and what would happen during the procedure. Six months after a diagnostic or treatment procedure of abnormal Pap test, women also reported decreased spontaneous sexual interest, frequency of intercourse, sexual arousal, and frequency of orgasm (Rogstad, 2002).

\section{Economic Burden}

In addition to negative physical and psychological outcomes that have been associated with HPV infection, there is also substantial economic burden. A study to examine the health care costs of cervical HPV-related disease in a U.S. health care setting 
reported that excluding the indirect cost, a routine Pap test approximately costs $\$ 60$ (Insinga, Glass, \& Rush, 2004). Costs that were associated with abnormal diagnoses ranged from \$299 for atypical squamous cells to \$2,349 for high-grade CIN (Insinga et al., 2004).

Estimated treatment costs for localized cervical cancer was at $\$ 20,255$ and for distance invasive cervical cancer was at $\$ 36,912$ per patient (Chesson, Blandford, Gift, Tao, \& Irwin, 2004). Approximately one to six billion dollars are spent in the U.S. annually for cervical cancer screening and treatment of pervasive and invasive cancerous lesions - making HPV the second most costly STI, second only to HIV (Frazer et al., 2006).

As previously mentioned, evidence also supports a role of high-risk HPV in other malignant lesions (e.g., anal, penile, vulva, vaginal, head and neck cancers). The epidemiology and costs associated with these cancers are not well-documented (Frazer et al., 2006). However, the economic burden of cancer generally is substantial. One study calculated the direct medical cost of cancers (i.e., brain, colorectal, lung, ovarian, pancreatic, prostate, and lymphoma) during 1999 to 2000 at $\$ 32,629$ per patient. For anogenital warts, the average treatment cost after a new diagnosis is $\$ 446$. The total direct cost associated with anogenital warts for all age-groups is \$167.4 million (Chesson et al., 2004).

\section{HPV and College Women}

College student enrollment was 20.4 million in 2009 (U.S. Census Bureau, 2011). College enrollment is expected to continue to set new records through 2017. Between 2007 and 2017, the enrollment is expected to increase by $10 \%$. Despite decreases in the traditional college-age population during the late 1980s and early 1990s, the traditional college-age population (18 to 24 years old) rose 16 percent between 1997 and 2007(National Center for Education Statistics, 2009). Historically, men were expected to attend college and obtained 
professional jobs. Women were presumed to be a homemaker or working for low-paid administrative or service labor. However, things have changed in the last three decades. By the 1980s, the majority of new freshman attending college each year were females. In 2004, 9.9 million women were attending the nation's accredited postsecondary schools, compared to only 7.4 million men; since then the gender gap has only grown (Education Portal, 2007; Lewin, 2006).

Even though higher education and younger age are positively related with health status in general, women attending college are still exposed to various risk factors that make them susceptible to adverse health outcomes such as unintentional or intentional injuries, unintended pregnancy, and STIs, including HPV (CDC, 1997). As previously mentioned, it is estimated that $75 \%$ of all new HPV infection, or 4.6 million cases annually, occur among men and women 15-24 years of age (Weinstock et al., 2004) and the HPV infection prevalence is highest among young women aged 20 to 24 years (Dunne et al., 2007). College-age women are among those at greatest risk of acquiring HPV because a number of physiological, behavioral, and psychosocial factors increase college-age women's risk of HPV (CDC, 2007; Linnehan \& Groce, 1999).

Physiologically, it has been hypothesized that adolescent and young women are most at risk because of the cervical maturation process following menarche. During this normal process, the squamous columnar junction of the cervix (transformation zone) naturally undergoes squamous metaplasia - a process of rapid cell differentiation and replication. This epithelium type is a natural host to HPV because it requires both cell differentiation and replication to sustain protein expression and viral replication (Fraser et al., 2006). If early initiation of sexual intercourse occurred during this process, risk of acquiring HPV may 
increase because squamous epithelium can be more susceptible to infection. In addition, smoking is another factor that possibly makes young women susceptible for HPV infection and cervical cancer because tobacco may lower the body's immune responses and help HPV16 grow faster (Gunnell et al., 2006).

Most young adults attending colleges or universities are living away from home and adult supervision for the first time, and are provided with an environment in which to engage in unprotected high risk sexual behaviors. The 2010 National College Health Assessment reported that most college women (69.9\%) have had vaginal intercourse. Most of college women $(86 \%)$ are single and $10 \%$ are married or in a long term relationship. Close to a quarter $(24 \%)$ of college women have more than two sexual partners within the last 12 months (American College Health Association [ACHA], 2010). Among college women who had vaginal intercourse within the last 30 days, $40.7 \%$ either never or rarely used a condom or other protective barriers (ACHA, 2010).

Drinking is another common factor that may place college women at higher risk for HPV infection and other STIs. A study indicated high rates of alcohol use and binge drinking as well as a fairly large number of daily drinkers among college students. College women had a higher prevalence of using alcohol in the previous 30 days and a higher rate of binge drinking than non-college women at the same age (Johnston, O’Malley, \& Bachman, 2003). Drinking was related to the decision to have sex and to indiscriminate forms of risky sexual behaviors (e.g., having multiple or casual sex partners, not using condom) (Cooper, 2002). Over $13 \%$ of college women reported that they had unprotected sex as a consequence of alcohol in the past 12 months (ACHA, 2010). College students aged 18 to 24 years (19.3\%) were also significantly more likely than students 25 years or older $(13.1 \%)$ to have 
used alcohol or drugs at last sexual intercourse (CDC, 1997). In addition, college students may overestimate the extent to which their peers are sexually active. Most students underestimated the extent to which other students are sexually responsible in their personal behaviors and attitudes. While most students who are sexually active have had only one partner in the recent past but college women's perception is that most have had multiple partners (Berkowitz, 2003). This is an incorrect perception which can lead to an assumed norm of multiple partners (Berkowitz, 2003).

Another factor that can increase college women vulnerability to HPV is environment resources. As Flaskerud and Winslow (1998) described, environmental resources are operationalized as access to health care and quality of care. The lack of these environmental resources leads to increased morbidity and premature mortality. College students aged 21 to 24 years old may not have a regular resource of healthcare services, unless their employers provide health insurance or unless they attend a college with some healthcare services (Koumans et al., 2005). With the lack of environment resources, college women may not be able to routinely obtain Pap test, receive appropriate treatment for abnormal Pap tests, and receive health education regarding HPV prevention including HPV vaccine information (Jain et al., 2009).

\section{HPV Vaccine}

HPV Vaccine as a Primary Prevention Method

The opportunity for prevention of HPV infection was presented with the 2006 licensing of HPV vaccine in the United States. The quadrivalent HPV vaccine (HPV4;

Gardasil $^{\circledR}$ ) was approved for girls and women aged 9-26. Routine vaccination with a series of three doses is recommended for girls aged 11-12 and "catch-up" vaccination among girls 
and women aged 13-26 (CDC, 2010a). In 2009, a bivalent HPV vaccine (HPV2; Cervarix ${ }^{\circledR}$ ) was licensed for use in females aged 10-25. Both HPV2 and HPV4 are composed of viruslike particles and are not live vaccines. HPV2 is directed against two oncogenic types (HPV 16 and 18) which are accounted for $70 \%$ of cervical cancer. HPV4 is directed against two oncogenic types (HPV 16 and 18) and two non-oncogenic types (HPV 6 and 11) (CDC, 2010a). Similar to HPV4, HPV2 provides close to 100\% efficacy against HPV 16- and 18related CIN2/3 or AIS (CDC, 2010a). In all clinical trials, nearly $100 \%$ of participants developed the HPV antibody response one month after completing the 3-dose series (CDC, 2010a). Current evidence suggests that vaccine protection is maintained over a period of 6.4 years with HPV2 (GSK Vaccine HPV-007 Study Group, 2009) and 5.5 years with HPV4 (Stanley, 2008). At present, there is no evidence of a falling immunity with time and whether vaccination boosting will be required is a key unknown.

The Advisory Committee on Immunization Practice recommends vaccination with HPV2 or HPV4 for prevention of cervical cancers and pre-cancer lesions. Both Gardasil and Cervarix vaccines might provide protection against some other HPV-related cancers in addition to cervical cancer. However, current data recommends only Gardasil for protection against vulvar and vaginal cancers and pre-cancers (CDC, 2010a). Recently, Gardasil was also approved for use in males aged 9-26 for prevention of anal intraepithelial neoplasia, anal cancer, and genital warts (U.S. Food and Drug Administration, 2010).

Gardasil and Cervarix have the same dosing and administration. Each dose is 0.5 $\mathrm{mL}$, administered intramuscularly. The vaccines are administered in a 3-dose schedule. The second dose is administered one to two months after the first dose and the third dose is administered six months after the first dose (CDC, 2010a). Gardasil cost is approximately 
$\$ 360$ for three doses (Hager, 2009). Currently, there is no legislation that requires insurance providers to cover the cost of Gardasil (Dubois, 2010). However, the vaccine manufacturer (Merck) has Patient Rebate Program to rebate the cost of Gardasil if the patient insurance does not cover the entire cost of the vaccine. The patient out-of-packet payment is no more than $\$ 30$ per dose (Merck, 2011a). The patient without health insurance, older than 19 years old, and low income can also apply for Gardasil's Patient Assistance Program. If the patient is qualified, she/he can obtain Gardasil at no cost (Merck, 2011b). Cervarix cost is similar to Gardasil. The vaccine manufacturer (GlaxoSmithKline [GSK]) also has a Vaccine Access Program providing financial assistance for women between 19 to 25 years old who are low income and do not have a health insurance (GSK, 2011).

\section{HPV Vaccine Uptake Rate}

Both HPV vaccines have been proven to be safe and have high efficacy against HPV 16 and 18-related cervical pre-cancer lesions (CDC, 2010a). Studies conducted in 2007 showed that between 5 to $16.2 \%$ of the participants received at least one dose of an HPV vaccine (Allen et al., 2009; Caron, Kispert, \& McGrath, 2009; Caskey, Lindau, \& Alexander, 2009; Conroy et al., 2009; Kahn et al., 2008). A later study that collected data among 972 college women from 2007 to 2009 showed that $49 \%$ of the participants received at least one dose of an HPV vaccine (Roberts, Gerrand, Reimer, \& Gibbons, 2010). Similarly, a study published in 2010 reported that $43.6 \%$ of the participants received at least one dose of the HPV vaccine (Licht et al., 2010). In November, 2010, a survey conducted at a large, public university in California showed that only $30 \%$ of women aged 18 to 26 had received at least one dose of HPV vaccine (CSULB, 2011). 
National data similarly show low vaccine uptake. For adolescents aged 13-17, 44.3\% have received at least one dose and 26.7\% have received three doses of HPV vaccine (CDC, 2010b). For women aged 19-26, 17.1\% have received at least one dose of HPV vaccine (CDC, 2011b). A review literature reports that, depending on settings, the HPV vaccine completion rate is between 4\%-47\% among college-aged women (Sheinfeld Gorin et al., 2011). Overall, HPV vaccine uptake rates in the U.S. are considerably lower than many other developed countries (e.g., Australia, Canada, and Netherlands) (Sheinfeld Gorin et al., 2011). The low uptake result rose a question "why have college women not obtained the HPV vaccine while most of them are sexually active (70-77\%)?" (ACHA, 2010; CSULB, 2011).

\section{HPV Vaccine Controversy}

Gardasil is considered to be a "medical breakthrough" (Bailey, 2008) and the vaccine appears to be a cost-effective intervention with the potential to enhance both adolescent health and the quality of their adult lives (Rothman \& Rothman, 2009). The vaccine manufacturer has launched national print, television, and on-line advertisement campaigns in 2006. The messages and the methods Gardasil delivered presented important challenges. Marketing Gardasil vaccine as an anticancer vaccine appeared to create possible parental and public unease (Rothman \& Rothman, 2009). The controversy surrounding Gardasil focused on two main issues; vaccinating young girls against STI and determining whether Gardasil should be mandatory for all school-aged girls (Vamos et al., 2008).

A question regarding giving children a "license" for sex was raised. It was discussed that adolescents may not fully understand about HPV vaccine protection and may overgeneralize the vaccine to include protection against other STIs. Conservative politicians, 
religious groups, and advocacy groups have voiced concerns about whether receipt of HPV vaccine might also encourage unsafe sexual practices, promote premarital sex, and provide children tacit permission to engage in risky sexual behaviors. Mandating HPV vaccine may give young girls mixed messages between abstinence and premarital sex (Bailey, 2008; Vamos et al., 2008).

Vaccine cost to complete HPV vaccine series is also discussed widely. A new health disparity exists as women who have access to healthcare and routine screening are more likely to receive the HPV vaccine while women without access, who are likely the most vulnerable for cervical cancer, are less likely to obtain the vaccine (Vamos et al., 2008). In addition, some vaccine-related questions remain unanswered. Those questions include whether the prevalence of non-vaccine HPV types will increase, how long the immune response will last, whether the booster doses are needed, whether the long term data continue to reveal good tolerability and safety, and whether immunization discourage young women from having routine Pap test (Hager, 2009; Vamos et al.,2008).

Another concern was raised regarding the vaccine manufacturer intention to fund various education programs through professional medical associations in the U.S. While it might be reasonable for professional medical association (i.e., Society of Gynecologic Oncology, American Society for Colposcopy and Cervical Pathology, and American College Health Association) to promote medical intervention they believe in, it was questionable if those associations helped market the vaccine and influence decisions about the vaccine policy with the help of ready-made presentations, slide sets, e-mails, and letters (Haug, 2009; Rothman \& Rothman, 2009). Furthermore, another controversy was shown when a politician passed the mandatory vaccination bill in Texas without its state involvement and Gardasil 
manufacturer was suspected to engage in unduly influence of certain politicians to make such decision by providing funding for political campaigns (The Midwife, 2007). Low vaccine uptake rate and the various controversies raise two questions related to college-aged women-"what factors influence their decision to obtain the vaccine?" and "does the vaccine status associate with higher-risk sexual behaviors?"

\section{Factors Influencing HPV Vaccine Uptake and Sexual Behaviors}

Comprehensive literature review was performed to examine HPV and HPV vaccine attitudes among traditional college-aged women and the relationship between HPV vaccine uptake and subsequent sexual behaviors. The search engines PubMed, Medline, the Cumulative Index of Nursing and Allied Health Literature (CINAHL), and Google Scholar were used to identify research studies on the topic of HPV and HPV related-attitudes in college women. Search terms used were: HPV, Attitude, Belief, and Women, which produced 1,556 articles. Using wording criteria of: HPV infection, HPV vaccine, HPV vaccine uptake, attitude, belief, perception, adoption, and acceptability on the article titles, 62 non-repeated articles were chosen for abstract review. After excluding general reviews, commentaries, systemic review articles, and letters to the editor, 40 articles were reviewed. Then, studies conducted before the HPV4 vaccine became available, outside of the collegeaged woman population, and outside the United States were excluded from review. The decision to include only U.S. studies was based on the assumption that significant differences in HPV vaccine related knowledge, attitudes, and sexual behaviors might exist based on the vaccine's availability in a particular country, and its cultures, policies, and health care systems. 


\section{HPV and HPV Vaccine Knowledge}

Since Gardasil was approved in 2006, researchers have documented an increased awareness of HPV and HPV vaccine among college-aged women. Three studies conducted among college students, shortly after the vaccine was released, reported that $78.5-94.0 \%$ of college women had heard about HPV through various sources, especially from television and radio (Allen et al., 2009; Gerend \& Magloire, 2008; Lopez \& McHahan, 2007). Out of the women who were aware of HPV, most (89.0-92.0\%) knew that HPV causes cervical cancer. However, some (45\%) did not know HPV causes genital warts and $42 \%$ did not know that the vaccine exists to prevent certain types of HPVs (Lopez \& McHahan, 2007). Another study conducted among 293 female students at a large Northeastern State University showed similar result (Caron et al., 2008). Many of the female students (85\%) have heard about HPV and HPV vaccine. The most common sources of information were from television commercials. The study found correlations between how self-reported knowledge influenced attitudes, behaviors, and beliefs regarding the HPV vaccine (Caron et al., 2008). Nonetheless, these studies were conducted in 2007, not long after the vaccine was released.

In 2008, a study was conducted among 212 women aged between 18- 26 who attended three health clinics in Utah (Holguin, 2009). The finding was similar to previous studies that awareness was high $(81.1 \%)$ and many of them $(76.9 \%)$ knew the association between cervical cancer and HPV. However, $57.5 \%$ could not correctly identify proper ways

for decreasing risk of getting HPV infection. Many of them (79.2\%) also could not identify ways to prevent themselves from acquiring cervical cancer. A more recent study was conducted in 2009 among 739 college women (Gerend \& Shepherd, 2011). The study reported that over $97 \%$ of college women who have not received the vaccine were aware of 
HPV. The HPV knowledge score remains moderate (4.9 out of 10). Most female students (84\%) knew that genital HPV infection is linked to cervical cancer. Nevertheless, knowledge of the casual relationship between HPV and genital warts and the transient nature of most HPV infection was low (30\% and 16\%, respectively). Summarily, it appears that HPV awareness has been increased. College women also know that HPV infection is associated with cervical cancer. Nonetheless, overall HPV knowledge remains low. Insufficient HPV/ HPV vaccine knowledge may impede women from receiving HPV vaccine and participating in cervical cancer screening activities when they are at age of 21 (Head, Crosby, \& Moore, 2009).

\section{HPV and HPV Vaccine Related Attitudes}

Across various studies reviewed, HPV and HPV attitudes were often used interchangeably and measured through belief, opinion, perception, acceptability, and intention constructs. Despite the challenges of comparing findings across studies, many of the studies suggested that most participants (80.7-93.5\%) believed that contracting HPV would be severe and having cervical cancer would be devastating (Holguin, 2009; Lopez \& McMahan, 2007; Zimet, Weiss, Rosenthal, Good, \& Vichin, 2010). However, many participants (50-84.4\%) did not feel that they were at risk for HPV (Bynum, Wright, Brandt, Burgis, \& Bacon, 2009; Conroy et al., 2009; Licht et al., 2010; Roberts et al., 2010). This significant underestimation of personal risk can lead college-aged women to deter Pap tests and to decide not to get the HPV vaccine.

Interestingly, one study found that $72.4 \%$ of 1,401 participants falsely believed that HPV could be cured with the right treatment. Sexual history and relationship status were related to HPV risk perception. Women who had initiated sexual intercourse, had higher 
numbers of sexual partners, and had not been married were more concerned about getting HPV (Caron et al., 2009). These data suggested that sexual experience might influence women's attitudes toward HPV.

One study conducted with 293 women at a university setting reported a statistically significant relationship between HPV attitudes (concerns of contracting HPV) and HPV knowledge (Caron et al., 2009). Contrarily, another study conducted among 212 women at three health clinics concluded that perceived susceptibility was not significantly related to HPV knowledge (Holguin, 2009). Female college students (82.8\%) from a large public university agreed that females between 9 to 26 years old should be vaccinated against HPV. Among these female college women, many (69.1\%) were likely to recommend an HPV vaccine to others (Caron et al., 2009). Many studies reported that most young women (5379.5\%) intended to obtain HPV vaccine at some point in the future (Allen et al., 2009; Burke, Vail-Smith, White, Baker, \& Mitchelle, 2010; Bynum et al., 2009; Caron et al., 2009; Kahn et al., 2008). One study reported that only $26 \%$ of college-aged women had received or intended to obtain the vaccine and $38.2 \%$ of college-aged women were not sure if they would receive the vaccine (Holguin, 2009). Another study specifically indicated that $61.2 \%$ of college-aged women who never had had sex intended to get the HPV vaccine (Burke et al., 2010).

Normative belief and social norms (Allen et al., 2009; Kahn et al., 2008), perceived severity, perceived benefits, and knowledge were positively correlated with intention to obtain HPV vaccine (Kahn et al., 2008). Vaccination intention was also inversely associated with lack of insurance, perceived barriers, pregnancy history, and riskier sexual behaviors (one or more versus zero sexual partners in the past three months, never versus always used 
condoms). HPV knowledge was an independent predictor of vaccination intention. Normative beliefs, perceived barriers, perceived severity, and pregnancy history could predict vaccination intention (Kahn et al., 2008).

In summary, this literature review found that college-aged women generally had positive attitudes toward HPV vaccine and believed that the vaccine was very important. Most of them also intended to obtain the vaccine and indicated that they would likely recommend the vaccine to others. The relationship between knowledge, attitudes (i.e., normative beliefs, perceived severity, perceived benefits, and perceived barriers) and vaccination intention was statistically significant. Some sexual experience and knowledge might play a role in HPV risk perception. Lack of HPV and HPV vaccine knowledge may contribute to misperception (Caron et al., 2009) and negative attitudes toward the vaccine may also impact the vaccination intention (Ajzen, 1991).

Currently, no available study has directly examined what women think about getting vaccinated against HPV, what women think about mandating the vaccine, and how the vaccine controversies have made an impact on their decision to get the vaccine. The studies in this review also did not provide specific reasons why women believed that they were not at risk of acquiring HPV (Caron et al., 2009; Holguin, 2009; Licht et al., 2010; Lopez \& McMahan, 2007).

Sexual Behaviors Associated with Receipt of HPV Vaccine The HPV vaccine uptake rates have slowly increased among teenage and young women in the U.S. population. The rising vaccine uptake rates might suggest the possibility of a more generalized temporal increase in adherence with HPV vaccine recommendation (Licht et al., 2010). The relationship between HPV knowledge and vaccine uptake has been 
found to be inconsistent. Two studies found that HPV knowledge was not statistically different between the non-vaccinated and vaccinated groups (Conroy et al., 2009; Licht et al, 2010). On the other hand, two studies conducted at two different universities found that vaccination status was statistically correlated with knowledge (Allen et al., 2009; Roberts et al., 2010). HPV knowledge was significantly higher in the vaccinated group. This inconsistency supports the belief that knowledge is not directly linked to behaviors (Ajzen, 1991).

Attitudes related to HPV vaccine may also impact how college women decide whether or not to receive the HPV vaccine. A relationship between some types of attitudes (i.e., normative beliefs, perceived risk) and vaccination status was found. In a study conducted with 19-26 years old insured women, most (81.4\%) of those who had received the vaccine perceived the HPV vaccine as very important, while only $32.4 \%$ of those who had not received the vaccine thought that the HPV vaccine was very important (Rosenthal et al., 2010). A longitudinal study conducted at a teen health center showed that normative beliefs could predict vaccination status. Perceived barriers, perceived benefits, fear of a shot, perceived severity, and self-efficacy were not statistically different between non-vaccinated and vaccinated groups. Intention to receive the vaccine was unexpectedly not a predictor of vaccination uptake (Conroy et al., 2009). The researchers explained that given the fact that 90\% of non-vaccinated participants (at base line) had neither returned to the physician or been offered the vaccine, many of those intending to receive the vaccine might likely not have a chance to do so during the short follow-up period of six months. Moreover, the study sample was predominantly African American and $86.7 \%$ of non-vaccinated participants reported that concerns about insurance coverage prevented them from getting the vaccine. 
In two studies conducted at university settings, vaccination status was associated with perceived risk (Licht et al., 2010; Roberts et al., 2010), perceived communication with mother about sex, and approval from the mother (Roberts et al., 2010). As expected, undecided or contemplating participants had lower perceived severity, while vaccinated participants had significantly lower perceived barriers (Allen et al., 2009). Various studies have demonstrated that the reasons for not obtaining the HPV vaccine included cost (14.6$41.8 \%)$, concerns about side effects or efficacy $(<5-42.9 \%)$, lack of information (31.7$36.2 \%)$, lack of transportation (22\%), inactive sexual status (19.1\%), new vaccine (35.4\%), and others (i.e., pregnancy, monogamy/marriage, history of HPV infection) (23-54.9\%) (Burke et al., 2010; Bynum et al., 2009; Caskey et al., 2009; Conroy et al., 2009; Holguin, 2009; Zimet et al., 2010). Four studies reported an additional reason for not vaccinating was lack of insurance coverage (Conroy et al., 2009; Holguin, 2009; Rosenthal et al., 2010; Zimet et al., 2010). In these cases, perceived barriers might outweigh the vaccination intention. The women might intend to obtain the vaccine, but may not be able to do so because of a lack of insurance or financial resources.

Other factors associated with vaccination status included age, insurance coverage, pap test history, pregnancy history, having a regular primary care provider, student status, and physician recommendations (Caskey et al., 2009; Conroy et al., 2009; Rosenthal et al., 2010). STI diagnosis history and early sexual debut was not a significant predictor of vaccination (Caskey et al., 2009). A history of having vaginal sex, unprotected sex with a casual partner, and numbers of sexual partners were not associated with vaccination status (Roberts et al., 2010), but condom use at the last sexual intercourse was associated with vaccination status (Conroy et al., 2009). Vaccinated participants reported a significantly higher rate (60.8\%) of 
condom use at the last sexual intercourse compared to non-vaccinated participants (42.3\%). A cautious interpretation could be made that women who received the vaccine did not engage in higher risk behaviors after receiving the HPV vaccines. However, the question of whether the college-aged women have changed their sexual practice after the vaccination remains.

\section{Theory of Planned Behavior}

Ajzen and Fishbein (2004), social psychologists, formulated the theory of reasoned action (TRA) in the early 1960s based on expectancy-value model. The expectancy-value theory was originally created in order to explain and predict individual's attitudes toward objects and actions. Ajzen and Fishbein (2004) created the TRA after trying to estimate the discrepancy between attitude and behavior. The theory assumes that people are rational and make decisions based on information available to them. The theory focuses on the relationship among beliefs, attitudes, intention, and voluntary behaviors. The TRA explains that a person's behavior is determined by his/her intention to perform the behavior. Later on, the concept of perceived behavioral control was incorporated into the TRA to create the theory of planned behavior to enhance the predictive power of the theory (Ajzen, 1991).

The theory of planned behavior (TPB) posits that the best predictor of behavior is intention (Ajzen, 1991). Intention is the cognitive representation of a person's readiness to perform a given behavior and it is considered to be the immediate antecedent of behavior. This intention is determined by three things; attitude toward the specific behavior, subjective norms, and perceived behavioral control.

The theory of planned behavior refers to "attitude toward the behavior" as "the degree to which a person has favorable or unfavorable evaluation or appraisal of the behavior in question" (Ajzen, 1991). Attitudes are made up of the beliefs people hold about the object of 
the attitude and the associated evaluation of that belief. Attitude is "a product of each belief which is weighted by the evaluation of the outcome or attributes" (Ajzen, 1991). Attitude concerns with one's belief about the consequences of performing the behavior. Attitudes assumed to form a bipolar continuum, from negative evaluation on one end to a positive evaluation on the other (e.g., worthless-valuable, harmful-beneficial, undesirable-desirable, unfavorable-favorable). The TPB believes that human behavior is associated to sets of attitudes or personal belief. However, only specific attitudes toward the behavior in question can be expected to predict that behavior.

Behavioral beliefs strongly influence the individual's attitude about the desirability of any specific behavior (Ajzen, 1991). These beliefs underline and pre-condition an individual's attitude toward specific behaviors. People can hold great many beliefs about any given behaviors, but they can attend to only a relatively small number at any given moment. It is assumed that this salient belief, combining with subjective values of the expected outcomes, determine the prevailing attitude toward the behavior (Ajzen, 2010a).

Subjective norms are one's beliefs about how people they care about will view the behavior in question (Ajzen, 2010a). It is determined by normative beliefs. Normative belief is a perceived social pressure to engage or not to engage in a behavior. It is the perceived behavioral expectations of important referent individuals or groups (e.g., spouse, family, friends, and doctor). Subjective norms are the products of each normative belief weighted by motivation to comply. To predict someone's intention or behaviors, knowing these beliefs can be as important as knowing the person's attitudes.

Perceived behavioral control refers to people's perceptions of their ability to perform a given behavior (Ajzen, 2010a). It is assumed that perceived behavioral control is 
determined by control beliefs - the beliefs about the presence of factors that may facilitate or impede performance of the behavior. In other words, perceived behavioral control is a product of each control belief which is weighted by the perceived power of the control factor (Ajzen, 1991). Perceived behavioral control affects behavioral intention and the actual behavior.

In general, the more favorable the attitude toward the behavior, the more favorable subjective norms, and the greater the perceived behavioral control, the stronger the person's intention to perform the behavior in question (Ajzen, 2010a). The relative importance of attitude toward the behavior, subjective norms, and perceptions of behavioral control for the prediction of intentions is expected to vary from behavior to behavior and population to population (Ajzen \& Fishbein, 2004). The theory of planned behavior believes that knowledge plays an indirect role in behavioral intention and actual behavior (Ajzen, 2011). The TPB argues that although information in the form of behavioral-related beliefs is a component of the theory, whether that information is correct or incorrect is impertinent. Attitudes toward the vaccine, demographic characteristics, past behavioral experiences, and social norms are also indirect factors to the behavior (Ajzen, 2011). The TPB related constructs and their relationships are illustrated in Figure 1. 


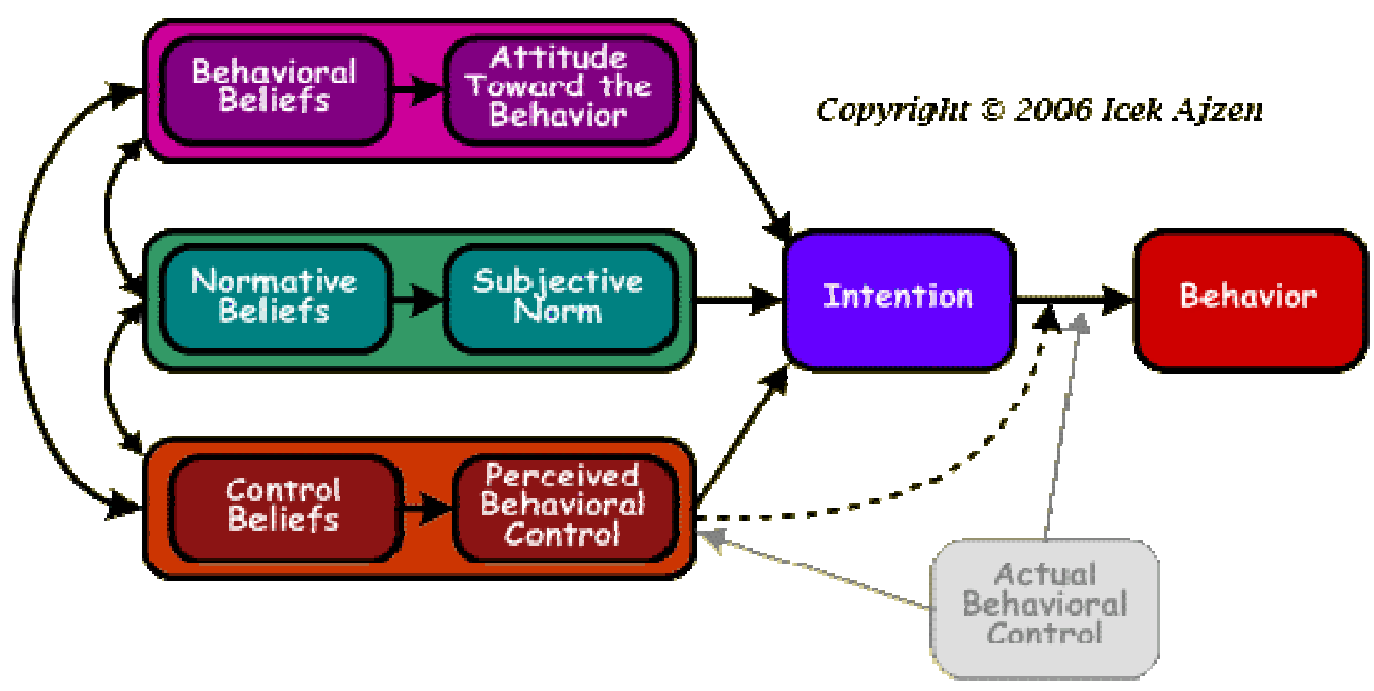

Figure 1. Theory of Planned Behavior Model (Ajzen, 2010a)

\section{Theory Application}

The TPB has been used in multiple studies focused on predicting health behaviors such as exercise, birth control behavior, condom use, and response to health messages about HPV vaccine (Costar, 2007). The TPB is applicable for use in the nursing discipline, especially in health promotion and disease prevention (McEwen \& Wills, 2007). Health behaviors may be explained by the TPB and some health prevention measures can be created by changing the factors (e.g., attitude, subjective norms, and perceived behavioral control). For example, nurse researchers (Jemmott, Jemmott, \& Fong, 1998) used the TPB as a study framework to evaluate the effects of abstinence and safer-sex HIV risk-reduction interventions on young African-American community. The intervention was designed based on the social cognitive theory and TRA/TPB theory to increase HIV/STI knowledge, strengthen behavioral beliefs, and increase self-efficacy and skills. 
The theory of planned behavior has been widely used to understand health-related behaviors in various populations, including the college-aged population (Costar, 2007). The theory provides a framework for understanding the antecedents to desired behaviors, such as HPV vaccine uptake and sexual behaviors. This dissertation was guided by the TPB and its application is illustrated in Figure 2. By using the TPB, findings from this study informed future interventions that aim to increase HPV vaccine uptake rate.

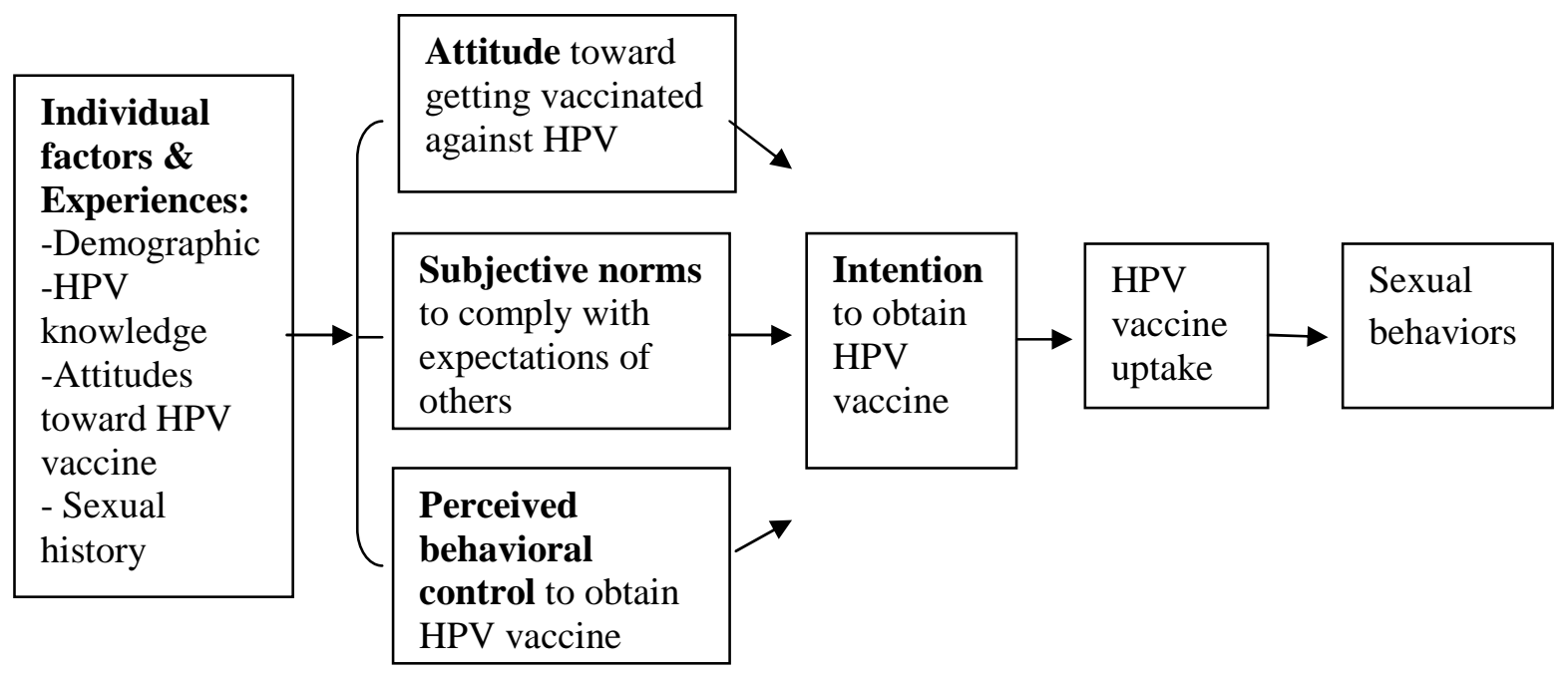

Figure 2. Study Theoretical Framework 


\section{CHAPTER 3}

\section{METHODOLOGY}

\section{Research Design}

This study used a cross-sectional design with a convenience sample to identify factors that influence HPV vaccine uptake among college women and to examine the post-vaccine sexual behaviors/practices of college-aged women. The theory of planned behavior served as the theoretical framework for the study.

\section{Setting and Sample}

The sample for this study consisted of female, undergraduate college students between the ages of 18 to 26 years. This age range was chosen because it represents the traditional age range of college students. The maximum age range also aligns with the age limit (26 years old) to receive the HPV vaccine. Participants were recruited from California State University_Long Beach (CSULB), where the student body is diverse. A random sampling list of the students' email addresses was requested through CSULB Enrollment Services. After retrieving all female undergraduate student email addresses, the Enrollment Services excluded the students who were younger than 18 and older than 26 years old. Then, the email addresses were sorted based on the student ethnicities; Caucasian, AfricanAmerican, Asian, and Hispanic. Within each ethnicity, the sample was chosen by using an SPSS program to randomly choose 800 of the retrieved email addresses. However, in the African-American group, only 674 eligible students were enrolled. Thus, a total of 3,074 email addresses was obtained.

The sample size calculation for two-tailed statistical tests was based on the following parameters: power of 0.8 , moderate effect size $(0.3)$, and alpha equals 0.05 . For correlation 
coefficients, 84 vaccinees and 84 non-vaccinees were needed (Faul, Erdfelder, Buchner, \& Lang, 2009; Munro, 2005). Forty-five non-vaccinees were needed for multiple regression analysis (with four predictors) based on a priori power analysis by $\mathrm{G}^{*}$ Power computer program (Faul et al., 2009). A minimum of 242 subjects (both vaccinees and non-vaccinees) was needed for logistic regression with odds ratio of 1.5 (assuming positive attitudes related to vaccination) (Faul et al., 2009). Alternatively, a minimum of 20 cases per predictor was needed for logistic regression. For five predictors, at least 100 subjects were needed (Leech, Barrett, \& Morgan, 2008). For ANCOVA group comparison between vaccinees and nonvaccinees, 90 subjects were needed for each group (Faul et al., 2009).

\section{Procedures for Data Collection}

Institutional Review Board approval was obtained for this study. An email invitation to participate in the study was sent to 3,074 enrolled women at the university in February, 2012. The email contained information about HPV and the purpose of the study. In the email invitation, women were directed to click on a web-based survey (i.e., SurveyMonkey link) if they were interested in study participation.

The first page on the web-based survey was an informed consent page (Appendix A). At the end of the informed consent page, there were two boxes stating that either the college woman agreed or did not agree to participate in the study. When the woman did not agree to participate, SurveyMonkey webpage would automatically close. When the woman agreed to participate, she was directed to another page to complete the study questionnaire. To enhance study participation, two email reminders were sent one week and two weeks after the initial study invitation was sent, unless an individual requested to be removed from the email list. 
A "prize" strategy to enhance participation in the research study was utilized. Study participants had the opportunity to draw a prize, if they were one of the first 305 participants to come to the Student Health Services (SHS) on campus. There were 305 prizes available (Five $\$ 100$, ten $\$ 50$, and $290 \$ 10$ Beach Club gift cards). The Beach Club is a university card that can be used to make purchases at the bookstore and various food vendors on campus. Information about prizes was provided to participants on the informed consent page. Instructions on how to obtain the prize was written on the Closing Statement, the last page of the survey.

When the participants arrived at SHS on campus, they needed to provide their email address so the researcher could confirm that this was a randomly chosen respondent. Their email address was checked off (from the email list provided by the Enrollment Services) so that they did not attempt to draw more than one prize at a later time or someone who was not chosen for the study attempts to draw a prize. To provide optimal anonymity, the researcher did not open the data collected in the SurveyMonkey web link to confirm the participant's answers so that there was no link between the participant's email address with the responses on the electronic file. The web-based survey was deactivated four weeks after the invitation was sent out. The data set from SurveyMonkey, in the Excel format, was downloaded to the researcher's computer. Then, the researcher converted the Excel format data file to SPSS format data file by using "Open data" function in SPSS.

\section{Protection of Human Subjects}

Permissions to conduct the study were obtained from the University of MissouriKansas City Social Sciences Institutional Review Board (SSIRB) and California State University-Long Beach Institutional Review Board prior to beginning study procedures. The 
IRB authorization agreement between UMKC and CSULB and CSULB IRB approval letter are attached in Appendix B and C. To protect human subjects:

1. The electronic informed consent was sent to the potential participants. If the participants chose to complete the survey, then it was assumed that they understand their rights as a human subject. The informed consent explained the safeguards undertaken by the researcher to ensure the privacy of the subjects.

2. Under DHHS Human Subjects Guidelines (46.116), the researcher requested that the signature requirement on the informed consent form be waived. This request was necessary because the electronic survey could hardly be practicably carried out without the waiver or alteration.

3. To minimize self-selection bias and increase candid response regarding sexual practice questions, the purpose of the study was simplified and generalized as "the purpose of this study is to examine what college women know, think, and do about HPV and HPV vaccine".

4. The participants were provided with the researcher contact information. The participants could contact the researcher to ask and clarify any questions before they proceeded to answer the survey.

5. The participants were informed in the consent that they might choose not to answer any particular question(s) on the questionnaire that they wished. They could either skip the questions or choose "prefer not to answer" answer choice if they did not wish to answer any specific questions.

6. Most importantly, the participants were informed that they might elect to withdraw from the study at any time without penalty.

7. There was no question asking about participant name, date of birth, or contact information. No specific information that could be linked to the participants.

8. The IP address tracking function on SurveyMonkey was disabled to provide anonymity for the participants.

\section{Measures}

The web based survey consisted of a questionnaire developed for the proposed study, "HPV and HPV vaccine related Knowledge, Attitudes, and Behaviors". This questionnaire 
was developed using constructs of the theory of planned behavior (Azjen, 1991). Items were constructed using the questionnaire construction guidelines described by Azjen (2010b).

The predictor variables of interest to this study were: knowledge, attitudes toward HPV vaccine, attitude toward getting vaccinated against HPV, subjective norms, and perceived behavioral control. Knowledge and attitudes toward HPV vaccine were considered as indirect predictors while attitude toward getting vaccinated against HPV, subjective norms, and perceived behavioral control were considered as direct predictors. The outcome variables were intention to obtain HPV vaccine, vaccine uptake, and sexual behaviors/practices.

\section{Validity and Reliability Testing}

Measures of HPV and HPV vaccine related Knowledge, Attitudes, and Behaviors Questionnaire were reviewed for their validity and reliability by the creator of theory of planned behavior and the committee members. An example of the questionnaire is attached as Appendix D. In addition to demographic and sexual history, the questionnaire inquired about knowledge, attitudes toward HPV vaccine, attitude toward getting vaccinated against HPV, subjective norms, perceived behavioral control, intention to receive the vaccine, vaccine status, and sexual behaviors. HPV controversial concerns have been incorporated into HPV knowledge and attitudes toward HPV vaccine items.

\section{Validity}

Face validity: The questionnaire was reviewed by three female college students, one health educator, and one lay person. To make the items succinct and clear, the questionnaire was revised according to the reviewers' questions or suggestions. 
Content validity: The initial questionnaire was reviewed by Dr.Icek Ajzen, creator of the theory of planned behavior. The draft revised questionnaire was refined based on input from the dissertation committee members. The draft questionnaire then was submitted to Dr.Icek Ajzen for finalization.

\section{Reliability}

As suggested by TPB's creator, pilot testing of the tool was conducted. The recruitment was conducted in two rounds. The first week, the researchers emailed college women that she personally knew. The second week, the researchers emailed her friends to pass the survey to female college students that they knew. The researcher specifically encouraged vaccinees to complete the survey because only 12 vaccinees responded during the first week. A total of 70 college women responded to the online survey. Ten respondents were excluded because they were not aware of HPV or HPV vaccine. Five were excluded because more than 20 percent of the responses were incomplete or the respondents failed to check the attention-testing checkpoints correctly. Out of 55 respondents available for analysis, there were 25 non-vaccinees and 30 vaccinees. Internal consistency reliability, Cronbach's coefficient alpha was calculated for each sub-scale of the questionnaire. The results are as follows.

Knowledge: There were originally ten knowledge items—six items for HPV and four items for HPV vaccine. Responses were given as true, false, and "I don't know". If the answer was correct, one point was given. If the answer was incorrect or "I don't know", zero point was given. A higher total score indicated higher HPV and HPV vaccine knowledge. After checking for item difficulty, "Women who receive HPV vaccine do not have to use condoms during sexual intercourse" item was deleted because 100 percent of women 
answered the item correctly. The final knowledge items included six items for HPV and three items for HPV vaccine.

Attitudes toward HPV vaccine: Nine semantic differential-scale items were tested to measure attitudes toward HPV vaccine. These items included the attitudes on calling HPV vaccine an anti-cancer vaccine, calling HPV vaccine a STD vaccine, and mandating HPV vaccine for all young girls. Responses were given on a 7 point scale. Good/useful/ desirable/beneficial/favorable/pleasant (for me) represented positive attitudes while bad/worthless/undesirable/harmful/unfavorable/unpleasant (for me) represented negative attitudes. The higher total score indicated more positive attitudes toward HPV vaccine. Cronbach's coefficient alpha for the entire attitudes toward HPV vaccine scale was 0.77 . Cronbach's coefficient alpha for the subscales; anti-cancer vaccine, STD vaccine, and mandatory vaccine were $0.76,0.89$, and 0.87 , respectively. The final attitudes toward HPV vaccine items remained as they were.

Attitude toward getting vaccinated against HPV: Six semantic differential-scale items were tested to measure attitude toward getting vaccinated against HPV. For non-vaccinees, the statement of attitude was "my getting vaccinated against HPV would be...". For vaccinees, the statement of attitude was "I thought that my getting vaccinated against HPV would be...". Responses were given on a 7 point scale. Good/useful/desirable/ beneficial/ favorable/pleasant (for me) represented positive attitude while bad/worthless/undesirable/ harmful/unfavorable/unpleasant (for me) represented negative attitude. The higher total score indicated more positive attitude on getting vaccinated against HPV. Cronbach's coefficient alpha for the attitude toward getting vaccinated against HPV scale was 0.79 . For the non-vaccinee group, Cronbach's coefficient alpha was 0.91. For the vaccinee group, 
Cronbach's coefficient alpha was 0.64 . Two respondents noted that the statement could have been simplified. The final statements of attitude were simplified as "my getting an HPV vaccine would be..." and "I thought that my getting an HPV vaccine would be...".

Subjective norms: Five items were used to measure subjective norms (1=strongly disagree to $5=$ strongly agree). The present tense was used in the statements for nonvaccinees while the past tense was used in the statement for vaccinees (e.g., "I feel under social pressure to get vaccinated against HPV" VS "I felt under social pressure to get vaccinated against HPV"). Strongly agree represented a positive response while strongly disagree represented negative response. The higher total score indicated more positive subjective norms. Cronbach's coefficient alpha for the subjective norms was 0.73 . For the non-vaccinee group, Cronbach's coefficient alpha was 0.79. For the vaccinee group, Cronbach's coefficient alpha was 0.71 . The final subjective norms items remained as they were.

Perceived behavioral control: Five items were tested to measure perceived behavioral control ( $1=$ strongly disagree to $5=$ strongly agree). The present tense was used in the statements for non-vaccinees while the past tense was used in the statement for vaccinees (e.g., "Getting vaccinated against HPV is beyond my control" VS "Getting vaccinated against HPV was beyond my control"). Strongly agree represented a positive response while strong disagree represented negative response, except one reverse-score item. The higher total score indicated more positive perceived behavioral control. Cronbach's coefficient alpha for the perceived behavioral control was 0.67. For the non-vaccinee group, Cronbach's coefficient alpha was 0.77 . For the vaccinee group, Cronbach's coefficient alpha was 0.57 . 
One item was deleted to increase the entire Cronbach's coefficient alpha to 0.71 . Four perceived behavioral control items were used to conduct the study.

Intention to obtain HPV vaccine: Four items were tested to measure intention to obtain HPV vaccine (1=strongly disagree to 5=strongly agree). Strongly agree represented a positive response while strong disagree represented negative response. The higher total score indicated stronger intention to obtain HPV vaccine. Cronbach's coefficient alpha for the intention to obtain HPV vaccine scale was 0.93 . The items remained as they were. Intention to obtain HPV vaccine variable was measured with non-vaccinee group only.

HPV vaccine uptake: One item with the responses of yes or no was used to measure vaccine status. Yes represented a positive response while no represented a negative response. With the positive response, a vaccine receipt time period question was asked. With the negative response, an open-ended question was asked for the reason why.

Sexual behaviors/practices: Structured questions with multiple choice answers were used to ask for numbers of sexual partners in a lifetime, numbers of sexual partners in the past 12 months, STI prevention methods, condom use frequency, numbers of sexual partners before receiving an HPV vaccine (for vaccinees), and numbers of sexual partners after receiving an HPV vaccine (for vaccinees).

\section{Data Analysis}

Data were analyzed using the Statistical Packet for the Social Sciences (SPSS) 19.0. Descriptive statistics were used to describe participant demographics (i.e., age, ethnicity, religion, health insurance status, class major), sexual history (i.e., relationship status, sexual experience, partner genders, age of fist sexual intercourse, STI diagnosis, Pap test status), and the variables of interest (i.e., HPV/HPV vaccine knowledge, attitudes toward HPV vaccine, 
attitude toward getting vaccinated against HPV, subjective norms, perceived behavioral control, intention to obtain HPV vaccine, vaccine uptake, sexual behaviors). Independent $t$ tests and chi-square tests were used to compare differences in demographic, sexual history, and the variables of interest between vaccinees and non-vaccinees. The inferential statistics analyses were conducted in order to answer the research questions:

Research question \#1: What is the relationship between HPV/HPV vaccine related knowledge, attitudes toward HPV vaccine, attitude toward getting vaccinated against HPV, subjective norms, perceived behavioral control, intention to receive the vaccine, and vaccine uptake among college women?

Based on theory of planned behavior, knowledge and attitudes toward HPV vaccine are considered as indirect predictors while attitude toward getting vaccinated against HPV, subjective norms, and perceived behavioral control are considered as direct predictors. The outcome variables are intention to obtain HPV vaccine, vaccine uptake, and sexual behaviors/practices. Sub-analyses were conducted as follows:

1. Pearson's correlation coefficients were used to describe the relationships between indirect predictor variables (knowledge and attitudes toward HPV vaccine) and direct predictor variables (attitude toward getting vaccinated against HPV, subjective norms, and perceived behavioral control).

2. Point-biserial correlation coefficients were used to describe the relationships between indirect predictor variables (knowledge and attitudes toward HPV vaccine), direct predictor variables (attitude toward getting vaccinated against HPV, subjective norms, and perceived behavioral control) and the outcome variable-vaccine uptake.

3. Hierarchical logistic regression analysis was used to examine the relative contribution of predictor variables (attitude toward getting vaccinated against HPV, subjective norms, and perceived behavioral control) to vaccine uptake. Hierarchical logistic regression (Method: Enter) was used to control confounding variables.

4. In non-vaccinee group, Pearson's correlation coefficients was used to describe the relationships between indirect predictor variables (knowledge and attitudes toward 
HPV vaccine), direct predictor variables (attitude toward getting vaccinated against $\mathrm{HPV}$, subjective norms, and perceived behavioral control), and the outcome variable-intention to obtain HPV vaccine.

5. In non-vaccinee group, hierarchical multiple regression analysis was used to examine the relative contribution of the predictor variables (attitude toward getting vaccinated against HPV, subjective norms, and perceived behavioral control), to intention to obtain HPV vaccine. Hierarchical multiple regression (Method: Enter) was used to control confounding variables.

Research question \#2: Are there differences in sexual behaviors between college

women who have and have not received the HPV vaccine?

1. Analysis of covariance (ANCOVA) was used to examine the mean differences of numbers of sexual partners in a lifetime and numbers of sexual partners in the past 12 months between women who have received and have not received the vaccine while accounting for demographic, sexual history, and indirect predictor variables as covariates.

2. Chi-square tests were used to examine the differences of condom use experience and condom use frequency between vaccinees and non-vaccinees.

3. For vaccinees who already have had sexual intercourse before vaccine initiation, paired $t$-test was used to examine the mean difference between the number of sexual partners before and after the vaccination. 


\section{CHAPTER 4}

\section{RESULTS}

The study was conducted, using constructs of the theory of planned behavior, to identify factors that influence HPV vaccine uptake among college women and to examine the post-vaccine sexual behaviors/practices of college-aged women. An email invitation was sent to 3,074 undergraduate female students; 800 (26\%) Caucasians, 800 (26\%) Asians, 800 (26\%) Latinos, and 674 (22\%) African-Americans. Ten of the emails returned with delivery failure notification. Two reminders were emailed out at Week One and Week Two to 3,064 students. Of these, 486 responded to the invitation, one student declined to participate in the study and one student requested to be taken off from the email reminder list—representing a response rate to the survey of $15.8 \%$. Out of the remaining 484 participants, $13(2.6 \%)$ failed on attention-testing items (which identified if the subjects paid attention when answering the survey questions), two participants did not complete any items on the survey after they agreed to participate, and 27 participants had more than $20 \%$ of items missing. Hence, there were 442 participants that qualified for inclusion in the study.

Of the 442 participants, $410(92.8 \%)$ had heard about HPV and out of these, 389 (94.9\%) had heard about HPV vaccine. Out of the 389 participants who had heard about HPV vaccine, 209 (54.4\%) reported having received at least one dose of an HPV vaccine, $175(45.6 \%)$ reported not having initiated an HPV vaccine, and five $(1.3 \%)$ preferred not to indicate the vaccine status-leaving 384 participants for further data analysis (Figure 3). 


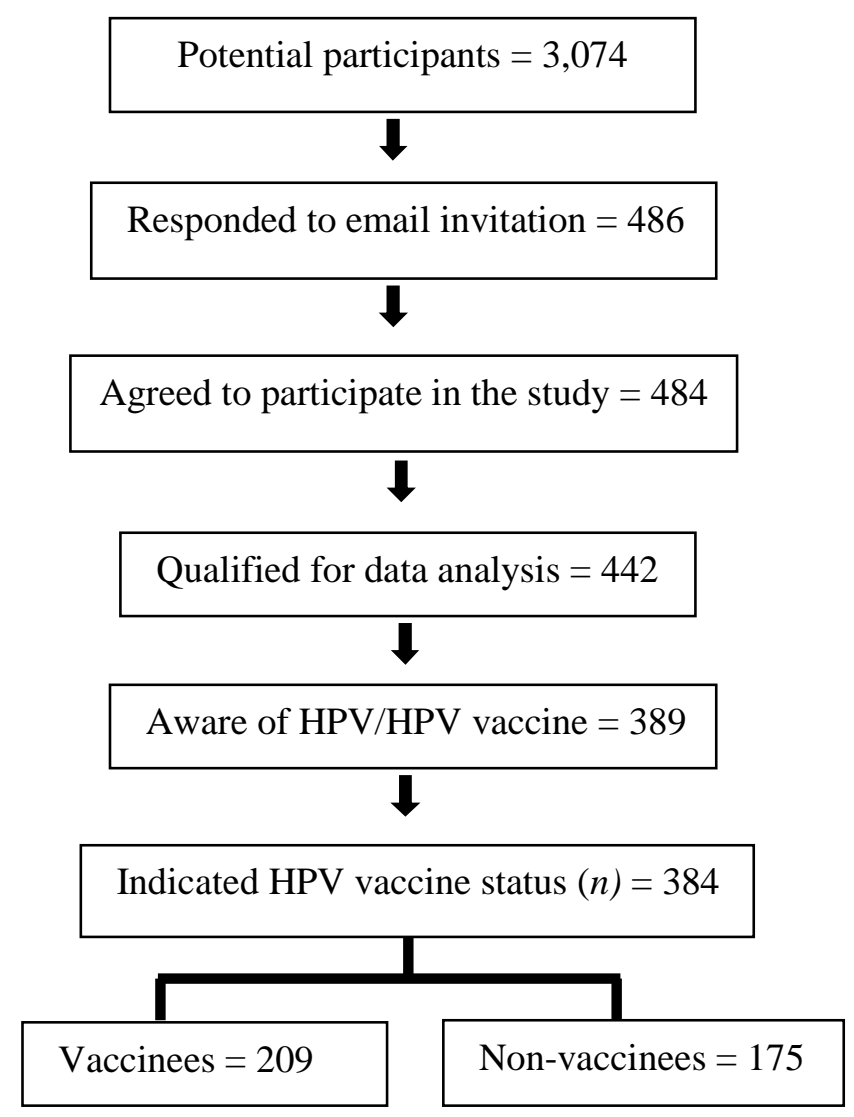

Figure 3. Summary of the Number of Responses

\section{Reliability of the 'HPV and HPV vaccine related Knowledge, Attitudes, and Behaviors' questionnaire}

Among the 384 college women participants (vaccinees $=209$ and non-vaccinees $=$ 175), the majority (93.8\%) completed all items on the HPV and HPV vaccine related Knowledge, Attitudes, and Behaviors questionnaire. Only 24 participants had one to three items with missing values. These missing values were replaced by the item mean as suggested by Downey and King (1998). Internal consistency reliability, Cronbach's coefficient alpha was calculated for Attitudes toward HPV Vaccine scale, Attitude toward Getting Vaccinated against HPV scale, Subjective Norms scale, Perceived Behavioral Control scale, and Intention to Obtain HPV Vaccine scale. The results are as follows: 
Attitudes toward HPV Vaccine (nine items): Cronbach's coefficient alpha for the entire scale was 0.82. Cronbach's coefficient alpha for the subscales; anti-cancer vaccine, STD vaccine, and mandatory vaccine were $0.86,0.89$, and 0.90 , respectively. The Cronbach's coefficient alpha was not calculated for each sub-group (vaccinees and nonvaccinees) because the same scale was used for both groups.

Attitude toward Getting Vaccinated against HPV (six items): Cronbach's coefficient alpha for the scale was 0.87 . Cronbach's coefficient alpha was also calculated for each group because the statements for each group were not exactly the same-For non-vaccinees, the statement of attitude was "my getting vaccinated against HPV would be...". For vaccinees, the statement of attitude was "I thought that my getting vaccinated against HPV would be...". For the non-vaccinee group, Cronbach's coefficient alpha was 0.82 . For the vaccinee group, Cronbach's coefficient alpha was 0.89 .

Subjective Norms (five items): Cronbach's coefficient alpha for the scale was 0.66. Cronbach's coefficient alpha was also calculated for each group because the statements for each group were not exactly the same-For non-vaccinees, the present tense was used and for vaccinees, the past tense was used. For the non-vaccinee group, Cronbach's coefficient alpha was 0.73. For the vaccinee group, Cronbach's coefficient alpha was 0.53 . After an item analysis was conducted, item \#3 "I feel (felt) under social pressure to get vaccinated against HPV" was deleted to increase the reliability of the tool. Cronbach's coefficient alpha for the four-item scale was 0.72 . For the non-vaccinee group, Cronbach's coefficient alpha was 0.72 . For the vaccinee group, Cronbach's coefficient alpha was 0.65.

Perceived Behavioral Control (four items): Cronbach's coefficient alpha for the scale was 0.70 . Cronbach's coefficient alpha was also calculated for each group because the 
statements for each group were not exactly the same-For non-vaccinees, the present tense was used and for vaccinees, the past tense was used. For the non-vaccinee group, Cronbach's coefficient alpha was 0.78 . For the vaccinee group, Cronbach's coefficient alpha was 0.66 .

Intention to obtain HPV vaccine (four items): Only non-vaccinees completed this scale. Cronbach's coefficient alpha for the intention to obtain HPV vaccine scale was 0.96.

\section{Participant Characteristics}

\section{Demographic Characteristics}

Among the 384 participants who indicated their vaccine status, the mean age was 20.75 years $(S D=1.87)$. Of 375 participants indicating their ethnicity, $29.6 \%$ were Caucasian, 22.4\% were Asian, 22.7\% were Latino, and 15.2\% were African-American. The remaining $10.1 \%$ participants indicated that they had more than one ethnicity by specifying their ethnicities in the "other" comment box (Table 1). More than a half of participants (61.4\%) were Christians, $26.0 \%$ indicated no religion, and $12.6 \%$ indicated other religions (e.g., Buddhist, Muslim, Hindu, and Jewish). Most of the participants in this study (75.1\%) had health insurance and $66.8 \%$ of them were enrolled in non-health related majors. When demographic characteristics were compared between vaccinee group and non-vaccinee group, the HPV vaccine uptake was significantly associated with age $(p<.001)$ and ethnicity $(p=0.02)$ (Table 1). Among African American participants, most (63.8\%) had not obtained the vaccine. Among Asian participants, the majority (63.1\%) had obtained the vaccine. 
Table 1

Demographic Characteristics of Vaccinees and Non-Vaccinees ${ }^{*}$

\begin{tabular}{|c|c|c|c|c|}
\hline & Entire group & Non-Vaccinees & Vaccinees & $p$-Value \\
\hline Age & $M=20.8(n=353)$ & $M=21.1(n=164)$ & $M=20.4(n=189)$ & $<.001^{\mathrm{a}}$ \\
\hline Ethnicity & $(n=375)$ & $(n=173)$ & $(n=202)$ & $0.03^{\mathrm{b}}$ \\
\hline Caucasian & $29.6 \%$ & $31.2 \%$ & $28.2 \%$ & \\
\hline Asian & $22.4 \%$ & $17.9 \%$ & $26.2 \%$ & \\
\hline Latino & $22.7 \%$ & $20.8 \%$ & $24.3 \%$ & \\
\hline Black & $15.2 \%$ & $20.8 \%$ & $10.4 \%$ & \\
\hline Other & $10.1 \%$ & $9.2 \%$ & $10.9 \%$ & \\
\hline Religion & $(n=373)$ & $(n=170)$ & $(n=203)$ & $0.74^{\mathrm{b}}$ \\
\hline Christianity & $61.4 \%$ & $63.5 \%$ & $59.6 \%$ & \\
\hline Other & $12.6 \%$ & $11.8 \%$ & $13.3 \%$ & \\
\hline None & $26.0 \%$ & $24.7 \%$ & $27.1 \%$ & \\
\hline Insurance status & $(n=374)$ & $(n=171)$ & $(n=203)$ & $0.40^{\mathrm{b}}$ \\
\hline Yes & $75.1 \%$ & $73.1 \%$ & $76.8 \%$ & \\
\hline No & $24.9 \%$ & $26.9 \%$ & $23.2 \%$ & \\
\hline Class majors & $(n=374)$ & $(n=172)$ & $(n=202)$ & $0.82^{b}$ \\
\hline Health-related & $33.2 \%$ & $32.6 \%$ & $33.7 \%$ & \\
\hline Non health-related & $66.8 \%$ & $67.4 \%$ & $66.3 \%$ & \\
\hline
\end{tabular}

Note: $\quad M=$ mean, ${ }^{\mathrm{a}}=$ by independent $t$-test,${ }^{\mathrm{b}}=$ by chi-square test.

* A number of responses ( $n$ ) differ because the participants chose not to answer or inadvertently skipped the questions 


\section{Sexual History}

Among participants that reported their relationship status $(n=383)$, most were single $(46.5 \%)$ or dating $(50.7 \%)$. Three quarters $(75.3 \%)$ reported that they were sexually active and most (92.7\%) only had sex with males (Table 2). Age at first sexual intercourse ranged from nine to 23 years $(M=17.08, S D=2.03)$. Of the participants who reported their STI history $(n=259)$, most $(83.0 \%)$ had not been diagnosed with an STI, while $6.6 \%$ had been diagnosed with HPV and/or genital warts, and $10.4 \%$ had been diagnosed with other STIs (i.e., genital herpes, gonorrhea, chlamydia, trichomoniasis). Out of those who had a Pap test $(n=174), 13.2 \%$ had an abnormal Pap test result. When comparing sexual history between the vaccinee group and non-vaccinee group (Table 2), the HPV vaccine status was significantly associated with age of first sexual intercourse $(p<.001)$. However, the HPV vaccine uptake status was not significantly associated with relationship status, sexual experience, partner genders, STI diagnosis, and Pap test status.

Table 2 Sexual History of Vaccinees and Non-Vaccinees*

\begin{tabular}{lcccc}
\hline & Entire groups & Non-Vaccinees & Vaccinees & $p$-value \\
\hline Relationship status & $(n=383)$ & $(n=174)$ & $(n=209)$ & $0.44^{\mathrm{b}}$ \\
Single & $46.5 \%$ & $50.0 \%$ & $43.5 \%$ & \\
Dating & $50.7 \%$ & $47.1 \%$ & $53.6 \%$ & \\
Married & $2.9 \%$ & $2.9 \%$ & $2.9 \%$ & \\
Ever having sex & $(n=369)$ & $(n=170)$ & $(n=199)$ & $0.32^{\mathrm{b}}$ \\
Yes & $75.3 \%$ & $72.9 \%$ & $77.4 \%$ & \\
No & $24.7 \%$ & $27.1 \%$ & $22.6 \%$ & \\
\hline
\end{tabular}

Table 2 Continued 


\begin{tabular}{lcccc}
\hline & Entire groups & Non-Vaccinees & Vaccinees & $p$-value \\
\hline Partners & $(n=273)$ & $(n=124)$ & $(n=149)$ & $0.72^{\mathrm{c}}$ \\
Men & $92.7 \%$ & $94.4 \%$ & $91.3 \%$ & \\
Women & $4.4 \%$ & $3.2 \%$ & $5.4 \%$ & \\
Both & $2.9 \%$ & $2.4 \%$ & $3.3 \%$ & \\
Age of first sex & $M=17.1(n=270)$ & $M=17.6(n=122)$ & $M=16.7(n=148)$ & $<.001^{\mathrm{a}}$ \\
STI diagnosis & $(n=259)$ & $(n=120)$ & $(n=139)$ & $0.84^{\mathrm{b}}$ \\
Yes & $17.0 \%$ & $17.5 \%$ & $16.5 \%$ & \\
No & $83.0 \%$ & $82.5 \%$ & $83.5 \%$ & \\
Pap test status & $(n=174)$ & $(n=76)$ & $(n=98)$ & $0.36^{\mathrm{b}}$ \\
Abnormal & $13.2 \%$ & $10.5 \%$ & $15.3 \%$ & \\
Normal & $86.8 \%$ & $89.5 \%$ & $84.7 \%$ & \\
\hline
\end{tabular}

Note: $\quad M=$ mean, ${ }^{a}=$ by independent $t$-test, ${ }^{b}=$ by chi-square test, ${ }^{c}=$ by fisher's exact test. *A number of responses $(n)$ differ because the participants chose not to answer or inadvertently skipped the questions

\section{Descriptions of the Variables of Interest}

HPV/HPV Vaccine Knowledge

Among 384 participants, the HPV/HPV vaccine knowledge mean score was 6.70 out of $9(S D=1.69$, range $0-9)$. The knowledge mean score among non-vaccinees was 6.62 $(S D=1.62)$ and among vaccinees was $6.76(S D=1.74)$. The independent $t$-test revealed that the difference on HPV knowledge between the two groups was not significantly different $(t=-0.80, d f=382, p=0.43)$.

The knowledge items answered correctly by most participants in both groups concerned the need of routine Pap test after vaccination (90.3\%-93.3\%), HPV vaccine nonprotection against other STIs (92.8\%-93.7\%), and the association between HPV and cervical cancer (86.3-88.5\%). Knowledge of HPV causing genital warts and the risk of exposing to 
HPV was quite low in both groups; correct answers were only $43.5 \%-46.9 \%$ and $42.9 \%$ $45.5 \%$, respectively (Table 3 ).

Table 3

HPV/HPV Vaccine Knowledge: Percentages of Correct Answers

\begin{tabular}{lcc}
\hline \multicolumn{1}{c}{ Knowledge Statements } & $\begin{array}{c}\text { Non-Vaccinees } \\
(n=175)\end{array}$ & $\begin{array}{c}\text { Vaccinees } \\
(n=209)\end{array}$ \\
\hline $\begin{array}{l}\text { 1. HPV can cause genital warts } \\
\text { 2. HPV can cause cervical cancer }\end{array}$ & $46.9 \%$ & $43.5 \%$ \\
3. Most people with genital HPV have no visible signs or \\
symptoms \\
$\begin{array}{l}\text { 4. Using a condom can provide partial protection against } \\
\text { HPV }\end{array}$ \\
$\begin{array}{l}\text { 5. I can transmit HPV to my partner(s) even if I have no } \\
\text { HPV symptoms }\end{array}$ \\
$\begin{array}{l}\text { 6. One out of two women will be diagnosed with HPV once } \\
\text { in their lifetime }\end{array}$ \\
$\begin{array}{l}\text { 7. Only sexually active women should receive the HPV } \\
\text { vaccine }\end{array}$ \\
$\begin{array}{l}\text { 8. Women who receive HPV vaccine do not need to get } \\
\text { routine Pap smear/test }\end{array}$ \\
$\begin{array}{l}\text { 9. HPV vaccine protects against all sexually transmitted } \\
\text { infections }\end{array}$ & $72.9 \%$ & $71.7 \%$ \\
\hline
\end{tabular}

Attitudes toward HPV Vaccine

Among the 384 vaccinees and non-vaccinees who participated in this study, the overall mean score on attitude toward the vaccine was $38.24(S D=10.57$, on a possible range of 9-63). The attitudes toward HPV vaccine mean score among non-vaccinees was 37.55 and among vaccinees was 38.82. Both groups tended to have a positive attitude toward 
mandatory vaccination $(M=14.04$ and 16.35 , on a possible range of $3-21)$ and had slightly negative attitudes toward calling the HPV vaccine an anti-cancer vaccine or a STD vaccine. Independent $t$-test analysis indicated that the overall attitudes toward HPV vaccine was not significantly different between the two groups $(t=-1.17, d f=382, p=0.24)$. For the subscales, the attitude toward mandating HPV vaccine mean score was significantly higher in the vaccinee group $(t=-4.54, d f=382, p=<.001)$. However, the attitude toward calling HPV vaccine a STD vaccine mean score was slightly, but significantly lower in the vaccinee group $(t=2.05, d f=382, p=0.04)$. The attitudes toward HPV vaccine results are shown in Table 4 .

Table 4

Attitudes toward HPV Vaccine

\begin{tabular}{|c|c|c|c|c|c|}
\hline \multirow[t]{2}{*}{ Attitudes toward HPV vaccine } & \multicolumn{2}{|c|}{$\begin{array}{l}\text { Non-Vaccinees } \\
\qquad(n=175)\end{array}$} & \multicolumn{2}{|c|}{$\begin{array}{c}\text { Vaccinees } \\
(n=209)\end{array}$} & \multirow[t]{2}{*}{$p$-value } \\
\hline & $M$ & $S D$ & $M$ & $S D$ & \\
\hline Attitudes toward HPV vaccine & 37.55 & 10.29 & 38.82 & 10.78 & 0.24 \\
\hline Calling HPV vaccine: Anti-cancer vaccine & 11.66 & 4.62 & 11.67 & 4.85 & 0.98 \\
\hline Calling HPV vaccine: STD vaccine & 11.85 & 5.11 & 10.79 & 4.96 & 0.04 \\
\hline Mandatory vaccination & 14.04 & 5.07 & 16.35 & 4.89 & $<.001$ \\
\hline
\end{tabular}

Note: $M=$ Mean, $S D=$ Standard Deviation.

Attitude toward Getting Vaccinated Against HPV

The attitude toward getting vaccinated against HPV mean score among 384 participants was $32.15(S D=7.85$, range 6-42). The attitude toward getting vaccinated against HPV mean score among non-vaccinees was 30.25 and among vaccinees was 33.73 
(on a possible range of 6-42). Both groups tended to have a positive attitude toward vaccination against HPV (Table 5). Use of an independent $t$-test to explore the difference of the mean scores, revealed that the attitude toward getting vaccinated against HPV mean score was significantly different between the non-vaccinee and vaccinee groups $(t=-4.36$, $d f=341.68$ [Equal variances not assumed], $p<.001)$.

Table 5

Attitude toward Getting Vaccinated against HPV

\begin{tabular}{lcccc}
\hline & $M$ & $S D$ & Range & Possible Range \\
\hline Entire group & 32.15 & 7.85 & $6-42$ & $6-42$ \\
Non-vaccinees & 30.25 & 8.35 & $6-42$ & \\
Vaccinees & 33.73 & 7.05 & $6-42$ & \\
\hline
\end{tabular}

Note: $M=$ Mean, $S D=$ Standard Deviation.

\section{Subjective Norms}

Among 384 participants, the subjective norms mean score was 14.17 ( $S D=3.21$, range 4-20). The subjective norms mean score among non-vaccinees was $12.91(S D=3.11)$ and among vaccinees was $15.20(S D=2.91)$. Both groups tended to have positive subjective norms, with the vaccinee group having more positive subjective norms. Independent $t$-test analysis also revealed that the subjective norms mean score was significantly different between non-vaccinee and vaccinee groups $(t=-7.51, d f=382, p<.001)$. Details of percentages of participants who either agreed or strongly agreed on subjective norms statements are in Table 6. 
Table 6

Percentage of Participants Who either Agreed or Strongly Agreed with

Subjective Norms Statements

\begin{tabular}{lcc}
\hline \multicolumn{1}{c}{ Subjective Norms Statements } & $\begin{array}{c}\text { Non-Vaccinees } \\
(n=175)\end{array}$ & $\begin{array}{c}\text { Vaccinees } \\
(n=209)\end{array}$ \\
\hline $\begin{array}{l}\text { Most people who are important to me think (thought) } \\
\text { that I should get vaccinated against HPV }\end{array}$ & $25.7 \%$ & $63.2 \%$ \\
$\begin{array}{l}\text { It is (was) expected of me that I get (got) vaccinated } \\
\text { against HPV }\end{array}$ & $26.3 \%$ & $57.4 \%$ \\
$\begin{array}{l}\text { My doctor approves (approved) of my getting } \\
\text { vaccinated against HPV }\end{array}$ & $73.7 \%$ & $94.3 \%$ \\
Most women like me are vaccinated against HPV & $36.6 \%$ & 37.8 \\
\hline
\end{tabular}

\section{Perceived Behavioral Control}

Among the 384 participants, the perceived behavioral control (PBC) mean score was 16.71 $(S D=2.66$, range=6-20). The PBC mean score among non-vaccinees was 17.36 $(S D=2.35)$ and among vaccinees was $16.16(S D=2.78)$. Both groups tended to have strong perceived behavioral control. However, an independent $t$-test analysis indicated that the nonvaccinee group had stronger PBC mean scores when compared to the vaccinee group $(t=4.57$, $d f=382$ [equal variances not assumed], $p<.001$ ). Details of percentages of participants who either agreed or strongly agreed on PBC statements are in Table 7. 
Table 7

Percentage of Participants Who either Agreed or Strongly Agreed with

Perceived Behavioral Control Statements

\begin{tabular}{lcc}
\hline \multicolumn{1}{c}{ PBC Statements } & $\begin{array}{c}\text { Non-Vaccinees } \\
(n=175)\end{array}$ & $\begin{array}{c}\text { Vaccinees } \\
(n=209)\end{array}$ \\
\hline $\begin{array}{l}\text { I can (could) get vaccinated against HPV as I want } \\
\text { (wanted) to. }\end{array}$ & $90.9 \%$ & $83.2 \%$ \\
$\begin{array}{l}\text { I am (was) confident that I can (could) get vaccinated } \\
\text { against HPV }\end{array}$ & $87.4 \%$ & $88.0 \%$ \\
$\begin{array}{l}\text { Getting vaccinated against HPV is (was) beyond my } \\
\text { control [Reversed score] }\end{array}$ & $85.2 \%$ & $72.3 \%$ \\
$\begin{array}{l}\text { Whether I get (got) vaccinated against HPV is (was) } \\
\text { entirely up to me }\end{array}$ & $93.7 \%$ & $63.2 \%$ \\
\hline
\end{tabular}

\section{Research Question One}

What is the relationship between HPV/HPV vaccine related knowledge, attitudes toward HPV vaccine, attitude toward getting vaccinated against HPV, subjective norms, perceived behavioral control, intention to receive the vaccine, and vaccine uptake among college women?

Based on the theory of planned behavior, knowledge and attitudes toward HPV vaccine are considered indirect predictors while attitude toward getting vaccinated against HPV, subjective norms, and perceived behavioral control are considered direct predictors. The outcome variables are intention to obtain HPV vaccine, vaccine uptake, and sexual behaviors/practices. 


\section{Relationships between Indirect Predictors, Direct Predictors, and Vaccine Uptake}

\section{Indirect Predictors VS Direct Predictors}

Pearson's correlation coefficient analyses were used to examine the relationship between indirect predictors (knowledge and attitudes toward HPV vaccine) and direct predictors (attitude toward getting vaccinated against HPV, subjective norms, and perceived behavioral control). Results in Table 8 show small but significant positive correlations between HPV knowledge and three direct predictors—attitude toward getting vaccinated against $\operatorname{HPV}(r=0.15, p<0.01)$, subjective norms $(r=0.15, p<0.01)$, and perceived behavioral control $(r=0.11, p<0.05)$. Those with higher knowledge scores tended to report increases in attitude toward getting vaccinated against HPV, subjective norms, and perceived behavioral control. Significant correlations were also found between attitudes toward the HPV vaccine and two direct predictors—attitude toward getting vaccinated against $\operatorname{HPV}(r=0.37, p<0.01)$ and subjective norms $(r=0.36, p<0.01)$. Those with positive attitudes toward the HPV vaccine tended to report positive attitude toward getting vaccinated against HPV and positive subjective norms. In addition, among direct predictors, attitude toward getting vaccinated against HPV was positively correlated with subjective norms $(r=0.41, p<0.01)$ and perceived behavioral control $(r=0.13, p<0.05)$. However, subjective norms and perceived behavioral control were not significantly correlated $(r=-0.02, p>0.05)$.

\section{Indirect Predictors, Direct Predictors, and Vaccine Uptake}

Point-biserial correlation coefficients were used to examine the relationships between the indirect predictor variables (knowledge and attitudes toward HPV vaccine), the direct predictor variables (attitude toward getting vaccinated against HPV, subjective norms, and 
perceived behavioral control) and the outcome variable—vaccine uptake. Results in Table 8 indicated significant positive correlations between HPV vaccine uptake and attitude toward getting vaccinated against HPV $(r=0.22, p<0.01)$ and subjective norms $(r=0.36, p<0.01)$. Vaccinees tended to report increases in attitude toward getting vaccinated against HPV and subjective norms. The vaccine uptake was inversely significantly correlated with perceived behavioral control. Vaccinees tended to report a decrease in perceived behavioral control ( $r=$ $-0.26, p<0.01)$. The vaccine uptake was not significantly correlated with HPV knowledge $(r=0.04, p>0.05)$ and attitudes toward HPV vaccine $(r=0.06), p>0.05)$.

Table 8

Bivariate Correlation Results between Indirect Predictors, Direct Predictors, and Vaccine Uptake $(n=384)$

\begin{tabular}{|c|c|c|c|c|c|c|}
\hline & \multicolumn{6}{|c|}{ Variables } \\
\hline & VAX & $\mathrm{K}$ & AV & AGV & SN & PBC \\
\hline Vaccine Uptake & 1.0 & & & & & \\
\hline Knowledge & .04 & 1.0 & & & & \\
\hline Attitudes: Vaccine & .06 & .09 & 1.0 & & & \\
\hline Attitude: Getting Vaccinated & $.22^{* *}$ & $.15^{* *}$ & $.37^{* *}$ & 1.0 & & \\
\hline Subjective Norms & $.36^{* *}$ & $.15^{* *}$ & $.36^{* *}$ & $.41^{* *}$ & 1.0 & \\
\hline Perceived Behavioral Control & $-.23^{* *}$ & $.11^{*}$ & .08 & $.13^{* *}$ & -0.02 & 1.0 \\
\hline $\begin{array}{l}\text { Notes: VAX }=\text { Vaccine uptake } \\
\text { AGV }=\text { Attitude toward getting } \\
\text { PBC }=\text { Perceived behavioral co } \\
{ }^{*} p<0.05,{ }^{* *} p<0.01\end{array}$ & $\begin{array}{l}\text { knowle } \\
\text { d again }\end{array}$ & $\begin{array}{l}\mathrm{AV}= \\
\mathrm{HPV}, \mathrm{S}\end{array}$ & $\begin{array}{l}\text { ttitude } \\
=\text { Subj }\end{array}$ & $\begin{array}{l}\text { toward } \\
\text { tive no }\end{array}$ & $\begin{array}{l}\text { PV va } \\
\text { as, }\end{array}$ & \\
\hline
\end{tabular}




\section{Determining Predictors of Vaccine Uptake}

In assuming that those who had not heard about HPV and HPV vaccine also had not received the vaccine, the vaccine uptake rate among the participants that were qualified for data analysis $(n=442)$ was approximately $47.3 \%$. Age when the vaccinees obtained HPV vaccine ranged from 13 to 24 years old, with a mean of $17.17(S D=2.60)$.

From the results presented above, HPV vaccine uptake was significantly associated with age, ethnicity, and age of first sexual intercourse. HPV vaccine uptake was also significantly related with the direct predictors - attitude toward getting vaccinated against HPV, subjective norms, and perceived behavioral control. While HPV knowledge and attitudes toward HPV vaccine were significantly correlated with the predictor variables, they were not significantly correlated with HPV vaccine uptake. Thus, hierarchical logistic regression was used to examine the relative contribution of the predictor variables to the vaccine uptake (the assumptions of observations being independent, multicollinearity, and independent variables being linearly related to the logit were checked and met). Variables achieving bivariate significance were entered into a two block hierarchical logistic regression model, using direct entry in both blocks. To control for confounding, the first block contained only likely covariates — age, ethnicity, and age of first sexual intercourse. The second block contained three significant correlated direct predictors.

The Omnibus Test of Model Coefficients indicated that, when all six variables were considered together, the logistic regression model was statistically significant $\left(\chi^{2}=51.88\right.$, $d f=6, n=246, \mathrm{p}<0.01)$. According to the model summary, approximately between $19.0 \%$ $\left(\right.$ Cox \& Snell $\mathrm{R}^{2}$ ) and $25.4 \%\left(\right.$ Nagelkerke $\left.\mathrm{R}^{2}\right)$ of the variance in the vaccine uptake was accounted for by the six variables. The Hosmer and Lemeshow Test was not statistically 
significant ( $p=0.90)$, indicating the data fitted the model. After controlling for age, ethnicity, and age of first sexual intercourse, only subjective norms and perceived behavioral control remained significant in the multivariate model. Table 9 presents the odds ratios, suggesting that the odds of obtaining an HPV vaccine increases as subjective norms increase and perceived behavioral control decreases.

Table 9

Logistic Regression Predicting HPV Vaccine Uptake ( $n=384)$

\begin{tabular}{lcccc}
\hline \multicolumn{1}{c}{ Variables } & $B$ & $S E$ & Odds ratio & $p$-value \\
\hline Age & -.10 & .08 & .90 & .22 \\
Ethnicity & .06 & .11 & 1.05 & .62 \\
Age of First Sexual Intercourse & -.14 & .08 & .87 & .07 \\
Attitude: Getting Vaccinated & .01 & .02 & 1.01 & .57 \\
Subjective Norms & .23 & .06 & 1.26 & $<.001$ \\
Perceived Behavioral Control & -.19 & .06 & .83 & .002 \\
\hline
\end{tabular}

\section{Determining Predictors of Intention to Obtain HPV Vaccine among Non-Vaccinees}

Based on the theory of planned behavior, HPV vaccine related behaviors are determined by their intention to perform the behaviors. Intention is considered to be the immediate antecedent of behavior (Ajzen, 1991). Understanding what factors influence the intention to obtain HPV vaccine may increase the vaccine uptake rate.

Among 174 non-vaccinees, the intention to obtain the vaccine mean score was 13.38 $(S D=4.35$, range $=4-20)$. Some $(42.5 \%)$ either agreed or strongly agreed with the statement "I intend to get vaccinated against HPV" and 34.4\% either agreed or strongly agreed with the 
statement "I have decided to get vaccinated against HPV". Less than a half (42.5\%) either agreed or strongly agreed with the statement "I plan to get vaccinated against HPV" and $58.6 \%$ either agreed or strongly agreed with the statement "I expect to get vaccinated against HPV at some point". Most (93.7\%) of non-vaccinees provided various reasons for not obtaining an HPV vaccine in the free-text comment box. Some non-vaccinees provided more than one reasons. A total of 180 reasons were categorized in Table 10.

Table 10

Reasons for Not Obtaining an HPV Vaccine

\begin{tabular}{lll}
\hline Reasons & Frequency & $\%$ \\
\hline Low risk perception (one partner, consistent condom use, "no need") & 39 & 21.7 \\
$\begin{array}{l}\text { Not a priority ("never thought about it", no motivation, laziness, } \\
\text { distraction, too busy, "no specific reason") }\end{array}$ & 31 & 17.2 \\
Need of more vaccine information (on vaccine efficacy and safety) & 28 & 15.6 \\
Cost and/or no insurance coverage & 24 & 13.3 \\
$\begin{array}{l}\text { Health care providers (having not suggested it, having not seen a } \\
\text { doctor) }\end{array}$ & 16 & 8.9 \\
General dislike toward shots (fear or dislike of shots, hospital) & 8 & 4.4 \\
Never having had sexual intercourse & 7 & 3.9 \\
Waiting to obtain the vaccine (already scheduled for vaccination) & 7 & 3.9 \\
Mother/Parents advised not to obtain the vaccine & 6 & 3.3 \\
Scare of vaccine side effects (through news or friends) & 3.2 \\
Having been already diagnosed with HPV & 4 & 1.7 \\
Vaccine coverage (not preventing all HPV strains or all STIs) & 3 & 2.2 \\
Misc. (not knowing where to get the vaccine, HPV infection is not & 3 &
\end{tabular}


Pearson's correlation coefficients were used to examine the relationships between the indirect predictor variables (knowledge and attitudes toward HPV vaccine), the direct predictor variables (attitude toward getting vaccinated against HPV, subjective norms, and perceived behavioral control) and the outcome variable-Intention to obtain HPV vaccine among non-vaccinee group. Results indicated significant correlations between intention to obtain HPV vaccine and indirect predictors—-knowledge $(r=0.17, p<0.05)$ and attitudes toward HPV vaccine $(r=0.54, p<0.01)$. The non-vaccinees with higher intention to obtain HPV vaccine tended to have higher HPV knowledge and more positive attitudes toward HPV vaccine.

The intention to obtain HPV vaccine was also strongly significantly correlated with attitude toward getting vaccinated against HPV $(r=0.74, p<0.01)$ and subjective norms $(r=0.65, p<0.01)$. The non-vaccinees with higher intention to obtain HPV vaccine tended to report increases in attitude toward getting vaccinated against HPV and subjective norms. The intention to obtain HPV vaccine was also significantly correlated with perceived behavioral control $(r=0.20, p<0.01)$. The intention to obtain HPV vaccine was not significantly correlated with demographic and sexual history variables.

When testing for multiple regression assumption, Mahalonobis Test indicated 11 multivariate outliers $\left(\chi^{2}>12.59, d f=6, p=0.05\right)$. Thus, 164 non-vaccinees were used in hierarchical multiple regression to examine the relative contribution of the predictor variables to the intention to obtain HPV vaccine. Variables achieving bivariate significance were entered into a two block hierarchical multiple regression model, using direct entry in both blocks. To control for confounding, the first block contained only likely covariates-HPV knowledge and attitudes toward HPV vaccine. The second block contained three significant 
correlated direct predictors. The results indicated that when only HPV knowledge and attitudes toward HPV vaccine were entered, attitudes toward HPV vaccine significantly predicted intention to obtain HPV vaccine, $F(2,161)=35.68, p<.001$, adjusted $R^{2}=0.31$. The variance $(30.7 \%)$ in intention to obtain HPV vaccine could be predicted by HPV knowledge and attitudes toward HPV vaccine. When the direct predictor variables (attitude toward getting the vaccine, subjective norms, and perceived behavioral control) were added, they significantly improved the prediction, $R^{2}$ change $=0.35, F(3,158)=53.29, p<.001$. The entire group of variables significantly predicted intention to obtain HPV vaccine, $F(5,158)=60.15$, $p<.001$, adjusted $R^{2}=0.65$. However, only attitude toward getting vaccinated against HPV and subjective norms significantly contributed to the model, with the attitude toward getting vaccinated against HPV contributed the most to the prediction (Table 11).

\section{Table 11}

Hierarchical Multiple Regression Analysis Summary for Attitude toward Getting Vaccinated against HPV, Subjective Norms, and Perceived Behavioral Control, Controlling for HPV Knowledge and Attitudes toward HPV Vaccine, Predicting Intention to Obtain HPV Vaccine $(n=164)$

\begin{tabular}{|c|c|c|c|c|c|}
\hline Variables & $B$ & $S E B$ & $\beta$ & $R^{2}$ & $\Delta R^{2}$ \\
\hline Step1 & & & & .31 & .31 \\
\hline Knowledge & .31 & .17 & .12 & & \\
\hline Attitudes: Vaccine & .21 & .03 & $.53^{* *}$ & & \\
\hline Constant & 3.35 & 1.45 & & & \\
\hline Step 2 & & & & .66 & .35 \\
\hline Knowledge & -.01 & .12 & -.00 & & \\
\hline Attitudes: Vaccine & .21 & .02 & .09 & & \\
\hline Attitude: Getting Vaccinated & .26 & .31 & $.51^{* *}$ & & \\
\hline Subjective Norms & .47 & .08 & $.33^{* *}$ & & \\
\hline Perceived Behavioral Control & .16 & .09 & .08 & & \\
\hline Constant & -4.71 & 1.83 & & & \\
\hline
\end{tabular}




\section{Research Question Two}

Are there differences in sexual behaviors between vaccinees and non-vaccinees?

Out of 369 participants reporting sexual experience, 278 (75.3\%) reported having had sexual intercourse. The number of sexual partner(s) a lifetime ranged from one to 40, with a mean of 4.37 ( $S D=4.84)$. The number of sexual partner(s) in the past 12 months ranged from zero to 10 , with a mean of $1.52(S D=1.33)$. Most $(84.5 \%)$ of the participants reported that they had used condoms to prevent STI. However, among 156 participants who had sexual intercourse in the past 30 days, only $50.6 \%$ used condoms more than $75 \%$ of the time.

Comparisons of Sexual Behaviors between Non-Vaccinees and Vaccinees

The Number of Sexual Partner(s) in a Lifetime

Among 278 participants who reported having had sexual experience (124 nonvaccinees and 154 vaccinees), 269 indicated the number of sexual partner(s) in a lifetime. The average number of sexual partner(s) in their lifetime was $3.73(S D=3.70)$ for nonvaccinees $(n=123)$ and $4.90(S D=5.60)$ for vaccinees $(n=146)$. When examining for variable associations, the number of sexual partner(s) in a lifetime was significantly correlated with age of first sexual intercourse $(r=-0.32, p<.001)$ and HPV/HPV vaccine knowledge $(r=0.27$, $p<.001)$. Both indirect variables were entered as covariates.

Levene's test was significant $(F=7.93, p=0.01)$. However, the cell sizes were similar (122 and 146). Alternative measure for homogeneity of variances was also conducted. The ratio of the highest variance (31.28) and lowest variance (13.60) was slightly above two (2.33). Thus, using ANCOVA was acceptable given how the SPSS calculated ANCOVA (Field, 2009; Leech et al., 2008). The results indicated that the interaction between vaccine 
uptake and age of first sexual intercourse was not significant $(F=0.50, p=0.48)$. The interaction between vaccine uptake and HPV/HPV vaccine knowledge was not significant $(F=2.03, p=0.16)$. Age of first sexual intercourse and HPV/HPV vaccine knowledge were significant covariates (Table 12). After controlling the covariates, average numbers of sexual partner(s) in a lifetime were not significant between the two groups $(F=0.75, p=0.39)$. The adjusted means of the number of sexual partner(s) in a lifetime was 4.11 for non-vaccinees and 4.59 for vaccinees.

\section{Table 12}

Analysis of Covariance for the Number of Sexual Partner(s) in a Lifetime as a Function of Vaccine Uptake, Using Age of First Sexual Intercourse and HPV/HPV Vaccine Knowledge as Covariates

\begin{tabular}{lcccc}
\hline Source & $d f$ & $M S$ & $F$ & $p$-value \\
\hline Age of First Sexual Intercourse & 1 & 531.06 & 26.88 & $<.001$ \\
HPV Knowledge & 1 & 399.50 & 20.22 & $<.001$ \\
Vaccine Uptake & 1 & 14.81 & 0.75 & .39 \\
Error & 264 & 19.75 & & \\
\hline
\end{tabular}

The Number of Sexual Partner(s) in the Past 12 Months

Among 278 participants who reported having had sexual experience, 270 indicated the number of sexual partner(s) in the past 12 months. The average number of sexual partner(s) in the past 12 months was $1.44(S D=1.20)$ for non-vaccinees $(n=123)$ and 1.59 $(S D=1.43)$ for vaccinees $(n=147)$. When examining for variable associations, the number of 
sexual partner(s) in the past 12 months was significantly correlated with the number of sexual partner(s) in a lifetime $(r=0.48, p<.001)$.

ANCOVA assumptions were met. The results indicated that the interaction between vaccine uptake and the number of sexual partner(s) in a lifetime was not significant $(F=2.06$, $p=0.15)$. The number of sexual partner(s) in a lifetime, as a covariate, was significant $(F=78.25, p<.001)$. After controlling the covariate, average numbers of sexual partner(s) in the past 12 months were not significantly different between the two groups $(F=0.00, p=0.98)$ (Table 13). The adjusted means of the number of sexual partner (s) in the past 12 months was 1.52 for non-vaccinees and 1.52 for vaccinees.

\section{Table 13}

Analysis of Covariance for the Number of Sexual Partner (s) in 12 Months as a Function of Vaccine Uptake, Using the Number of Sexual Partner(s) in a Lifetime as a Covariate

\begin{tabular}{lcccc}
\hline \multicolumn{1}{c}{ Source } & $d f$ & $M S$ & $F$ & p-value \\
\hline Lifetime Sexual Partner (s) & 1 & 107.44 & 78.25 & $<.001$ \\
Vaccine Uptake & 1 & 0.00 & 0.00 & .98 \\
Error & 265 & 1.37 & & \\
\hline
\end{tabular}

\section{Condom Use}

Among 124 non-vaccinees, $103(83.1 \%)$ reported ever using a condom to prevent STI. Among 154 vaccinees, $132(85.7 \%)$ reported ever using a condom to prevent STI. Chisquare test reported that condom use practice was not significantly different between the two groups $\left(\chi^{2}=0.37, p=0.54\right)$. 
Among 156 participants who reported their condom use frequency when they had sex in the past thirty days, 74 were non-vaccinees and 82 were vaccinees. In the non-vaccinee group, 37 (50.0\%) reported condom use more than $75 \%$ of the time. Similarly, $42(51.2 \%)$ vaccinees reported condom use more than $75 \%$ of the time. Chi-square test reported that condom use frequency was not significantly different between the two groups $\left(\chi^{2}=0.05\right.$, $p=0.98)$.

\section{Comparison of Numbers of Sexual Partners \\ Before and After Vaccination}

In an attempt to explore the difference between the number of sexual partners before and after the vaccination, 154 vaccinees who reported ever having sex were examined. Among these, 121 vaccinees indicated their number of sexual partners and age when vaccinated. Of 121 vaccinees, 52 vaccinees had sexual intercourse before they obtained an HPV vaccine.

To calculate the number of sexual partners (per year) before vaccination, the number of sexual partners before vaccination was divided by the number of year from first sexual intercourse to vaccination year. The number of sexual partners before vaccination (per year) ranged from 0.14 to 11.00 , with a mean of $1.47(S D=1.81)$. To calculate the number of sexual partners (per year) after vaccination, the number of sexual partners after vaccination was divided by the number of year from vaccination year to present. The number of sexual partners after vaccination (per year) ranged from 0 to 5.29, with a mean of $0.90(S D=1.16)$. Paired $t$-test analysis indicated no significant difference in numbers of sexual partners (per year) before and after vaccination $(t=1.83, d f=51, p=0.07)$. 


\section{A Summary of the Findings}

This study found various significant findings. The key points of the findings are in the following:

1. Age, ethnicity, and age of first sexual intercourse were associated with vaccine uptake.

2. Both non-vaccinee and vaccinee groups had good HPV/HPV knowledge mean scores. The knowledge items answered correctly by most participants in both groups concerned the need of routine Pap test after vaccination and HPV vaccine non-protection against other STIs. However, the knowledge of HPV association to genital warts and risk of HPV exposure was low.

3. Both non-vaccinee and vaccinee groups had positive attitudes toward mandatory vaccination. Nonetheless, both groups had slightly negative attitudes toward calling HPV vaccine an anti-cancer or a STD vaccine.

4. Both non-vaccinee and vaccinee groups had positive attitudes toward getting vaccinated against HPV, subjective norms, and strong perceived behavioral control. However, the non-vaccinee group unexpectedly had stronger perceived behavioral control.

5. HPV/HPV knowledge was significantly correlated with three direct predictors attitude toward getting vaccinated against HPV, subjective norms, and perceived behavioral control. Similarly, attitudes toward the HPV vaccine were significantly correlated with attitude toward getting vaccinated against HPV and subjective norms. Nevertheless, HPV/HPV vaccine knowledge and attitudes toward the vaccine were not significantly related to vaccine uptake.

6. Vaccine uptake was positively related to attitude toward getting vaccinated against HPV and subjective norms. However, the vaccine uptake was inversely correlated with perceived behavioral control.

7. Vaccine uptake could be predicted by subjective norms and perceived behavioral control. The odds of obtaining an HPV vaccine increases as subjective norms increase and perceived behavioral control decreases.

8. Among non-vaccinees, intention to obtain the vaccine was significantly correlated with the indirect predictors (HPV/HPV knowledge and attitudes toward HPV vaccine) and the three direct predictors. However, only attitude toward getting vaccinated against $\mathrm{HPV}$ and subjective norms could significantly predict the intention to obtain the vaccine.

9. Vaccinee group and non-vaccinee group were not significantly different in the number of sexual partner(s) in a lifetime and the number of sexual partner(s) in the past 12 months. They were also not significantly different in condom use experience and condom use frequency.

10. Among vaccinees, the numbers of sexual partners (per year) before and after vaccination were not significantly different. 


\section{CHAPTER 5}

\section{DISCUSSION}

This study found that age and ethnicity were associated with vaccine uptake while religion, class major, and health insurance status were not. A few prior studies conducted among young women aged 13 to 26 in various settings (i.e. national, teen health centers, national managed care registration) showed that age and health insurance status were associated with vaccine uptake while ethnicity was not (Caskey et al., 2009; Conroy et al., 2009; Rosenthal; 2010). However, one study conducted among college women at a large public university reported that race was significantly associated with HPV vaccine initiation, with African-American less likely to report obtaining the vaccine (Bernarczyk, Birkhead, Morse, Doleyres, \& McNutt, 2011). Cautious interpretation about the associations between the vaccine uptake and demographic variables should be made because these studies were conducted in different settings.

Age of first sexual intercourse was associated with vaccine uptake while relationship status, sexual experience (ever having sex), partner genders, STI diagnosis history, and Pap test status were not. Prior studies conducted among young women in a variety of settings (i.e., national, teen health centers, metropolitan community) showed that vaccine uptake was not associated with age of first sexual intercourse, relationship status, STI diagnosis history, and sexual experience (Caskey et al., 2009; Conroy et al., 2009; Manhart et al, 2011). Two studies conducted among women younger than 26 years old at teen health center/health clinics reported the association between the vaccine uptake and Pap test status (Conroy et al., 2009; Vanderpool, Casey, \& Crosby, 2010), but a national study conducted among women aged 19-22 reported no significant association between the two variables (Caskey et al., 
2009). The finding discrepancies of the associations between the vaccine uptake and sexual history variables may due to the different types of sample and settings requited for the studies. In addition, based on the theory of planned behavior (TPB), inconsistency of association findings between demographic, sexual history, and vaccine uptake might be because these demographic and sexual history variables are only considered as individual factors and experiences which did not directly influence the vaccine uptake (Ajzen, 2011).

Since the first HPV vaccine was approved in 2006, most participants in this study had heard about HPV and HPV vaccine. The HPV awareness rate was similar to other studies conducted with female college students in the past few years (Allen et al., 2009; Dillard \& Spear, 2010; Gerend \& Magloire, 2008). However, the vaccination rate has slowly climbed.

National studies conducted in 2009 reported that $44.3 \%$ of adolescent aged 13-17 and $17 \%$ of women aged 19-26 have received at least one dose of an HPV vaccine (CDC,2010b; CDC, 2011b). For this study, the vaccine uptake rate among women aged 18-26 was $47.3 \%$-an increase from 30\% vaccine uptake rate among the same population in 2011 (CSULB, 2011). The rising vaccine uptake rates among women aged 18-26 might suggest the possibility of a more generalized temporal increase in adherence with HPV vaccine recommendations among younger age group of women now enrolled in college.

\section{Indirect Predictors of HPV Vaccine Uptake}

This study identified several important correlates of vaccine uptake and ruled out questionable correlates (knowledge and attitudes toward HPV vaccine). While HPV/HPV vaccine knowledge was significantly positively correlated with the direct predictor variables (attitude toward getting vaccinated against HPV, subjective norms, and perceived behavioral control), HPV/HPV vaccine knowledge was not significantly correlated with HPV vaccine 
uptake-similarly to prior studies which showed that HPV/HPV vaccine knowledge between non-vaccinee and vaccinee groups were not significantly different (Caskey et al., 2009; Conroy et al., 2009, Dillard \& Spear, 2010). In accordance to the TPB, the finding confirmed that knowledge is not directly linked to a behavior-HPV/HPV vaccine knowledge alone is not sufficient to motivate vaccination. Another factor related to the knowledge indifference could be that even though the vaccinees must have been given a Vaccine Information Sheet (VIS) to read before they were vaccinated (CDC, 2012a), the vaccine administration might occur when they were young and/or the VIS might be given to the parents instead.

When examining HPV/HPV knowledge in detail, the study found that both vaccinee and non-vaccinee groups had good HPV/HPV vaccine related knowledge. Consistent with previous studies that were conducted among young women at various universities (Dillard \& Spear, 2010; Gerend \& Shepherd, 2011; Head et al., 2009; Lopez \& McMahan, 2007), over $90 \%$ of college women in both groups knew that that routine Pap test needs to be continued after the vaccination. They also knew that HPV vaccine does not protect against other STIs. These findings may dispel the myths that college women might not seek routine Pap test because they might misunderstand that they would no longer need a Pap test after the vaccination (Hager, 2009; Vamos, et al., 2008). Furthermore, the finding dispels the concern that college women might place themselves at higher risk for STIs due to the misunderstanding that HPV vaccine covered all STIs (Hager, 2009; Vamos, et al., 2008).

When the first HPV became available in 2006, it brought not only the first primary prevention method against cervical cancer, but also controversies over mandatory vaccination in young girls, promoting the vaccine as an anti-cancer vaccine, and calling the 
vaccine an STI vaccine (Vamos, et al., 2008). While public discussions were made, no available evidence reported on what college women actually thought about these issues. This study found that both non-vaccinee and vaccinee groups tended to have positive attitudes toward HPV vaccine. Nevertheless, when examining the subscales, both groups did not support the ideas of calling HPV vaccine an anti-cancer or an STD vaccine. The overall positive attitude toward the vaccine was apparently a result of strong positive attitude toward mandatory vaccination in both non-vaccinee and vaccinee groups, especially in the vaccinee group which significantly favored mandatory vaccination more than non-vaccinee group. Based on this finding, mandatory vaccination proposal would not be unacceptable to this population. Promoting the vaccine as an anti-cancer vaccine or an STD vaccine might be a disadvantage.

In accordance with the TPB explanation, this study also found that there was no significant association between attitudes toward the vaccine and vaccine uptake. Thus, intervention to increase vaccination uptake rate in college women should not focus on the indirect predictors-knowledge or attitudes toward HPV vaccine.

\section{Direct Predictors of HPV Vaccine Uptake}

The findings indicated that both vaccinee and non-vaccinee groups had positive attitude toward getting vaccinated against HPV. They viewed that getting vaccinated against HPV was good, desirable, and beneficial. Both vaccinees and non-vaccinees also had positive subjective norms. They believed that their significant others would want or wanted them to obtain the vaccine. They also believed that their health care providers would support them to do so. Furthermore, both groups also had strong perceived behavioral control—-they believed that obtaining the vaccine was within their control. 
According to the TPB assumption, the more positive attitudes, subjective norms, and stronger perceive behavioral control, the higher probability of intention to get vaccinated, and consequently the higher probability of vaccine uptake. The correlation results confirmed that HPV vaccine uptake was significantly positively correlated with attitude toward getting vaccinated against HPV and subjective norms. However, the vaccine uptake was unexpectedly negatively correlated with perceived behavioral control. After controlling for confounding variables, logistic regression revealed that HPV vaccine uptake was predicted by subjective norms and perceived behavioral control.

Currently, there is no available research conducted specifically on the association between vaccine uptake and attitude toward getting vaccinated against HPV. A few studies conducted among women aged 18-26 at universities and health clinics found that HPV vaccine uptake was positively related to some types of attitudes or beliefs (i.e., risk perceptions, HPV vaccine importance) (Licht et al., 2010; Roberts et al, 2010; Vanderpool et al., 2010). Studies conducted among college-aged women at universities and health clinics also reported the positive associations between vaccine uptake and subjective norms relatedfactors such as normative beliefs (Conroy et al., 2009), approval from peers (Manhart et al., 2011), approval from mother (Roberts et al., 2010), vaccine discussion with provider (Bernarczyk et al., 2011), and provider recommendation (Rosenthal et al., 2011). The consistent findings suggested that efforts to increase vaccine uptake should be made through increasing positive attitude toward getting vaccinated against HPV and subjective normsespecially subjective norms. Health care provider's recommendation and encouragement from significant others (i.e., mother and peers) are critical in order for the college women to obtain an HPV vaccine. 
For the association between vaccine uptake and perceived behavioral control, this study found that vaccinees tended to report significantly lower perceived behavioral control when compared to the non-vaccinees. Prior studies also reported inconsistent findings on the association between vaccine uptake and perceived behavioral control (Allen et al., 2009, Conroy et al., 2009). One study conducted among college women indicated that vaccinees had significantly lower perceived barriers (Allen et al., 2009), but another study conducted among young women aged 13-26 at a health clinic reported that self-efficacy was not statistically associated with vaccine uptake (Conroy et al., 2009). In addition, this study finding was not in line with the theory of planned behavior assumption. However, this unexpected outcome might occur because the perceived behavioral control variable was measured after the vaccine administration, so the vaccinees' perceptions of control were likely to have taken into account whatever difficulties they encountered (Ajzen, personal communication, March 28, 2012). In other words, it appeared that the actual experience of getting vaccinated raised women's perceptions of the difficulties involved, thereby lowering perceived behavioral control (obtaining the vaccine was more difficult than what the vaccinees perceived).

Interestingly, significant associations were also found among the direct predictorsattitude toward getting vaccinated against HPV, subjective norms, and perceived behavioral control. According to the TPB, these three variables are conceptually independent predictors of intention. However, empirically they are usually found to be intercorrelated because the same information can influence behavioral, normative, and/or control beliefs-the theoretical antecedents of attitude, subjective norms, and perceived behavioral control (Ajzen, 2011). 


\section{Predictors of Intention to Obtain HPV Vaccine among Non-Vaccinees}

Intention to obtain HPV vaccine was significantly positively correlated with the indirect predictors-HPV/HPV vaccine knowledge and attitudes toward HPV vaccine and direct predictors - attitude toward getting vaccinated against HPV, subjective norms, and perceived behavioral control. Some prior studies also supported this evidence. A couple of studies conducted among young women aged 13-26 found that intention to obtain HPV vaccine was positively correlated with HPV knowledge, normative beliefs, and social norms, and inversely correlated with perceived barriers (Allen et al., 2009; Kahn et al., 2008). A study conducted among female college students between 2007 and 2009 also found that intention to obtain HPV vaccine was positively correlated with perceived parental approval, perceive risk, and perceived benefit from the vaccine (Patel et al., 2012).

However, for this study, when indirect and direct variables were entered into the prediction model of intention to obtain HPV vaccine, only attitude toward getting vaccinated against HPV and subjective norms significantly contributed to the prediction model, with the attitude toward getting vaccinated against HPV contributed the most to intention to obtain HPV vaccine. This finding confirmed the TPB assumption that the influence of indirect variables was mediated by the direct predictors. The finding was also supported by prior study which used an integrative model as a framework. The study conducted among college women found that attitude, subjective norms, and perceived control predicted intention to vaccinate (Dillard, 2011). The result of this study suggested that to increase intention to obtain HPV vaccine among the catch-up group, efforts should be made to increase positive subjective norms and attitude toward getting vaccinated against HPV. HPV vaccination 
promotion programs (e.g., flyers, TV advertisements, radio announcement) targeting health care providers, parents, and social norms may be beneficial. Furthermore, intervention may incorporate strategies to increase favorable attitude toward getting vaccinated against HPV through changing some behavioral beliefs such as risk perception.

As the finding revealed, some non-vaccinees believed that they were not or at low risk of acquiring HPV and some of them also did not place vaccination as their priority. However, most of them were sexually active with the average number of close to four sexual partners in their lifetime. In addition, while most of non-vaccinees knew that HPV can cause cervical cancer, be asymptomatic, and be transmitted to partners without any symptoms, less than a half of them knew that HPV also causes genital warts and $50 \%$ of women will be diagnosed with HPV once in their lifetime (CDC, 2012b). Not knowing enough about these facts might contribute to incorrect behavioral beliefs (of perceived risk and perceived severity) which could impede the attitude toward getting vaccinated against HPV. Promoting these facts as a part of the HPV vaccination promotion programs may also be beneficial. When women understand their risk and HPV severity, they may put vaccination at a higher priority.

Furthermore, since approximately $16 \%$ of non-vaccinees need more vaccine information, providing or advertising on vaccine safety, efficacy, and long term research may be necessary to help the non-vaccinees making a decision. The vaccine patient assistant programs can also be publicly promoted to help those with concerns about cost and insurance coverage. 


\section{Sexual Behaviors/Practices and HPV Vaccination}

Another controversy related to HPV vaccine uptake was whether vaccinees have placed themselves at higher risk in their sexual behaviors/practice. The study found that both vaccinee and non-vaccinee groups were not different in their sexual history except that vaccinee group started having sexual intercourse earlier than non-vaccinee group. After controlling the covariates, this study found that the number of lifetime sexual partner(s) was not associated with vaccine uptake which was consistent with previous studies (Conroy et al., 2009; Manhart et al., 2011; Roberts et al., 2010). In addition, when examining for more recent sexual behaviors, this study found that numbers of sexual partner(s) in the past 12 months were not significantly different between non-vaccinee and vaccinee groups.

This study also revealed that both vaccinee and non-vaccinee groups were not significantly different in using condom as their STI prevention method. Condom use frequency was also not significantly different between vaccinees and non-vaccinees that had sex in the past 30 days. Along this line, another study conducted among 13-26 years old women at a teen health center indicated that condom use with the last sexual intercourse was actually higher in the vaccinee group (Conroy et al., 2009). A recent study conducted among young women aged 13-26 also showed that vaccinees reported continued need for safer sexual behaviors after the vaccination (Kowalczyk Mullins et al., 2012).

Furthermore, this study's finding indicated that among non-vaccinees who had sexual intercourse before the vaccination, the number of sexual partner per year before vaccination was not significantly different from the number of sexual partner per year after vaccination. Thus, this preliminary evidence shows that sexual practices are not different whether college 
women have obtained the vaccine or not and if college women have obtained the vaccine, it does not mean that they may place themselves at higher risk in their sexual practices.

\section{Conclusion}

Findings from this study suggest that college women have positive attitudes toward getting vaccinated against HPV. While vaccine uptake and intention to obtain HPV vaccine are correlated with attitude toward getting vaccinated, subjective norms, and perceived behavioral control, subjective norms consistently predicts intention to obtain HPV vaccine and vaccine uptake. Strategies to ensure that those who are eligible for catch-up vaccination are vaccinated should certainly include attention to college women's subjective norms. Attention to strengthen non-vaccinated college women's behavioral beliefs, including correcting risk perception may also increase attitude toward getting vaccinated and, in turn, increase the vaccination uptake rate. Even though there could be several factors that influence college women's decision to obtain the vaccine, cost of the vaccine factor can be eliminated through more public advertisements of the manufacturers' patient assistant programs.

The study also suggests that college women have positive attitude toward mandatory vaccination and those who have positive attitudes toward HPV vaccine tend to have positive attitude toward getting vaccinated against HPV and subjective norms. Mandatory vaccination, with an opt-out option may be appropriate to increase the vaccine uptake rate.

Finally, the preliminary finding regarding the indifferences in sexual behaviors between non-vaccinated and vaccinated women and the number of sexual partners before and after vaccination may help dispel the myth that vaccinated women practice riskier sexual 
behaviors. Myth regarding the vaccine encouraging unsafe sexual practice may also be disregarded.

\section{Limitations}

Several efforts were made to minimize potential threats to validity. However, the study findings must be interpreted within the context of the following known limitations:

1. A convenience-based sample of college women from one university may not be generalized to all college women throughout the U.S.

2. Self-report measures can be subjected to reporting biases that may be present among participants with strong feelings for HPV and HPV vaccine. Participants may also over or under-estimate their actual feelings or behaviors.

3. Data on vaccination timeline, sexual history, and sexual behaviors were collected through self-report and were not confirmed with medical records. Recall bias may occur. Retrospective reports on attitudes, subjective norms, and perceived behavioral control among vaccinees may also be biased.

4. An email survey may save time and cost in conducting a research study (Sax, Gilmartin, \& Bryant, 2003) and may be suitable for college students since most of them (98.4\%) own at least one computer (Salaway \& Caruso, 2007). However, the response rates to email surveys have been somewhat low, at approximately $20 \%$ (CSULB, 2011; Sax et al. 2003). For this study, after email reminders and subject incentive strategies were used, the response rate was at 15.8\%-yielding a concern regarding a non-response bias. In addition, the bi-model response curve may occur due to the higher representation of the extremes (Johnson, 2011; Lahaut, Jansen, Mheen, \& Garretsen, 2002). While low response rates alone do not necessarily translate to bias, it is suggested that generally, at least $50 \%$ response rate should be attempted (Polit \& Beck, 2006). A method to explore non-response bias by comparing background characteristics between the early and late respondents was performed (Sax et al., 2003). By using analysis of variance and chi-square tests, demographic and sexual history data were compared between the respondents who responded to the first email invitation, who responded after the first reminder, and who responded after the second reminder. The results indicated that there was no difference of age, ethnicity, religion, health insurance status, class major, relationship status, sexual experience, partner genders, age of first sexual intercourse, STI diagnosis, and Pap test status among the three groups. With the indifference between three groups of respondents, it is assumed that non-response bias may not be significant. 


\section{Recommendations for Future Research}

This study provides evidence of factors related to and predicting intention to obtain HPV vaccine and vaccine uptake, potential studies can be further conducted to gain insight and strengthen the evidence. Future studies should include a qualitative research using a focus group method to seek deeper understanding on why college women do not perceive themselves at risk for HPV infection and why some women decide not to get vaccinated against HPV. Similarly, a focus group can be conducted among vaccinees to explore how parents and health care providers influence their decision to obtain the vaccine and if the vaccinees would still make the same decision now.

By using the findings from this study, a pilot HPV vaccine promotion program can be tailored to increase subjective norms. The promotion program may include increasing health care provider's recommendation to obtain the vaccine during college women's office visit or sending HPV/HPV health educational brochures to college women's parents. An experimental design study can be conducted to examine the effectiveness of the promotion program on vaccine uptake among college women who have not obtained an HPV vaccine.

While females have primarily been the priority of HPV vaccine research, male, especially male having sex with male are also impacted by HPV. The HPV cumulative prevalence in men was estimated to be as high as over 70\% (Dunne et al., 2006). To decrease HPV infection, genital warts, and cervical and anogenital cancers, HPV primary prevention efforts should be equally made across the genders. Since late 2009, the FDA approved Gardasil for use in males aged 9-26. However, research related to HPV vaccine uptake in male population is very limited. Currently, the vaccine uptake rate among young men is unknown and HPV vaccine promotion campaign or health education programs also 
focus only on female population. Future HPV vaccine related-research should include male population. Another study using the theory of planned behavior can be conducted to examine the relationship between knowledge, attitudes, subjective norms, perceived behavioral control, intention to vaccinate, and vaccine uptake among young male population. The current HPV and HPV vaccine related Knowledge, Attitudes, and Behaviors Questionnaire can also be adjusted to appropriately measure these variables in male population. Once the vaccine uptake rate is known and the predictors of vaccine uptake among male population are identified, appropriate interventions to increase the vaccine uptake can be tailored so that both genders are responsible and protected against HPV.

\section{Implications for Practice}

This research, guided by the theory of planned behavior, provides new and important information that contributes to the understanding of HPV vaccine uptake rates and the complex interplay of HPV/HPV vaccine knowledge, attitudes toward HPV vaccine, attitude

toward getting vaccinated against HPV, subjective norms, perceived behavioral control, and intention to obtain HPV vaccine. The study revealed that subjective norms are a key factor in the decision to receive the HPV vaccine. Based on the results of this study, a health care provider may influence young college women to obtain the vaccine by encouraging and discussing about HPV and HPV vaccine during the office visit.

The study findings also yielded a research-based foundation for the development of interventions to increase the number of young women who receive the HPV vaccine. Not only individual-level intervention, but population-level HPV vaccine promotions can be focused on increasing positive HPV vaccine-related subjective norms such as health care providers, mothers, and peers. 
Perhaps the most significant aspect of this study was its ability to address the current controversy about whether or not HPV vaccine status impacts sexual behaviors/practices. While it is critical that health care providers continue to discuss safer sexual practices with college women, findings from this study indicate that HPV vaccination does not encourage unsafe sexual practice.

Finally, the results of this study can be used to inform public policy decision-making about a mandate for the HPV vaccine. Mandating HPV vaccination with an opt-out option should be discussed at the public health policy maker's level. Accompanying mandatory vaccination with tailored interventions focusing on positive subjective norms relevant to specific individuals, communities, and the public at-large, have the potential to increase the HPV vaccine uptake rate. Such an increase would result in decreasing the rate of HPV infection, cervical cancer, and negative HPV-related health outcomes. 
APPENDIX A

INFORMED CONSENT 


\section{Consent for Participation in a Research Study}

You are being invited to participate in an online research study, conducted by Nop Ratanasiripong, a Ph.D in nursing candidate at the University of Missouri, Kansas City. The purpose of this study is to examine what college women know, think, and do about HPV and HPV vaccine.

Your participation is voluntary and you may choose to participate or to withdraw your participation at anytime. Your decision will not adversely affect your standing with the university or your grades. There is no cost to you to participate. There are also no direct benefits to you as a participant in this study; however, the first 305 participants who come to the Student Health Services after completing the survey will have a chance to draw a prize from five $\$ 100$, ten $\$ 50$, and $290 \$ 10$ Beach Club gift cards.

Your participation in this study will involve completion of a survey that has 51 questions. The survey may take about 15 minutes to complete. There is a risk that these questions may be emotionally upsetting to you. Some questions ask about sexual activities. You can refuse to answer any individual question by clicking on the "prefer not to answer" button or skip the questions. You are also free to discontinue the survey at anytime. If you opt to not complete the survey, your responses will not be recorded in our database. If you need any assistance regarding your emotional concerns, please contact Counseling and Psychological Services at (562) 985-4001.

Your email address is among a randomly selected sample, representing female undergraduate students at California State University, Long Beach. Your responses are treated anonymously and cannot be linked back to you because your identifiable information is not collected and your computer IP address is not tracked. While every effort will be made to keep confidential all of the information you complete and share, confidentiality cannot be absolutely guaranteed. Individuals from the University of Missouri-Kansas City and California State University, Long Beach Institutional Review Boards (committees that review and approve research studies), Research Protections Program, and federal regulatory agencies may look at records related to this study for quality improvement and regulatory functions.

Thank you in advance for your candid responses on the survey. If you have any questions about the study or experience technical difficulties with the survey, please call Nop Ratanasiripong at (562) 481-2932 or email her at nratanas@ @ csulb.edu. Although it is not the University's policy to compensate or provide medical treatment for persons who participate in studies, if you think you have been injured as a result of participating in this study, please call the IRB Administrator of UMKC's Social Sciences Institutional Review Board at 816235-1764.

Once you have completed the survey, print out the "thank you" page or write down the prize code appearing on the page. Then, visit the Student Health Services, Health Resource Center, Room 268. If you are one of the first 305 participants, you will have a chance to draw a prize there. 
I have read and understood this consent form.

$\square$ Yes, I agree to participate in this online study. By checking on "Yes, I agree to participate" box below, you are attesting to the fact that you are at least 18 years old and are freely giving consent to participate in the study.

I decline to participate in this online study.

Thank you for your participation!

Nop Ratanasiripong, RN, MSN, Ph.D (c)

University of Missouri, Kansas City

School of Nursing

2464 Charlotte Street

Kansas City, MO 64108

Phone number: 562-481-2932

Fax number: 562-985-8040

Email address: ntr7g5@umkc.edu 
APPENDIX B

IRB AUTHORIZATION AGREEMENT BETWEEN UMKC AND CSULB 
Sample text for an Institution wilh a Federalwide Assurance (FWA) ro rely on an IRB outside their ithtitution (institutions may use this sample as a guide to develop their own agreement)

\section{IRB Authorization Agreement}

Name of Institution or Organization Providing IRB Review (Institution A): California State University Long Beach

IRB Registration \#: ${ }^{00000815}$ Federalwide Assurance (FWA) \#, if any: 00000022

Name of Institution Relying on the Desiguated IRB (Institution B):

University of Missouri-Kansas City

OHRP Federalwide Assurance (FWA) \#:

The Officials signing below agree that UMKC may rely on the designated

IRB for review and continuing oversight of its human subject research described below: (check one)

( This agreement applies to all human subject research covered by Institution B's FWA.

$\sqrt{ }$ This agreement is limited to the following specific protocol(s):

Name of Rescarch Project: What Colleqe Women Know

Name of Principal Investigator: Nop Ratanasiripona

Sponsor or Funding Agency: Award Number, if any:

(प) Other (describe):

The teview and continting oversight performed by the designated IRB will meet the human subjects protection requirements of Institution B's OHRP-approved FWA. The IRB at Institution A will follow written procedures for reporting its findings and actions to appropriate officials at Institution $B$.

Relevant minutes of IRB meetings will be made available to Institution $B$ upon request. Institution $B$ remains responsible for ensuring compliance with the IRB's determinations and with the terms of its OHRP-approved Assurance. This document must be kept on file at both institutions and provided to OHRP upon request.

Signature of Signalory official (Institution A): Al RUSSO

Print Full Name: Al RuSSO Institutional Title: Director of Research Compoiance

Signature of Signatory Official (Institution B)

Print Full Name: Institutional Title:

Ted R. Knous, Ph.D.

Assoctate Vice Chancellor for Research

University of Missourl - Kansas Clly 
APPENDIX C

CSULB IRB APPROVAL LETTER 


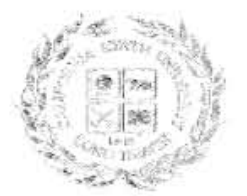

\section{CALIFORNIA STATE UNIVERSITY, IONG BFACH}

January 13, 2012

OFFICE OF UNIVERSITY RESEARCH

Ms. Nop Ratanasiripong

Student Health Services

California State University, Long Beach

1250 Bellflower Boulevard

Long Beach, California 90840

Re: "What College Women Know, Think, and Do about HPV and HPV Vaccine" [Protocol \#12-145i]

Dear Ms. Ratanasiripong:

This is to advise you that the Institutional Review Board for the Protection of Human Subjects (IRB) of California State University, Long Beach has reviewed your Protocol Application.

Your Application is approved. The requested modifications have been received, reviewed, and accepted.

Approval is for a period of one year from the date of this letter and conditional upon your willingness to carry out your continuing responsibilities under University Policy. If you would like to continue this research after this one year period, please submit a Renewal Application and an Annual Report to the Office of University Research two months prior to your expiration date of January 12, 2013.

1. You must clearly indicate in the header or footer of each page of your approved Informed Consent Form the approval and expiration dates of the protocol as follows: "Approved from January 13, 2012 to January 12,2013 by the CSULB IRB".

2. You are required to inform the Director or Senior Associate Director, Office of University Research, in writing (email is acceptable) within twenty-four hours of any adverse event in the conduct of research involving human subjects. The report shall include the nature of the adverse event, the names of the persons affected, the extent of the injury or breach of security, if any, and any other information material to the situation.

3. You may NOT change your research procedure involving human subjects without written permission from the Director, Office of University Research or the Chair of the IRB. Please use the Protocol Modification Form to request any changes.

4. Maintain your research records as detailed in the protocol.

In accordance with 45 CFR $46.117(\mathrm{c} / 2)$, the IRB waives the requirement to obtain a signed consent form from subjects. You will provide subjects with a written statement regarding the research.

Should you have any questions about the conduct of your research under this protocol, particularly about providing informed consent and unexpected contingencies, please do not hesitate to call the Office of University Research at 562-985-5314. We wish you the best of success in your research.

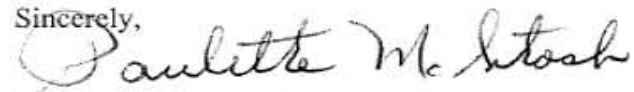

Paulette McIntosh, M.S.

Senior Associate Director

Office of University Research

c: Professor Maithe Enriquez 


\section{APPENDIX D}

HPV AND HPV VACCINE RELATED KNOWLEDGE, ATTITUDES, AND BEHAVIORS QUESTIONNAIRE 


\section{HPV and HPV vaccine Knowledge}

1. *Have you heard about Human Papillomavirus (HPV)?

- Yes

_ No (go to Page 4: Sexual History/Sexual Behaviors: SurveyMonkey used skipped pattern)

2. *Have you heard about HPV vaccine?

Yes

__ No (go to Page 4: Sexual History/Sexual Behaviors)

3. Throughout the survey, you will notice items that ask you to mark a specific response (for example, "Please check Disagree."). These items are there to help us make sure that your responses are being recorded correctly, so please follow the directions on these items.

4. Please read each statement below and answer whether it is "true" or "false". Please choose "I don't know" if you do not know the answer.

\begin{tabular}{|l|l|l|l|}
\hline & True & False & $\begin{array}{c}\text { I don't } \\
\text { know }\end{array}$ \\
\hline 1.HPV can cause genital warts & & & \\
\hline 2.HPV can cause cervical cancer & & & \\
\hline $\begin{array}{l}\text { 3.Most people with genital HPV have no visible signs or } \\
\text { symptoms }\end{array}$ & & & \\
\hline 4. Using a condom can provide partial protection against HPV & & & \\
\hline $\begin{array}{l}\text { 5.I can transmit HPV to my partner(s) even if I have no HPV } \\
\text { symptoms }\end{array}$ & & & \\
\hline $\begin{array}{l}\text { 6.One out of two women will be diagnosed with HPV once in } \\
\text { their life time }\end{array}$ & & & \\
\hline 7.Only sexually active women should receive the HPV vaccine & & & \\
\hline $\begin{array}{l}\text { 8. Women who receive HPV vaccine do not need to get routine } \\
\text { Pap smears/test }\end{array}$ & & & \\
\hline $\begin{array}{l}\text { 9.HPV vaccine protects against all sexually transmitted } \\
\text { infections }\end{array}$ & & & \\
\hline Please check "False" for this item & & & \\
\hline
\end{tabular}

NOTE: A "No return response" function was set up on SurveyMonkey so that the respondents were not able to go back to Knowledge questions to change the answers after they hit "next" button and saw the introduction of HPV/HPV vaccine on the next page. 
Human Papillomavirus (HPV) is a group of viruses that can cause genital warts and genital cancer (e.g. cervical cancer, anal cancer). Genital HPV infection is the most common sexually transmitted infection in the U.S. High-risk HPV types can cause cervical cancers. Low-risk HPV can cause genital warts. Two HPV vaccines are now available for girls/women aged 9-26.

\section{HPV vaccine status}

1. *Have you received any HPV vaccine?

_ No (go to Q 2)

Yes (go to Page 7)

__ Prefer not to answer (go to Page 11)

2. Why have you not obtained the HPV vaccine? 


\section{For NON-VACCINEES ONLY}

Please take a moment to tell us what you think about the possibility of getting vaccinated against HPV. Please note that some items and answer choices may seem very similar however, they are not the same.

\section{Attitudes toward Getting Vaccinated Against HPV}

My getting an HPV vaccine would be...

Bad: —1_:_2_:_3_:_4_:5_:_6__:_7_: Good

Worthless:

_1_-_2_:_3_:_4_:_5_:_6__:_7_: Useful

Desirable:

_1___2_:_3_:_4_:_5_:_6____7_: Undesirable

Beneficial:

_1___2_:_3_:_4_:_5_:_6____ __ : Harmful

Favorable:

—1_:_2_:_3_:_4_:_5_:_6____7_: Unfavorable

Pleasant (for me):

_1_:_2_:_3_:_4_:_5_:_6____ $\_$_ Unpleasant (for me)

\section{Attitudes toward HPV Vaccine}

Calling HPV vaccine an anti-cancer vaccine is...

Bad:

-1_:_2_:_3_:_4_:_5_:_6____ __: Good

Desirable:

_1_:_2_:_3_:_4_:_5_:_6____ 7_: Undesirable

Pleasant (for me):

_1_:_2_:_3_:_4_:_5_:_6____ __: Unpleasant (for me)

Calling HPV vaccine a STD vaccine is...

Bad:

$$
\text { —1_:_2_:_3_:_4_:_5_:_6_-__7_: Good }
$$

Desirable:

—1_:_2_:_3_:_4_:_5_:_6____ 7_: Undesirable

Pleasant (for me):

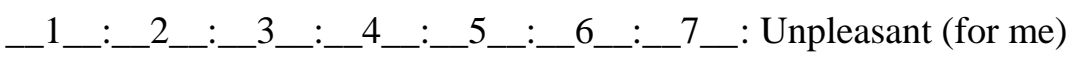

Mandating HPV vaccine for all young girls is...

Bad:

—1_:_2_:_3_:_4_:_5_:_6___-7_: Good

Worthless:

—1_:_2_:_3_:_4_:_5_:_6____ _ : Useful

Desirable:

—1_:_2_:_3_:_4_:_5_:_6____ 7_: Undesirable




\section{Subjective norms}

Please rate how strongly you agree or disagree with each of the following statements.

\begin{tabular}{|l|l|l|l|l|l|}
\hline & $\begin{array}{c}\text { Strongly } \\
\text { agree }\end{array}$ & Agree & Neither & Disagree & $\begin{array}{c}\text { Strongly } \\
\text { disagree }\end{array}$ \\
\hline $\begin{array}{l}\text { Most people who are important to me think } \\
\text { that I should get vaccinated against HPV }\end{array}$ & & & & & \\
\hline $\begin{array}{l}\text { It is expected of me that I get vaccinated } \\
\text { against HPV }\end{array}$ & & & & & \\
\hline $\begin{array}{l}\text { I feel under social pressure to get } \\
\text { vaccinated against HPV }\end{array}$ & & & & & \\
\hline $\begin{array}{l}\text { My doctor would support my getting } \\
\text { vaccinated against HPV }\end{array}$ & & & & & \\
\hline $\begin{array}{l}\text { Most women like me are getting } \\
\text { vaccinated against HPV }\end{array}$ & & & & \\
\hline $\begin{array}{l}\text { SD:I am always careful about my manner } \\
\text { of dress (T:1-5) }\end{array}$ & & & & \\
\hline $\begin{array}{l}\text { SD: If I could get into a movie without } \\
\text { paying and be sure I was not seen, I would } \\
\text { probably do it (F: 5-1) }\end{array}$ & & & & \\
\hline $\begin{array}{l}\text { SD: I can remember "playing sick" to get } \\
\text { out of something (F: 5-1) }\end{array}$ & & & & & \\
\hline
\end{tabular}

Perceived behavioral control

Please rate how strongly you agree or disagree with each of the following statements.

\begin{tabular}{|l|l|l|l|l|l|}
\hline & $\begin{array}{c}\text { Strongly } \\
\text { agree }\end{array}$ & Agree & Neither & Disagree & $\begin{array}{c}\text { Strongly } \\
\text { disagree }\end{array}$ \\
\hline $\begin{array}{l}\text { If I want to, I can get vaccinated against } \\
\text { HPV }\end{array}$ & & & & & \\
\hline $\begin{array}{l}\text { I am confident that I can get vaccinated } \\
\text { against HPV }\end{array}$ & & & & & \\
\hline Please check "Disagree" on this item & & & & & \\
\hline $\begin{array}{l}\text { Getting vaccinated against HPV is beyond } \\
\text { my control }\end{array}$ & & & & & \\
\hline $\begin{array}{l}\text { Whether I get vaccinated against HPV is } \\
\text { entirely up to me }\end{array}$ & & & & & \\
\hline
\end{tabular}

Intention to obtain an HPV vaccine

Please rate how strongly you agree or disagree with each of the following statements.

\begin{tabular}{|l|l|l|l|l|l|}
\hline & $\begin{array}{c}\text { Strongly } \\
\text { agree }\end{array}$ & Agree & Neither & Disagree & $\begin{array}{c}\text { Strongly } \\
\text { disagree }\end{array}$ \\
\hline I intend to get vaccinated against HPV & & & & & \\
\hline $\begin{array}{l}\text { I have decided to get vaccinated against } \\
\text { HPV }\end{array}$ & & & & & \\
\hline I plan to get vaccinated against HPV & & & & & \\
\hline $\begin{array}{l}\text { I expect to get vaccinated against HPV at } \\
\text { some point }\end{array}$ & & & & & \\
\hline
\end{tabular}




\section{Sexual History and Sexual Behaviors}

1. What is your relationship status?

$\begin{array}{ll}\text { Single } & \text { Widowed } \\ \text { Dating } & \text { Separated } \\ \text { Married } & \end{array}$

2. *Have you ever had sexual intercourse?

_ Yes

__ No (go to Page 11: Demographic)

__ Prefer not to answer (go to Page 11: Demographic)

3. You have had sex with...

_ Women

Men

_ Both

4. How old were you when you had sex for the first time?

5. How many sexual partners have you had in your life time?

6. How many sexual partners have you had in the past 12 months?

7. What methods did you use to prevent STDs? (Check all that apply)

_ Condoms

Abstinence

Monogamy (have only one partner)

Long term relationship (over a few years)

other, specify:

Prefer not answer

8. If you use condoms, how often did you use condoms in the past 30 days?

More than $75 \%$

$51-75 \%$

$26-50 \%$

Less than $25 \%$

I did not have sex in the past month

Not applicable 
9. Have you ever been diagnosed with any STD?(Check all that apply)

_ Gonorrhea

Chlamydia

_ Syphilis

Genital herpes

Human Papillomavirus (HPV) and/or genital warts

Other, specify:

I have not been diagnosed with any STD

10. *What was your most recent Pap smear result?

Normal

Abnormal

I have not had a Pap smear

I don't know what a Pap smear is

Prefer not to answer

Then, go to Page 11: Demographic 


\section{For VACCINEES ONLY}

Please take a moment to tell us what, prior to getting vaccinated, you thought about the possibility of getting vaccinated against HPV. Please note that some items and answer choices may seem very similar however, they are not the same.

\section{Attitudes toward Getting Vaccinated Against HPV}

I thought that my getting the HPV vaccine would be...

\begin{tabular}{|c|c|}
\hline Bad: & _-1_:2__:_3_:_4_: 5 5_:_6___7_ : Good \\
\hline Worthless: & _1_:_2_:_3_:_4__:_5_:_6_ $:$ _ 7_ : Useful \\
\hline Desirable: & 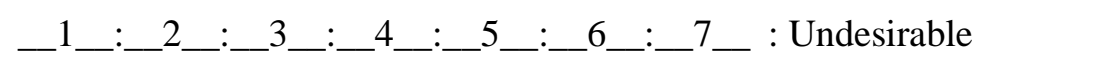 \\
\hline Beneficial: & 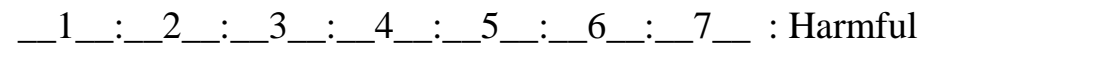 \\
\hline Favorable: & ____:_2_:_3_:_4__: 5__-_6___7_ : Unfavorable \\
\hline Pleasant (for me): & 1__: $2 \_: 3_{-}: 4_{-}: 5_{-}:{ }_{6} 6 \_:-7 \_:$Unpleasant (for me) \\
\hline
\end{tabular}

\section{Attitudes toward HPV Vaccine}

Calling HPV vaccine an anti-cancer vaccine is...

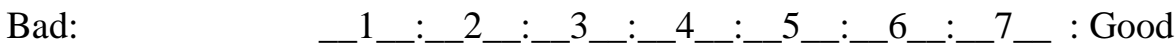

Desirable: ____:_2_:_3_:_4_:_5_:_6_:_7_ : Undesirable

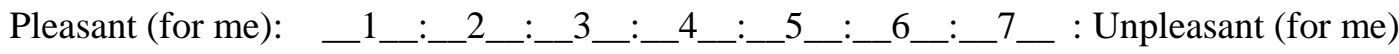

Calling HPV vaccine a STD vaccine is...

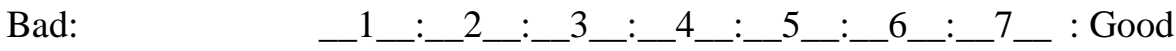

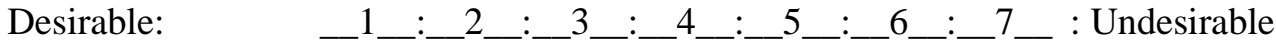

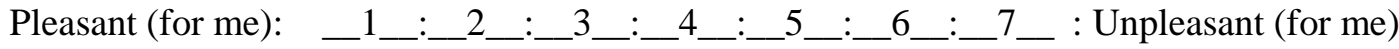

Mandating HPV vaccine for all young girls is...

Bad:

__ 1_:_2_:_3_:_4___5_:_6_:_7_ : Good

Worthless:

—1_:_2_:_3_:_4_:_5_:_6_:_7_ : Useful

Desirable:

_-1_:_2_:_3_:_4_:_5_:_6_:_7_ : Undesirable 


\section{Subjective norms}

Please rate how strongly you agree or disagree with each of the following statements.

\begin{tabular}{|l|l|l|l|l|l|}
\hline & $\begin{array}{c}\text { Strongly } \\
\text { agree }\end{array}$ & Agree & Neither & Disagree & $\begin{array}{c}\text { Strongly } \\
\text { disagree }\end{array}$ \\
\hline $\begin{array}{l}\text { Most people who are important to me } \\
\text { thought that I should get vaccinated against } \\
\text { HPV }\end{array}$ & & & & & \\
\hline $\begin{array}{l}\text { It was expected of me that I got vaccinated } \\
\text { against HPV }\end{array}$ & & & & & \\
\hline $\begin{array}{l}\text { I felt under social pressure to get vaccinated } \\
\text { against HPV }\end{array}$ & & & & & \\
\hline $\begin{array}{l}\text { My doctor approved of my getting } \\
\text { vaccinated against HPV }\end{array}$ & & & & & \\
\hline $\begin{array}{l}\text { Most women like me are vaccinated against } \\
\text { HPV }\end{array}$ & & & & & \\
\hline $\begin{array}{l}\text { SD:I am always careful about my manner of } \\
\text { dress (T:1-5) }\end{array}$ & & & & & \\
\hline $\begin{array}{l}\text { SD: If I could get into a movie without } \\
\text { paying and be sure I was not seen, I would } \\
\text { probably do it (F: 5-1) }\end{array}$ & & & & & \\
\hline $\begin{array}{l}\text { SD: I can remember "playing sick" to get } \\
\text { out of something (F: 5-1) }\end{array}$ & & & & & \\
\hline
\end{tabular}

\section{Perceived behavioral control}

Please rate how strongly you agree or disagree with each of the following statements.

\begin{tabular}{|l|l|l|l|l|l|}
\hline & $\begin{array}{c}\text { Strongly } \\
\text { agree }\end{array}$ & Agree & Neither & Disagree & $\begin{array}{c}\text { Strongly } \\
\text { disagree }\end{array}$ \\
\hline $\begin{array}{l}\text { I could get vaccinated against HPV as I } \\
\text { wanted to }\end{array}$ & & & & & \\
\hline $\begin{array}{l}\text { I was confident that I could get vaccinated } \\
\text { against HPV }\end{array}$ & & & & & \\
\hline Please check "Disagree" on this item & & & & & \\
\hline $\begin{array}{l}\text { Getting vaccinated against HPV was } \\
\text { beyond my control }\end{array}$ & & & & & \\
\hline $\begin{array}{l}\text { Whether I got vaccinated against HPV was } \\
\text { entirely up to me }\end{array}$ & & & & & \\
\hline
\end{tabular}




\section{Sexual History and Sexual Behaviors}

1. What is your relationship status?

$\begin{array}{ll}\text { Single } & \text { Widowed } \\ \text { Dating } & \text { Separated } \\ \text { Married } & \end{array}$

2. Have you ever had sexual intercourse?

- Yes

No (go to Page 11: Demographic)

__ Prefer not to answer (go to Page 11: Demographic)

3. You have had sex with...

Women

_ Men

Both

4. How old were you when you had sexual intercourse for the first time?

5. How many sexual partners have you had in your life time?

6. How many sexual partners have you had in the past 12 months?

7. When did you get the first dose of an HPV vaccine? Please write down the month and year in the space below. If you cannot remember the month, estimation is acceptable

8. How many sexual partners did you have before you received an HPV vaccine?

9. How many new sexual partner(s) have you had after you obtained an HPV vaccine? (Note: The number of sexual partners before AND after the vaccination should equal the number of sexual partners in your life time)

10. What methods did you use to prevent STDs? (check all that apply) Condoms

Abstinence Monogamy (having only one partner) Long term relationship (over a few years) Other, specify: Prefer not to answer 
11. If you use condoms, how often did you use condoms in the past 30 days?

More than $75 \%$

$51-75 \%$

$26-50 \%$

Less than $25 \%$

I did not have sex in the past month

Not applicable

12. Have you ever been diagnosed with any STI?(Check all that apply)

Gonorrhea

_ Chlamydia

Syphilis

Genital herpes

Human Papillomavirus (HPV) and/or genital warts

Other, specify:

I have not been diagnosed with any STD

13. *What was your most recent Pap smear result?

Normal

Abnormal

I have not had a Pap smear

I don't know what a Pap smear is

Prefer not to answer

Then, go to Page 11: Demographic 


\section{Demographic Information}

1. How old are you?

2. Please describe your ethnicity (check all that apply)

_ White

Asian

Latino

African-American/Black

Other, specify:

3. What is your religious background?

Buddhist

Catholic

Hindu

Muslim

Protestant

None

Other, specify:

4. Do you have health insurance?

Yes
No

5. What is your college major?

Health-related major

Non health-related major

6. If you have additional comments, please write in the box below: 
APPENDIX E

LETTER OF SUPPORT FROM CSULB VICE PRESIDENT 


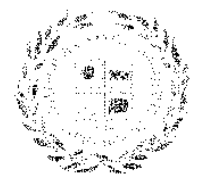

\section{CALIFORNIA STATE UNIVERSITY. LONG BEACH}

VICE PRESIDENT FOR STUDENT SERVICES

April 6, 2011

Nursing Research Review Committee

P.O. Box 504342

St. Louis. MO 63150

\section{Re: American Nurses Foundation Grant}

I am writing to express my support of the implementation of a research study, What College Women Know, Think, and Do about HPV and HPV Vaccine, at Califormia State University, Long Beach.

In our effort to enhance the health of college students, the results from this study will provide a research-based foundation to inform policy and clinical practice interventions to potentially increase HPV immunization rates among young women and, in the long run, contribute to decreased risk for cervical cancer and negative HPV-relatcd health outcomes.

Nop Ratanasiripong is aware that she needs to seek an approval from the Institutional Review Board for the Protection of Human Subjects at California State University, Long Beach, before she can implement the study with college women on campus.

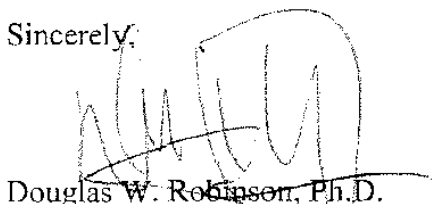

Douglas W. Robsen, Ph.D.

Vice President for Student Services 
APPENDIX F

EMAIL LETTER OF SUPPORT FROM CSULB ENROLLMENT SERVICES 


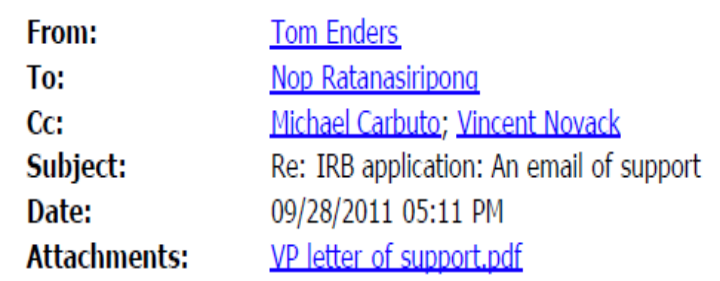

Nop...

I have reviewed your request and also consulted with Van Novack. Assistant VP Institutional Research since his office would have to produce the data since it requires sampling.

We both support this request and you can share this email as part of your IRB packet to reflect both of your support.

Once IRB approval is received, you will need to forward it to Van so that they can perform the sampling and provide the email addresses. They will need to exclude any student who has restricted their email from release based on FERPA. This is a very small number of students so will not affect the sampling.

Tom Enders

Associate Vice President

Enrollment Services

CSU Long Beach

$\checkmark$ Nop Ratanasiripong/StudentServices/CSULB 
APPENDIX G

LETTER OF SUPPORT FROM CSULB STUDENT

HEALTH SERVICES 


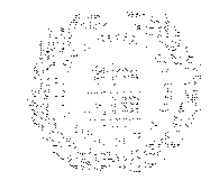

\section{CALIFORNIA STATE UNIVERSITY, LONG BEACH \\ STUDENT HEALTH SERVICES \\ A Accredited by Acrratitation 4sfociation \\ A for Antulatory Health Care, inc.}

March 24. 2011

To: Nursing Research Review Committee

Re: Americun Nurses Foundation grant

I am writing to express my support and approval to use the Student Health Services (SHS) as a main study site for the What College Women Know, Think, and Do about HPV and HPV Vaccine study. This stucy will use a theory-driven approach to: (1) to identify factors that influence HPV vaccine uptake among college women and (2) to examine the post-vaccine sexual behaviors/practices of college-aged ivomen. The study will be conducted by Nop Ratanasiripong, RN.MSN, Ph.D (student)

In our erfort to enhance the health of college students, the results from this study will provide an evidence-based foundation for the development of community health and clinical practice interventions to potentially increase IPV immunization rates which would decrase risk for cervical cancer and help reduce negative HPV-related health outcomes among college-aged US women.

I am happy to comply with Federal Regulations and University Policy established by Institutional Review Board for the Protection of Human Subjects at Califomia State University, l ong Beach.

Sincerely,

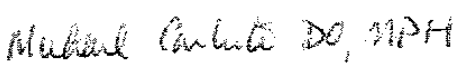

Michael Carbuto. D.O, M.P.H

Director and Chief of Medical Staff

Phone: $(562) 985-2208$

Fax: (562) 985-8404

Enail addiress: mearbutortesulb.edu

1250 BFILF1OWER EOULEVARD, LONG BEACH, CALIFORNLA 90840-0201, 562/985-4771 
APPENDIX H

EMAIL INVITATION FOR PARTICIPATION IN A RESEARCH STUDY 


\title{
Email Invitation for Participation in a Research Study
}

\author{
E-Mail Title: What College Women Know, Think, and Do about HPV and HPV Vaccine
}

My name is Nop Ratanasiripong and I am a Ph.D candidate in Nursing Program at University of Missouri, Kansas City (UMKC), currently working on my dissertation.

I am conducting a research about HPV (Human Papillomavirus) and HPV vaccine. The purpose of the study is to examine what college women know, think, and do about HPV and HPV vaccine. This study has been approved by the UMKC and CSULB Institutional Research Boards.

This e-mail is to invite you to participate in the study by completing a short online survey. The survey may take about 15 minutes to complete. Your participation is voluntary. Your responses will help the researcher to have better understanding of the research topic that will lead to development of a more appropriate HPV prevention program for this specific population.

The survey will be available online for a period of one month from the date of this e-mail, and can be completed from any computer with internet access at a time that is convenient for you. It will take about 15 minutes. There are no direct benefits to you as a participant in this study; however, the first 305 participants who come to the Student Health Services after completing the survey will have a chance to draw a prize from five $\$ 100$, ten $\$ 50$, and $290 \$ 10$ Beach Club gift cards.

We will be emailing out two reminders to you in about one and two weeks. If you wish to be removed from the research study reminder list, please reply to this message with the words "no e-mail" in the subject line, or send an email to nratanas@ @ csulb.edu

If you are interested to complete this survey, please click this link. A browser window will open to the survey, which starts with an informed consent page.

Your assistance is deeply appreciated.

Nop Ratanasiripong, RN, MSN, Ph.D (c)

University of Missouri, Kansas City

School of Nursing

2464 Charlotte Street

Kansas City, MO 64108

Phone number: 562-481-2932

Fax number: 562-985-8040

Email address: ntr7g5@umkc.edu 
APPENDIX I

EMAIL REMINDER FOR WEEK ONE 


\title{
Email Reminder to Participate in a Research Study (Week 1)
}

\author{
Email Title: Complete an HPV survey: A chance to win a prize
}

\section{Dear CSULB Student:}

We recently invited you to participate in an important online research study. The purpose of the study is to examine what college women know, think, and do about HPV and HPV vaccine.

If you have already completed the survey, we greatly appreciate your time and cooperation. If you have not completed the survey, we would greatly appreciate your input. We are seeking your support in conducting this short, one-time survey. The survey may take about 15 minutes to complete. Your participation is voluntary. Your response will be anonymous. The survey will not collect any personally identifying information and computer IP addresses will not be collected.

The survey will be available online for 3 more weeks, and can be completed from any computer with internet access at a time that is convenient for you. We will be emailing out another reminder to you in about one week. If you wish to be removed from the research study reminder list, please reply to this message with the words "no e-mail" in the subject line, or send an email to nratanas@ csulb.edu

There are no direct benefits to you as a participant in this study; however, the first $\mathbf{3 0 5}$ participants who come to the Student Health Services after completing the survey will have a chance to draw a prize from five $\$ 100$, ten $\$ 50$, and $290 \$ 10$ Beach Club gift cards.

If you are interested to complete the survey, please click this link. A browser window will open to the survey, which starts with an informed consent page.

Thank you for your participation,

Nop Ratanasiripong, RN,MSN, Ph.D (c)

University of Missouri, Kansas City

School of Nursing

2464 Charlotte Street

Kansas City, MO 64108

Phone number: 562-481-2932

Fax number: 562-985-8040

Email address: ntr7g5@umkc.edu 
APPENDIX J

EMAIL REMINDER FOR WEEK TWO 


\title{
Email Reminder to Participate in a Research Study (Week 2)
}

\author{
Email Title: Complete an HPV survey: A chance to win a prize
}

\section{Dear CSULB Student:}

We recently invited you to participate in an important online research study. The purpose of the study is to to examine what college women know, think, and do about HPV and HPV vaccine.

If you have already completed the survey, we greatly appreciate your time and cooperation. If you have not completed the survey, we would greatly appreciate your input. We are seeking your support in conducting this short, one-time survey. The survey may take about 15 minutes to complete. Your participation is voluntary. Your response will be anonymous. The survey will not collect any personally identifying information and computer IP addresses will not be collected.

The survey will be available online for 2 more weeks, and can be completed from any computer with internet access at a time that is convenient for you.

There are no direct benefits to you as a participant in this study; however, the first $\mathbf{3 0 5}$ participants who come to the Student Health Services after completing the survey will have a chance to draw a prize from five $\$ 100$, ten $\$ 50$, and $290 \$ 10$ Beach Club gift cards.

If you are interested to complete the survey, please click this link. A browser window will open to the survey, which starts with an informed consent page.

Thank you for your participation,

Nop Ratanasiripong, RN,MSN, Ph.D (c)

University of Missouri, Kansas City

School of Nursing

2464 Charlotte Street

Kansas City, MO 64108

Phone number: 562-481-2932

Fax number: 562-985-8040

Email address: ntr7g5@umkc.edu 


\section{REFERENCES}

Adams, M., Jasani, B., \& Fiander, A. (2007). Human Papillomavirus (HPV) prophylactic vaccination: Challenges for public health and implications for screening. Vaccine, 25, 3007-3013.

Ajzen, I. (1991). The theory of planned behavior. Organizational Behavior and Human Decision Processes, 50(2), 179-211.

Ajzen, I. (2010a). TPB diagram. Retrieved from http://people.umass.edu/aizen/tpb.diag.html.

Ajzen, I. (2010b). Constructing a theory of planned behavior questionnaire. Retrieved from http://people.umass.edu/aizen/pdf/tpb.measurement.pdf.

Ajzen, I. (2011). Icek Ajzen: Frequently asked questions. Retrieved from http://people.umass.edu/aizen/.

Ajzen, I., \& Fishbein, M. (2004). Questions raised by a reasoned action approach: Comment on Ogden (2003). Health Psychology, 23(4), 431-434.

Allen, J. D., Mohllajee, A. P., Shelton, R. C., Othus, M. K., Fontenot, H. B., \& Hanna, R. (2009). Stage of adoption of the Human Papillomavirus vaccine among college women. Preventive Medicine, 48, 420-425.

American College Health Association. (2010). National college health assessment: Spring 2010 reference group data report. Retrieved from http://www.achancha.org/docs/ ACHA-NCHA-II_ReferenceGroup_DataReport_Spring2010.pdf.

Association of Reproductive Health Professionals. (2009). Managing HPV: A new era in patient care. Retrieved from http://www.arhp.org/Publications-and-Resources/QuickReference-Guide-for-Clinicians/Managing-HPV.

Ault, K. A. (2006). Epidemiology and natural history of Human Papillomavirus infections in the female genital tract. Infectious Disease in Obstetrics and Gynecology, 40470, 1-5.

Bailey, R. (2008). Safety, efficacy, morality, the FDA gets religion. Retrieved from http://www.nccc-online.org/health_news/topics/controversial/planb_hpv.html.

Bernarczyk, R. A., Birkhead, G. S., Morse, D. L., Doleyres, H., \& McNutt, L. (2011). Human Papillomavirus vaccine uptake and barriers: Association with perceived risk, actual risk and race/ethnicity among female students at a New York State University, 2010. Vaccine, 29, 3138-3148.

Bell, S., Porter, M., Kitchener, H., Fraser, C., Fisher, P., Mann, E. (1995). Psychological response to cervical screening. Preventive Medicine, 24, 610-616. 
Berkowitz, A. D. (2003). Applying the social norms approach to sexual health \& sexual assault prevention. The Peer Educator, 26(4), 4-6.

Beutner, K. R., Reitano, M. V., Richwald, G. A., \& Wiley, D. J. (1998). External genital warts: Report of the American Medical Association consensus conference. Clinical Infectious Diseases, 27, 796-806.

Business Dictionary. (2010). Attitude. Retrieved from http://www.businessdictionary.com/ definition/attitude.html.

Burke, S. C., Vail-Smith, K., White, D. M., Baker, E., Mitchelle, T. (2010). Getting vaccinated against HPV: Attitudes, intentions, and perceived barriers of female undergraduates. College Student Journal, 44(1), 55-64.

Bynum, S. A., Wright, M. S., Brandt, H. M., Burgis, J. T., \& Bacon, J. L. (2009). Knowledge, beliefs, and attitudes related to Human Papillomavirus infection and vaccination, pap tests, and cervical intraepithelial neoplasia among adolescent girls and young women. Journal of the South Carolina Medical Association, 105(7), 267272.

California State University Long Beach. (2011). Health status survey report 2010. Long Beach, CA: Student Health Services.

Caron, R. M., Kispert, E., McGrath, M. J. (2008). College women's attitudes, behaviors, and beliefs regarding the HPV vaccine: Translation to health education practice. Retrieved from http://www.eric.ed.gov/ERICDocs/data/ericdocs2sql/ content_storage_01/0000019b/80/3e/a2/c0.pdf.

Caron, R. M., Kispert, E., McGrath, M. J. (2009). Human Papillomavirus (HPV) vaccine: attitudes, behaviors, and beliefs of at-risk women. The Internet Journal of Health, 9(2). Retrieved from http://www.ispub.com/journal/the_internet_journal_of_health/ volume_9_number_2_13/article_printable/human-papillomavirus-hpv-vaccineattitudes-behaviors-and-beliefs-of-at-risk-women.html.

Caskey, R., Lindau, S. T., \& Alexander, G. C. (2009). Knowledge and early adoption of the HPV vaccine among girls and young women: results of a national survey. Journal of Adolescent Health, 45(1), 453-462.

Castellsague, X. (2008). Natural history and epidemiology of HPV infection and cervical cancer. Gynecologic Oncology, 110(3), S4-S7.

Centers for Disease Control and Prevention (1997). Morbidity and mortality weekly report (MMWR) youth risk behavior surveillance: National college health risk behavior 
survey-United States, 1995, 46(55-6), 1-54. Retrieved from http://www.cdc.gov/mmwr/preview/mmwrhtml/00049859.htm.

Centers for Disease Control and Prevention. (2004). Report to congress: Prevention of genital Human Papillomavirus infection. Retrieved from http://www.cdc.gov/std/HPV/ 2004HPV\%20Report.pdf.

Centers of Disease Control and Prevention. (2007). HPV information for clinicians. Retrieved from http://www.cdc.gov/std/hpv/common-clinicians/ClinicianBro-fp.pdf.

Centers of Disease Control and Prevention (2009). Sexually transmitted disease surveillance 2008. Retrieved from http://www.cdc.gov/std/stats08/surv2008-Complete.pdf.

Centers for Disease Control and Prevention. (2010a). Morbidity and mortality weekly report: FDA licensure of bivalent Human Papillomavirus vaccine (HPV2, Cervarix) for use in females and undated $H P V$ vaccination recommendations from the advisory committee on immunization practices (ACIP). Retrieved from http://www.cdc.gov/mmwr/preview/mmwrhtml/mm5920a4.htm.

Centers for Disease Control and Prevention. (2010b). Morbidity and mortality weekly report (MMWR): National, state, and local area vaccination coverage among adolescents aged 13-17 years-United States, 2009, 59(32), 1018-1023. Retrieved from http://www.cdc.gov/mmwr/preview/mmwrhtml/mm5932a3.htm?s_cid=mm5932a3_e $\% 0 \mathrm{~d} \% 0 \mathrm{a}$.

Centers for Disease Control and Prevention. (2011a). Sexually transmitted diseases (STDs): genital HPV infection-fact sheet. Retrieved from http://www.cdc.gov/std/ HPV/STDFact-HPV.htm.

Centers for Disease Control and Prevention. (2011b). Statistics and surveillance: 2009 adult vaccination coverage, NHIS. Retrieved from http://www.cdc.gov/vaccines/statssurv/nhis/2009-nhis.htm.

Centers for Disease Control and Prevention. (2011c). Human Papillomavirus (HPV) associated cancers. Retrieved from http://www.cdc.gov/cancer/hpv/basic_info/.

Centers for Disease Control and Prevention. (2011d). Sexually transmitted diseases (STDs):HPV and men-fact sheet. Retrieved from http://www.cdc.gov/std/ hpv/stdfact-hpv-and-men.htm.

Centers for Disease Control and Prevention. (2012a). Vaccine information statement. Retrieved from http://www.cdc.gov/vaccines/pubs/vis/default.htm\#hpv.

Centers for Disease Control and Prevention. (2012b). Human papillomavirus. Retrieved from http://www.cdc.gov/hpv/. 
Chesson, H. W., Blandford, J. M., Gift, T. L., Tao, G., \& Irwin, K. L. (2004). The estimated direct medical cost of sexually transmitted diseases among American youth, 2000. Perspectives on Sexual and Reproductive Health, 36(1), 11-19.

Conroy, K., Rosenthal, S. L., Zimet, G. D., Jin, Y., Bernstein, D. I., Glynn, S., Kahn, J. A. (2009). Human Papillomavirus vaccine uptake, predictors of vaccination, and selfreported barriers to vaccination. Journal of Women's Health, 18(10), 1679-1686.

Cooper. M. L. (2002). Alcohol use and risky sexual behavior among college students and youth: Evaluating the evidence. Journal of Students on Alcohol Supplement, 14, 101-117.

Costar, H. (2007). Creative persuasive health message: Consideration of future consequences and intention to pursue vaccination against Human Papillomavirus (Doctoral dissertation, University of Maryland). Retrieved from http://drum.lib.umd.edu/bitstream/1903/7822/1/umi-umd-5107.pdf.

Daley, E. M., Perrin, K. M., McDermott, R. J., Vamos, C. A., Rayko, H. L., Packing-Ebuen, J. L., ... McFarlane, M. (2010). The psychosocial burden of HPV: A mixed-method study of knowledge, attitudes, and behaviors among HPV + women. Journal of Health Psychology, 15(2), 279-290.

Department of Health and Human Services. (2010). Topic and objectives index-healthy people. Retrieved from http://www.healthypeople.gov/2020/topicsobjectives 2020/default.aspx.

Dillard, J. P. (2011). An application of the integrative model to women's intention to be vaccinated against HPV: Implications for message design. Health Communication, 26, 479-486.

Dillard, J. P. \& Spear, M. E. (2010). Knowledge of Human Papillomavirus and perceived barriers to vaccination in a sample of US female college students. Journal of American College Health, 59, 186-190.

Downey, R. G. \& King, C. (1998). Missing data in Likert ratings: A comparison of replacement methods. The Journal of General Psychology, 125(2), 175-191.

Dubois, S. (2010). What went wrong with Gardasil. CNN Money. Retrieved from http://money.cnn.com/2010/09/06/news/companies/merck_Gardasill_problems. fortune/index.htm.

Dunne, E. F., Nielson, C. M., Stone, K. M., Markowitz, L. E., \& Giuliano, A. R. (2006). Prevalence of HPV infection among men: A systemic review of the literature. Journal of Infectious Diseases, 194, 1004-1057. 
Dunne, F. E., Ungerer, E. R., Sternberg, M., McQuillan, G., Swan, D. C., Patel, S. S., \& Markowitz, L. E. (2007). Prevalence of HPV infection among females in the United States. Journal of the American Medical Association, 297(8), 813-819.

Education Portal (2007). Leaving men behind: Women go to college in ever-greater numbers. Retrieved from http://education-portal.com/articles/Leaving_Men_Behind: Women_Go to_College in_Ever-Greater_Numbers.html.

Flaskerud, J. H., \& Winslow, B. J. (1998). Conceptualizing vulnerable populations healthrelated research. Nursing Research, 47(2), 69-78.

Farlex. (2011). The free dictionary. Retrieved from http://www.thefreedictionary.com/uptake.

Faul, F., Erdfelder, E., Buchner, A., \& Lang, A. G. (2009). Statistics power analyses using $\mathrm{G}^{*}$ Power 3.1: Test for correlation and regression analysis. Behavior Research Methods, 41(4), 1149-1160.

Field, A. (2009). Discovering Statistics Using SPSS ( $3^{\text {rd }}$ ed.). Thousand Oaks, CA: Sage Publications.

Frazer, I. H., Cox, J. T., Mayeaux, E. J., Franco, E. L., Moscicki, A. B., Palefsky, J. M., Ferris, D. G., ...Villa, L. L. (2006). Advances in prevention of cervical cancer and other Human Papillomavirus-related diseases. The Pediatric Infectious Disease Journal, 25(2), S65-S81.

Gerend, M. A., \& Magloire, Z. F. (2008). Awareness, knowledge, and beliefs about Human Papillomavirus in a racially diverse sample of young adults. Journal of Adolescent Health, 42, 237-242.

Gerend, M. A., \& Shepherd, J. E (2011). Correlates of HPV knowledge in the era of HPV vaccination: A study of unvaccinated young adult women. Women \& Health, 51(1), $25-40$.

GlaxoSmithKline Vaccine HPV-007 Study Group. (2009). Sustained efficacy and immunogenicity of the Human Papillomavirus (HPV)-16/18 AS04-adjuvanted vaccine: Analysis of a randomized placebo-controlled trial up to 6.4 years. Lancet, 374(9706), 1975-1985.

GlaxoSmithKline. (2011). Vaccine access program. Retrieved from http://www.gskforyou.com/18_programs.htm.

Gunnell, A. S., Tran, T. N., Torrang, A., Dickman, P. W., Sparen, P., Palmgren, J., Ylitano, N. (2006). Synergy between cigarette smoking and Human Papillomavirus type 16 in cervical cancer in situ development. Cancer Epidemiology, Biomarkers \& Prevention, $15,2141-2147$. 
Hager, D. W. (2009). Human Papillomavirus infection and prevention in the adolescent population. Journal of Pediatric and Adolescent Gynecology, 22, 197-204.

Haug, C. (2009). The risks and benefits of HPV vaccination. Journal of American Medical Association, 302(7), 795-796.

Head, S. K., Crosby, R. A., \& Moore, G. R. (2009). Pap smear knowledge among young women following the introduction of the HPV vaccine. Journal of Pediatric and Adolescent Gynecology, 22, 251-256.

Herrero, R., Hildesheim, A., Bratti, C., Sherman, M. E., Hutchinson, M., Morales, J.,... Schiffman, M. (2000). Population-based study of Human Papillomavirus infection and cervical neoplasia in rural Costa Rica, Journal of the National Cancer Institute, $92,464-474$.

Holguin, A. C. (2009). Determining the knowledge and attitudes of 18-to 26-year old women regarding cervical cancer, Human Papillomavirus, and the Human Papillomavirus vaccine (Master's thesis, Utah State University). Retrieved from http://digitalcommons.usu.edu/etd/464/.

Insinga, R. P., Glass, A. G., Rush, B. B. (2004). The health care costs of cervical Human Papillomavirus related-diseases. American Journal of Obstetrics and Gynecology, 191(1), 114-120.

Jain, N., Euler, G. L., Shefer, A., Lu, P., Yankey, D., \& Markowitz, L. (2009). Human Papillomavirus (HPV) awareness and vaccination initiation among women in the United States, national immunization survey-adult 2007. Preventive Medicine, 48, 426-431.

Jemmott, J. B., Jemmott, L. W., \& Fong, G. T. (1998). Abstinence and safer sex HIV riskreduction interventions for African American adolescents. Journal of American Medical Association, 279(19), 1529-1536.

Johnson, W. A. (2011). How non-response bias can ruin your mail survey. Retrieved from http://www.unsolicitedmarketingadvice.com/2007/07/02/how-non-response-bias-canruin-your-mail-survey/.

Johnston, L. D., O’Malley, P. M., \& Bachman, J. G. (2003). Monitoring the future national survey results on drug use, 1975-2002: Vol. II. college students and young adults ages 19-40. (NIH Pub. No. 03-5376). Bethesda, MD: National Institute of Drug Abuse. Retrieved from http://www.monitoringthefuture.org/pubs/ monographs/vol2_2002.pdf. 
Kahn, J. A., Rosenthal, S. L., Jin, Y., Huang, B., Namakydoust, A., Zimet, G. D. (2008). Rates of Human Papillomavirus vaccination, attitudes about vaccination, and Human Papillomavirus prevalence in young women. Obstetrics and Gynecology, 111(5), 1103-1110.

Kahn, J. A., Slap, G. B., Bernstein, D., Kollar, L. M., Tissot, A. M., Hillard, P. A., \& Rosenthal, S. L. (2005). Psychological, behavioral and interpersonal impact of Human Papillomavirus and pap test results. Journal of Women's Health, 14(7), 650659.

Kline, M. V. \& Huff, R. M. (2007). Health promotion in multicultural populations ( $2^{\text {nd }}$ ed.). Thousand Oaks, CA: Sage Publications.

Koumans, E. H., Sternberg, M. R., Motamed, C., Kohl, K., Schillinger, J. A., \& Markowitz, L. E. (2005). Sexually transmitted disease services at US colleges and universities. Journal of American College Health, 53(5), 211-217.

Kowalczyk Mullins, T. L., Zimet, G.D., Rosenthal, S. L., Morrow, C., Ding, L..., Kahn, J. A. (2012). Adolescent perceptions of risk and need for safer sexual behaviors after first Human Papillomavirus vaccination. Archives of Pediatrics \& Adolescent Medicine, 166(1), 82-88.

Kreuter, A., Potthoff, N. H., Brockmeyer, T., Gambichler, J., Swoboda, M..., Pfister, H. (2010). Anal carcinoma in human immunodeficiency virus-positive men: Results of a prospective study from Germany. British Journal of Dermatology, 162, 1269-1277.

Lahaut, V. M., Jansen, H. A., Mheen, D. V, \& Garretsen, H. F. (2002). Non-responses bias in a sample survey on alcohol consumption, Oxford Journals, 3(3), 256-260.

Leech, N. L., Barrett, K. C., \& Morgan, G. A. (2008). SPSS for intermediate statistics: Use and interpretation $\left(3^{\text {rd }}\right.$ ed.). New York, NY: Lawrence Erlbaum Associates.

Lerman, C., Miller, S. M., Scarborough, R., Hanjani, P., Nolte, S., \& Smith, D. (1991). Adverse psychologic consequences of positive cytologic cervical screening. American Journal of Obstetrics and Gynecology, 165(3), 658-662.

Lewin, T. (2006). At colleges, women are leaving men in the dust. Retrieved from http://www.nytimes.com/2006/07/09/education/09college.html?pagewanted=1\&_r=1.

Licht, .A. S, Murphy, J. M., Hyland, A. J. Fix, B. V., Hawk, L. W., \& Mahoney, M. C. (2010). Is use of the Human Papillomavirus vaccine among female college students related to Human Papillomavirus knowledge and risk perception? Sexually Transmitted Infection, 86(1), 74-78. 
Linnehan, M. J., \& Groce, N. E. (1999). Psychosocial and educational services for female college students with genital Human Papillomavirus infection. Family Planning Perspectives, 31(3), 137-141.

Lopez, R., \& McMahan, S. (2007). College women's perception and knowledge of Human Papillomavirus (HPV) and cervical cancer. Californian Journal of Health Promotion, 5(3), 12-25.

Maissi, E., Marteau, T. M., Hankins, M., Moss, S., Legood, R., Gray, A. (2004). Psychological impact of Human Papillomavirus testing in women with borderline or mildly dyskaryotic cervical smear test results: Cross sectional questionnaire study. BMJ, 328, 1-6.

Manhart, L. E., Burgess-Hull, A. J., Fleming, C. B., Bailey, J. A., Haggerty, K. P., \& Catalano, R. F. (2011). HPV vaccination among a community sample of young adult women. Vaccine, 29, 5238-5244.

Margolies, L. \& Goeren, B. (2009). Anal cancer, HIV, and gay/bisexual men. Retrieved from http://www.gmhc.org/files/editor/file/ti_0909.pdf.

McCaffery, K., Waller, J., Forrest, S., Cadman, L., Szarewski, A., Wardle, J. (2004). Testing positive for Human Papillomavirus in routine cervical screening: Examination of psychosocial impact. An International Journal of Obstetrics and Gynecology, 111, 1437-1443.

McEwen, M., \& Wills, E. M. (2007). Theoretical basis for nursing (2 ${ }^{\text {nd }}$ ed.). Philadelphia, PA: Lippincott Williams \& Wilkins.

Merck. (2011a). Patient rebate program. Retrieved from http://www.gardasilrebate.com/.

Merck. (2011b). Paying for Gardasil. Retrieved from http://www.gardasil.com/what-isgardasil/hpv-and-gardasil/assistance-programs/.

Merriam-Webster. (2011). Webster's collegiate dictionary. Retrieved from http://www.merriam-webster.com/dictionary/knowledge.

Moscicki, A. B. (2005). Impact of HPV infection in adolescent populations. Journal of Adolescent Health, 37, S3-S9.

Moscicki, A. B., Schiffman, M., Kjer, S., Villa, L. (2006). Chapter 5: Updating the natural history of HPV and anogenital cancer. Vaccine, 24(S3), 42-51.

Munro, B. H. (2005). Statistics methods for health care research $\left(5^{\text {th }}\right.$ ed.). Philadelphia, PA: Lippincott Williams \& Wilkins. 
National Cancer Institute. (2010). Pap test. Retrieved from http://www.cancer.gov/cancertopics/factsheet/detection/Pap-test.

National Center for Education Statistics (2009). Digest of Education Statistics: 2008 Retrieved on September 6, 2009, from http://nces.ed.gov/programs/digest/d08/.

Patel, D. A., Zochowski, M., Peterman, S., Dempsey, A. F., Ernst, S., \& Dalton, V. K. (2012). Human Papillomavirus vaccine intent and uptake among female college students. Journal of American College Health, 60(2), 151-161.

Polit, D., \& Beck, C. (2006). Essentials for nursing research: Methods, appraisal, and utilization. Philadelphia, PA: Lippincott Williams \& Wilkins.

Ratanasiripong, N. T. (in press). Review of Human Papillomavirus (HPV) infection and HPV vaccine-related attitudes and sexual behaviors among college-aged women in the U.S. Journal of American College Health.

Reed, M. B., Wang, R., Shillington, A. M., Clapp, J.D., \& Lange, J. E. (2007). The relationship between alcohol use and cigarette smoking in a sample of undergraduate college students. Addictive Behaviors, 32, 449-464.

Rogstad, K. E. (2002). The psychological impact of abnormal cytology and colposcopy. Transforming a well woman with no symptoms into a patient with fears and anxieties. An International Journal of Obstetrics and Gynecology, 109, 364-368.

Roberts, M. E., Gerrand, M., Reimer, R., \& Gibbons, .F. X. (2010). Mother-daughter communication and Human Papillomavirus vaccine update by college students. Pediatrics, 125(5), 982-989.

Rosenthal, S. L., Weiss, T. W., Zimet, G. D., Ma, L., Good, M. B., \& Vichnin, M. D. (2011). Predictors of HPV vaccine uptake among women aged 19-26: Importance of a physician's recommendation. Vaccine, 29(5), 890-895.

Rothman, S. M. \& Rothman, D. J. (2009). Marketing HPV vaccine: Implications for adolescent health and medical professionalism. Journal of the American Medical Association, 302(7), 781-786.

Rubin, M. M., \& Tripsas, C. K. (2010). Perceived uncertainty, coping strategies, and adaptation in women with Human Papillomavirus on pap smear. Journal of Lower Genital Tract Disease, 14(20), 81-89.

Salaway, G., \& Caruso, J. B. (2007). The ECAR study of undergraduate students and informational technology, 2007. Retrieved from http://www.educause.edu/ ECAR/TheECARStudyofUndergraduateStu/161967. 
Sax, L. J., Gilmartin, S. K., \& Bryant, A. N. (2003). Assessing response rates and nonresponse bias in web and paper surveys. Research in Higher Education, 44(4), 409-432.

Schiffman, M., \& Castle, P. E. (2003). Human papillomavirus: Epidemiology and public health. Archives of Pathology and Laboratory Medicine, 127(8), 930-934.

Sheinfeld Gorin, S. N., Glenn, B., \& Perkins, R. B. (2011). The Human Papillomavirus (HPV) vaccine and cervical cancer: Uptake and next steps. Advances in Therapies, 28(8), 615-639.

Stanley, M. (2007). Prevention strategies against the Human Papillomavirus: The effectiveness of vaccination. Gynecologic Oncology, 107,S19-S23.

Stanley, M. (2008). Immunobiology of HPV and HPV vaccines. Gynecological Oncology, 109, S15-S21.

Stanley, M. (2010). Pathology and epidemiology of HPV infection in females. Gynecological Oncology, 117, S5-10.

The Kinsey Institute. (2011). Frequently asked sexuality questions to the Kinsey Institute. Retrieved from http://www.kinseyinstitute.org/resources/FAQ.html.

The Midwife. (2007). Texas HPV vaccine controversy. Retrieved from http://www.bellytales.com/2007/02/07/texas-hpv-vaccine-controversy/.

U.S. Census and Bureau. (2011). Education, higher education, institutions, and enrollment. Retrieved from http://www.census.gov/compendia/statab/cats/education/ higher_education_institutions_and_enrollment.html.

U.S. Food and Drug Administration. (2010). FDA: Gardasil approved to prevent anal cancer. Retrieved from http://www.fda.gov/NewsEvents/Newsroom/ PressAnnouncements/ucm237941.htm.

Vamos, C. A., McDermott, R. J., \& Daley, E. M. (2008). The HPV vaccine: Framing the arguments for and against mandatory vaccination of all middle school girls. Journal of School Health, 78(6), 302-309.

Vanderpool, R. C., Casey, B. R., \& Crosby, R. A. (2010). HPV-related risk perceptions and HPV vaccine uptake among a sample of young rural women. Journal of Community Health, 36(6), 903-909.

Weinstock, H., Berman, S., \& Cates, J. W. (2004). Sexually transmitted diseases among American youth: incidence and prevalence estimates. Perspectives on Sexual and Reproductive Health, 36(1), 6-10. 
Winer, R. L., Kiviat, N. B., Hughes, J. P., Adam, D. E., Lee, S. K., Kuypers, J. M., \& Koutsky, L. A. (2005). Development and duration of Human Papillomavirus lesions, after initial infection. The Journal of Infectious Diseases, 191(5), 731-8.

Winer, R. L., Lee, S. K., Hughes, J. P., Adam, D. E., Kiviat, N. B.,\& Koutsky, L. A. (2003). Genital Human Papillomavirus infection: Incidence and risk factors in a cohort of female university students. American Journal of Epidemiology, 157(3), 218-226.

Winer, R. L., Hughes, J. P., Feng, Q., O'Reilly, S., Kiviat, N. B, Holmes, K. K, \& Koutsky, L. A. (2006). Condom use and the risk of genital Human Papillomavirus infection in young women. New England Journal of Medicine, 354, 2645-2654.

World Health Organization. (2006). New vaccines against cervical cancer major opportunity for developing world. Retrieved from http://www.who.int/mediacentre/ news/releases/2006/pr73/en/ index.html.

Zimet, G. D., Weiss, T. W., Rosenthal, S. L., Good, M. B., \& Vichnin, M. D. (2010). Reasons for non-vaccination against HPV and future vaccination intentions among 19-26 year-old women. BMC Women's Health, 10(27), 1-21. 


\section{VITA}

Nop Ratanasiripong was born and raised in Thailand. In 1994, she earned her Bachelor of Science in Nursing with honors and an extracurricular activities leadership award from Boromarajonani Nursing College, Thailand. After an intensive training in teaching, Ms. Ratanasiripong became an obstetrics-gynecology (OB-GYN) nursing instructor at her alma mater. In 1996, Ms. Ratanasiripong decided to pursue higher education and two years later, she received a Masters of Science in Nursing with honors from Mahidol University, Thailand. Ms. Ratanasiripong then continued to passionately teach OB-GYN nursing to nursing students at Siam University, Thailand.

In 2000, Ms. Ratanasiripong moved to California. After Ms. Ratanasiripong obtained her RN license in 2001, she worked as a nurse in various settings including L\&D, home health care, clinical research, and clinical teaching so that she could learn the American healthcare system, and increase her nursing skills. While Ms. Ratanasiripong was working as a clinical research nurse at Dow Pharmaceutical Sciences, she gained advanced training in research methodology and research coordination. Ms. Ratanasiripong also took on management and leadership roles until she relocated to Southern California in 2006. Since then, Ms. Ratanasiripong has been working as an Associate Director of Student Health Services, California State University-Long Beach where she utilizes her skills in management, nursing, clinical research, and health education.

In the summer 2009, Ms. Ratanasiripong began work toward her Ph.D. in Nursing. Her research interest is in the reduction STI rates and STI-related health disparities among young women. Upon completion of her degree requirements, Ms. Ratanasiripong plans to pursue her passion in teaching and research. She also wishes to expand her Medical 
Psychosocial Education (MPE) Volunteer program to help the poor and sick villagers in Thailand.

Ms. Ratanasiripong has published articles in peer-reviewed journals and presented her posters at national and local conferences. She is a member of the American College Health Association and the Association of Clinical Research Professionals. Ms. Ratanasiripong was awarded by the American Nurse Foundation research grant and the Pacific Coast College Health Association research grant in 2011. 